Aus der Abteilung Zelluläre und Molekulare Immunologie (Prof. Dr. rer. nat. J. Wienands)

im Zentrum Hygiene und Humangenetik

der Medizinischen Fakultät der Universität Göttingen

\title{
Regulation der „spleen tyrosine kinase“ Syk im \\ B-Zell-Antigen-Rezeptor-Signalweg
}

\author{
INAUGURAL - DISSERTATION \\ zur Erlangung des Doktorgrades \\ der Medizinischen Fakultät der \\ Georg-August-Universität zu Göttingen
}

vorgelegt von

Hanibal Bohnenberger

aus

Hardegsen

Göttingen 2013 
Dekan: Prof. Dr. rer. nat. H. K. Kroemer

I. Berichterstatter: Prof. Dr. rer. nat. J. Wienands

II. Berichterstatter/in: Prof. Dr. rer. nat. T. Pieler

III. Berichterstatter/in:

Tag der mündlichen Prüfung: 14. Januar 2014 


\section{Inhaltsverzeichnis}

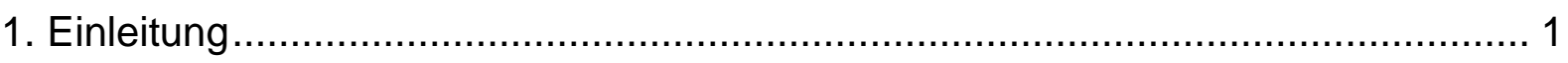

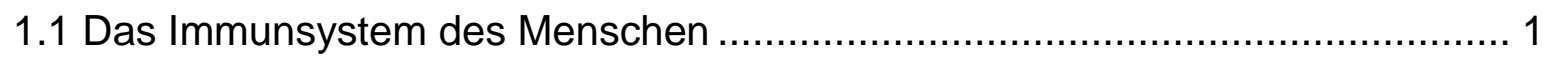

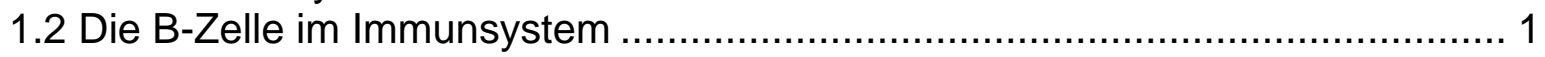

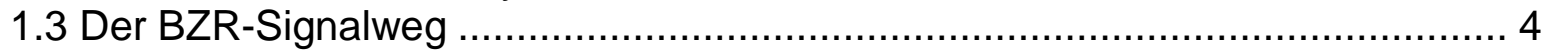

1.4 Die „spleen tyrosine kinase “ Syk ............................................................ 7

1.5 Massenspektrometrische Analysen von Signalwegen ................................ 10

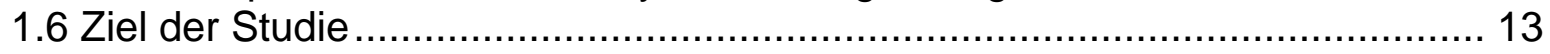

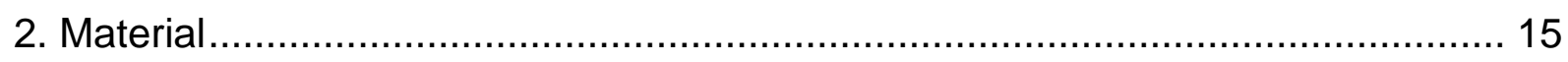

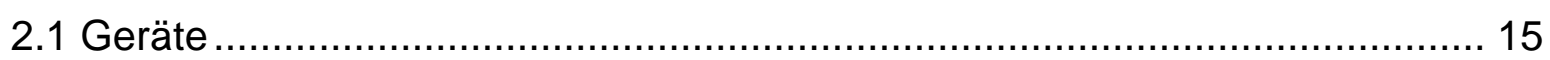

2.2 Computersoftware und Internetadressen ............................................... 16

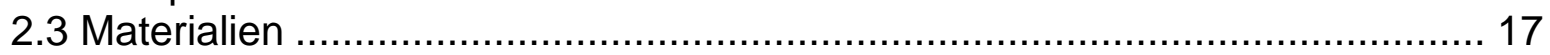

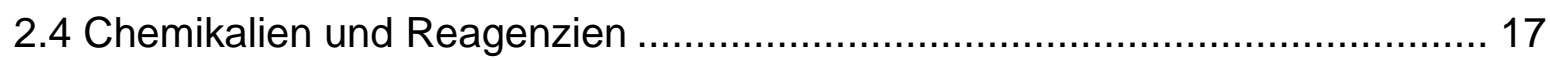

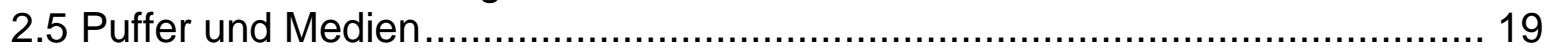

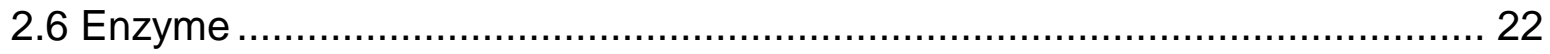

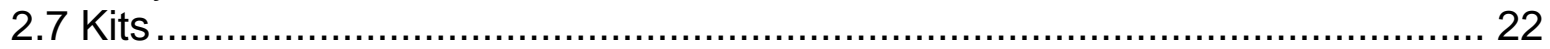

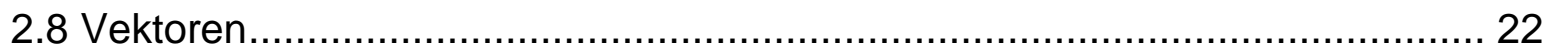

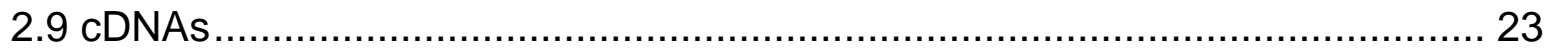

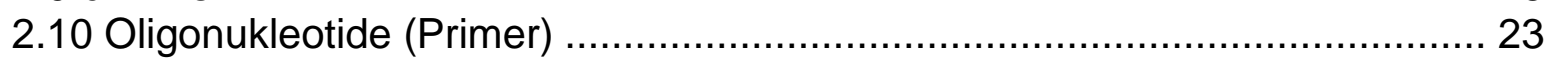

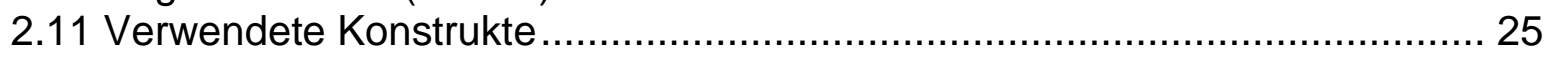

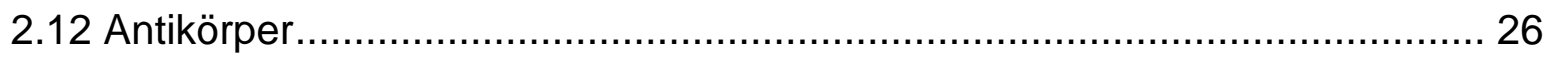

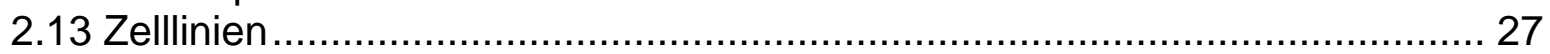

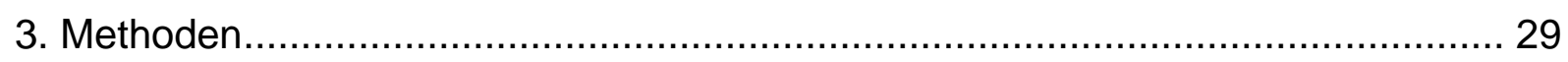

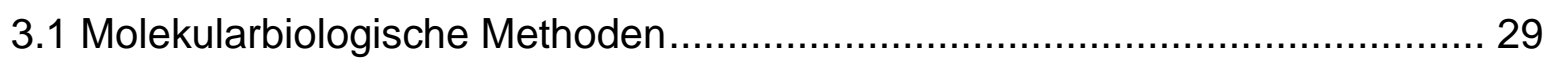

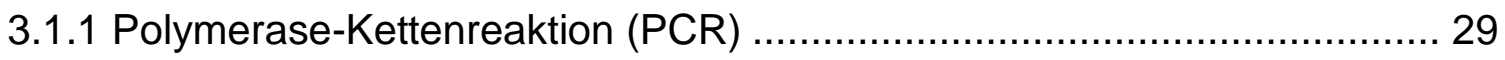

3.1.2 Mutagenese-Polymerase-Kettenreaktion .......................................... 29

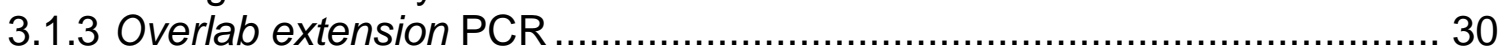

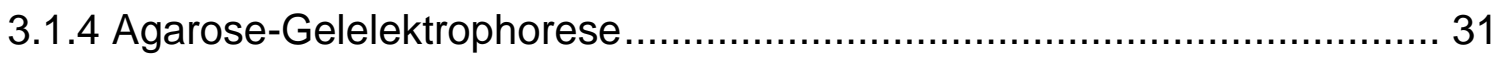

3.1.5 DNA-Extraktion aus Agarose-Gelen .................................................. 31

3.1.6 Klonierung von PCR-Produkten in den pCRII-TOPO-Vektor .................... 31

3.1.7 Herstellung kompetenter Bakterien ................................................... 32

3.1.8 Transformation von kompetenten Bakterien .......................................... 32

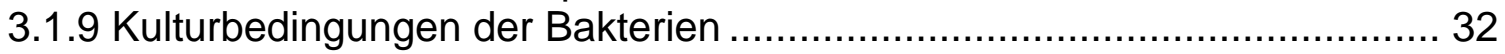

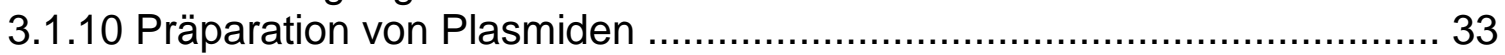

3.1.11 Konzentrationsbestimmung von Nukleinsäure................................... 33

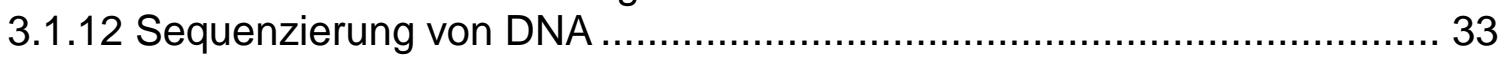

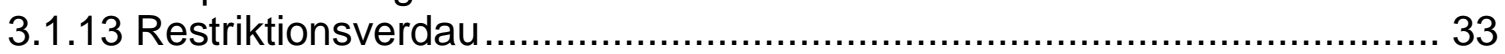

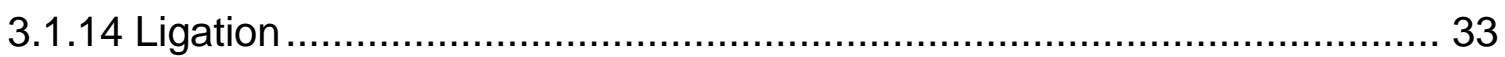

3.1.15 Linearisierung und Ethanolfällung von Vektoren .................................. 34

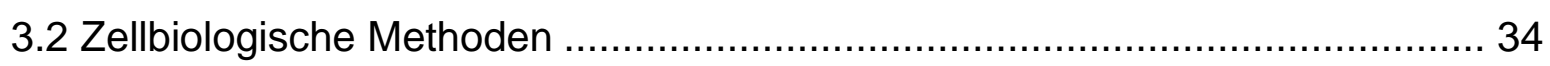

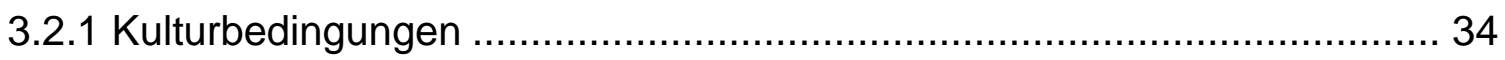

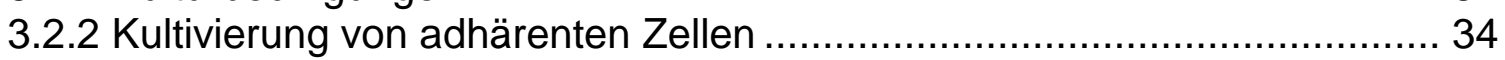

3.2.3 Auftauen und Einfrieren von Zellen .................................................. 35

3.2.4 Transfektion durch Elektroporation ...................................................... 35

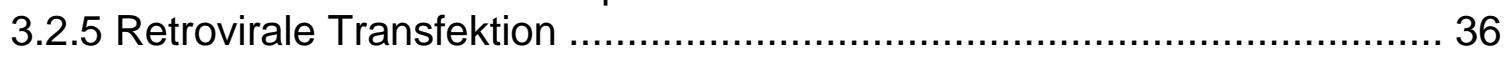

3.2.6 Analyse der Citrin-Expression ......................................................... 36 
3.2.7 Analyse der Oberflächenexpression von lgM ................................... 37

3.2.8 Analyse des BZR-abhängigen Kalziumionen-Einstroms ….................... 37

3.2.9 Stimulation von Zellen ............................................................... 38

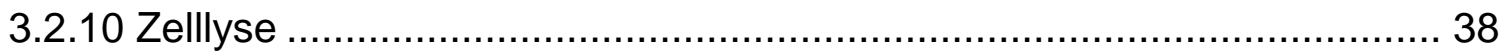

3.2.11 Konfokale Laser-Mikroskopie von lebenden Zellen .............................. 39

3.3 Proteinbiochemische Methoden ........................................................... 39

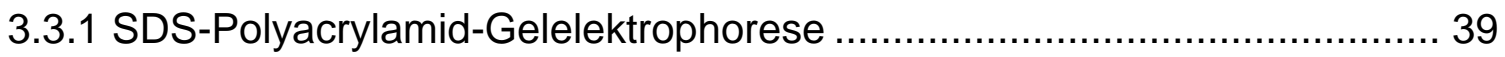

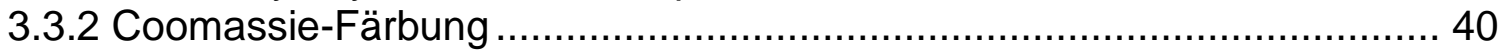

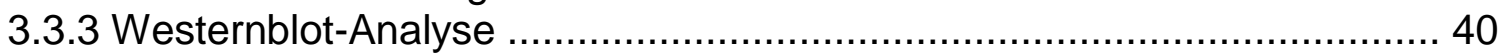

3.3.4 Expression und Isolation von GST-Proteinen ...................................... 41

3.3.5 Far-Westernblot .................................................................. 42

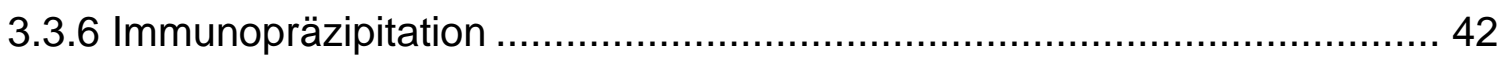

3.3.7 Affinitätspräzipitation mittels Streptaktin-Matrix .................................. 42

3.3.8 Bradfort-Methode zur Bestimmung von Proteinkonzentrationen .............. 43

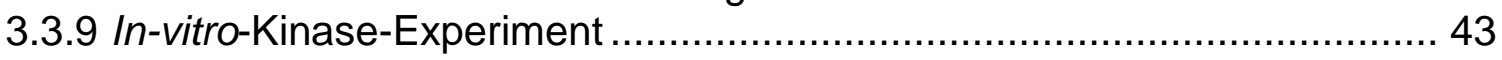

3.4 Massenspektrometrische Methoden ...................................................... 44

3.4.1 Polyacrylamid-Gelelektrophorese und In-Gel-Verdau von Proteinen ....... 44

3.4.2 Anreicherung von phosphorylierten Peptiden ....................................... 45

3.4.3 Hochleistungsflüssigkeitschromatographie (HPLC) ............................. 45

3.4.4 Massenspektrometrische Analyse ...................................................... 45

3.4.5 Auswertung der Daten mit MaxQuant und MsQuant .............................. 46

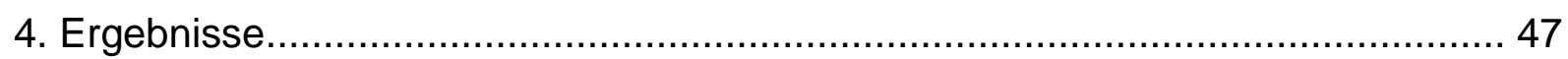

4.1 Expression von Strep-Syk in DT40- und DG-75-B-Lymphozyten .................. 47

4.2 Das Phosphorylierungsprofil von Syk in aktivierten B-Zellen ....................... 49

4.3 Die BZR-induzierte Phosphorylierungskinetik von Syk ............................... 51

4.4 Das Interaktom von Syk in ruhenden und aktivierten B-Zellen...................... 55

4.5 14-3-3y bindet an phosphoryliertes Serin 297 in humanem Syk ..................... 59

4.6 14-3-3y bindet direkt an phosphoryliertes Serin 297 ................................. 62

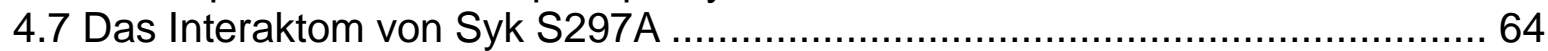

4.8 14-3-3 inhibiert die Bildung des Kalzium-Initiations-Komplexes .....................65

4.9 14-3-3 inhibiert die Phosphorylierung und Rekrutierung von Syk .................. 68

4.10 Cbl und 14-3-3 inhibieren Syk unabhängig voneinander............................ 72

4.11 Serinphosphorylierung beeinflusst die SH2-Domänen von Syk ................... 73

4.12 Prolinreiche Motive koppeln SLP65 über Cin85 an Syk …………................. 75

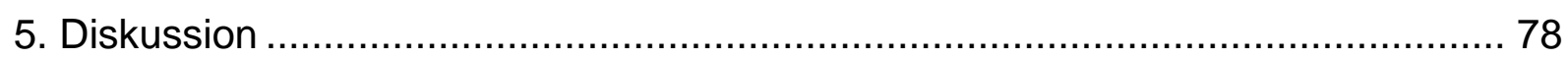

5.1 Die Phosphorylierungskinetik und das Interaktom von Syk......................... 78

5.2 Die Inhibition von Syk durch 14-3-3 ................................................... 81

5.3 Serinabhängige Beeinflussung der SH2-Domänen von Syk ........................ 85

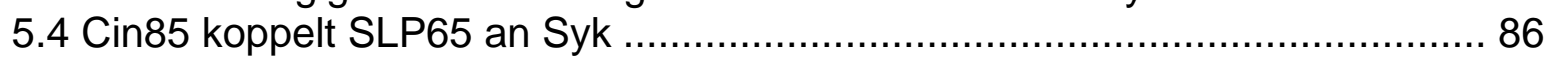

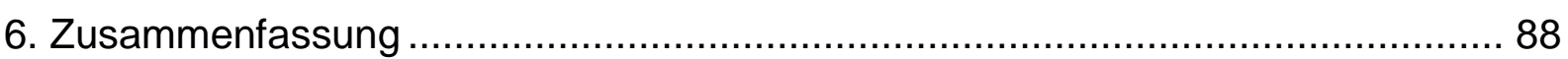

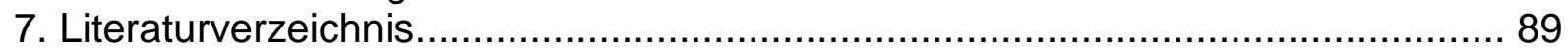




\section{Publikationsliste}

\section{Teile dieser Arbeit wurden Publiziert in:}

Bohnenberger $\mathbf{H}$, Oellerich T, Engelke M, Hsiao HH, Urlaub H, Wienands $J$

Complex phosphorylation dynamics control the composition of the Syk interactome in B cells, Frontline Article, European Journal of Immunology, 2011

Oellerich T, Bremes V, Neumann K, Bohnenberger H, Dittmann $K$, Hsiao HH, Engelke M, Schnyder T, Batista FD, Urlaub H, Wienands J

The B-cell antigen receptor signals through a preformed transducer module of SLP65 and CIN85, EMBO Journal, 2011

\section{Teile dieser Arbeit wurden als Poster vorgestellt:}

Oellerich T, Bremes V, Neumann K, Bohnenberger H, Dittmann K, Hsiao HH, Engelke $M$, Schnyder T, Batista FD, Urlaub $H$, Wienands $J$

SLP65 and CIN85 control antigen receptor signaling, Keystone Symposia, Brecktonridge, USA, 2010

Oellerich T, Bremes V, Neumann K, Bohnenberger H, Engelke M, Dittmann K, Hsiao $H H$, Urlaub $H$, Wienands $J$

Composition and dynamic reorganization of the Syk/SLP65 interactomes as revealed by functional proteomics, 14th International Congress of Immunology, Kobe, Japan, 2010

\section{Weitere Publikationen zu dem Thema der Doktorarbeit:}

Oellerich $T$, Oellerich $M$, Engelke $M$, Hsiao $H H$, Zhang J, Bohnenberger $\mathbf{H}$, Berg $T$, Wienands J, Bug G, Brandts $C$, Urlaub $H$, Serve $H$ $\beta 2$-integrin-derived signals induce cell survival and proliferation of AML blasts by activating a SYK/STAT signaling axis, Blood, 2013

Lösing M, Goldbeck I, Manno B, Oellerich T, Schnyder T, Bohnenberger H, Stork B, Urlaub H, Batista F, Wienands J, Engelke $M$

The Dok-3/Grb2 signal module attenuates Lyn-dependent activation of Syk in B cell antigen receptor microclusters. Journal of Biological Chemistry, 2012 


\section{Abkürzungsverzeichnis}

Abb.

ABTS

Akt

ALV

Amp

AP

AP-1

APS

ATCC

BASH

BLNK

BPB

BSA

Btk

Bw

BZR

CARMA1

Cbl

CCL

CD

CDNA

Cin85

CS

Cy-5

DAG

$\mathrm{ddH}_{2} \mathrm{O}$

DMEM

DMSO

dNTP

1D-PAGE

DTT

EBV

ECL

E.coli

EDTA

EGTA

ELISA

Erk

$F(a b)$

FCS

$\mathrm{Fw}$

Gab2

GFP

GST

HEPES

HPLC

HRPO

Hsp

IAA

$\lg$

IKK

IP

$\mathrm{IP}_{3}$
Abbildung

Azino-di-(3-ethylbenzthiazolin)-6-sulfonsäure

Protein-Kinase $B$

avian leucosis virus

Ampicillin

Affinitätspräzipitation

Activator protein 1

Ammoniumpersulfat

American type culture collection

$B$ cell adapter containing SH2-Domain

$B$ cell linker protein

Bromphenolblau

Bovines Serum-Albumin

Bruton's Tyrosin-Kinase

Backward

B-Zell-Antigen-Rezeptor

CARD-containing MAGUK protein 1

Casitas $B$ cell lineage lymphoma

Geklärte zelluläre Lysate

Cluster of differentiation

Complementary desoxyribonucleic acid

Cbl-interacting protein of $85 \mathrm{kDa}$

Hühnchen-Serum

Cyanin-5

Diacylglycerol

Doppelt deionisiertes Wasser

Dulbeccos minimal essential medium

Dimethylsulfoxid

2'-desoxynucleoside-5'-trisphosphate

Eindimensionale Polyacrylamid-Gelelektrophorese

Dithiothreitol

Epstein-Barr-Virus

Enhanced chemical luminescence

Escherichia coli

Ethylendiamintetraessigsäure

Ethylenglycoltetraessigsäure

Enzyme linked immunosorbent assay

Extracellular signal regulated kinase

Antigenbindendes Fragment

Fetales Kälber-Serum

Forward

GRB2 associated binder 2

Grün-fluoreszierendes Protein

Glutathion-S-Transferase

2-[4-(2-Hydroxyethyl)-1-Piperazinyl]-Ethansulfon-Säure

Hochleistungsflüssigkeitschromatographie

Meerrettich-Peroxidase

Hitzeschockprotein

Indol-3-Essigsäure

Immunglobulin

Inhibitor of nuclear factor kappa B kinase

Immunopräzipitation

Inositol-1,4,5-Trisphosphat 


\begin{tabular}{|c|c|}
\hline IPI & Internationaler Protein-Index \\
\hline IPTG & Isopropyl-1-thio-galactopyranosid \\
\hline ITAM & Immunoreceptor tyrosine based activation motif \\
\hline IKB & Nuclear factor kappa B inhibitor \\
\hline JNK & C-Jun N-terminal kinase \\
\hline Kan & Kanamycin \\
\hline kB & Kilobase \\
\hline LAT & Linker for activation of $T$ cells \\
\hline LB & Lysogeny bRoth, Karlsruhe \\
\hline LC-MS/MS & Liquid chromatography tandem mass spectrometry \\
\hline LDS & Lithium dodecyl sulfate \\
\hline LTQ-Orbitrap & Linear trap quadrupole orbitrap \\
\hline Lyn & Lck/yes-related novel kinase \\
\hline $\mathrm{m} / \mathrm{z}$ & Masse / Ladung \\
\hline MAP-Kinase & Mitogen activated protein kinase \\
\hline $\mathrm{MHC}$ & Major histocompatibility complex \\
\hline MMLV & Murine leukemia virus \\
\hline MOPS & 3-Morpholinopropansulfonsäure \\
\hline MS & Massenspektrometrie \\
\hline MS/MS & Tandem-Massenspektrometrie \\
\hline NFAT & Nuclear factor of activated T cells \\
\hline NF-kB & Nuclear factor for $\mathrm{K}$-gene in B cells \\
\hline OD & Optische Dichte \\
\hline NP40 & IGEPAL CA-630 \\
\hline PAGE & Polyacrylamid-Gelelektrophorese \\
\hline PBS & Phosphate buffered saline \\
\hline PCR & Polymerase-Kettenreaktion \\
\hline $\mathrm{PH}$ & Pleckstrin homology \\
\hline $\mathrm{PI3K}$ & Phosphatidylinositol-3-Kinase \\
\hline $\mathrm{PIP}_{2}$ & Phosphatidylinositol-4,5-bisphosphat \\
\hline $\mathrm{PIP}_{3}$ & Phosphatidylinositol-3,4,5-trisphosphat \\
\hline PKC & Protein-Kinase C \\
\hline PLC & Phospholipase C \\
\hline PLK1 & Polo-like kinase 1 \\
\hline PTM & Posttranslationale Modifikation \\
\hline Puro & Puromycin \\
\hline RasGRP3 & RAS guanyl releasing protein 3 \\
\hline RhoH & Rho-related GTP-binding protein \\
\hline RPMI & Roswell Park Memorial Institute \\
\hline RT & Raumtemperatur \\
\hline S297A & Serin 297 mutiert zu Alanin \\
\hline SDS & Sodium dodecyl sulfate \\
\hline Sek1 & SAPK/ERK kinase 1 \\
\hline $\mathrm{SH}$ & Src-homology domain \\
\hline SHP & SH-domain protein tyrosine phosphatase \\
\hline SILAC & stable isotop labeling of aminoacids in cellculture \\
\hline SLP65 & SH2-Domain-containing leukocyte protein of $65 \mathrm{kDa}$ \\
\hline SLP76 & SH2-Domain-containing leukocyte protein of $76 \mathrm{kDa}$ \\
\hline Src & Rous sarcoma oncogene \\
\hline Std. Abw. & Standardabweichung \\
\hline Syk & Spleen tyrosine kinase \\
\hline TAE & Tris-Azetat-EDTA-Puffer \\
\hline TEMED & Tetramethylethylendiamin \\
\hline TFB & Transformation buffer \\
\hline
\end{tabular}




\begin{tabular}{|c|c|}
\hline $\mathrm{TiO}_{2}$ & Titanium-Dioxid \\
\hline TOM1L1 & Target of myb1-like 1 \\
\hline TRAP1 & Tumor necrosis factor type 1 receptor-associated protein \\
\hline Tris & Tris(hydroxymethyl)-aminomethan \\
\hline TZR & T-Zell-Antigen-Rezeptor \\
\hline UV & Ultraviolett \\
\hline Vav & Vav oncogene \\
\hline VSV-G & Vesicular stomatitis virus glycoprotein \\
\hline $\mathrm{v} / \mathrm{v}$ & Volume / Volumen \\
\hline$w / v$ & Masse / Volumen \\
\hline WB & Westernblot \\
\hline wt & Wildtyp \\
\hline X-Gal & 5-Bromo-4-Chloro-3-Indolyl-Galactopyranosid \\
\hline Zap-70 & $70 \mathrm{kDa}$ zeta chain associated protein \\
\hline
\end{tabular}

\begin{tabular}{|l|l|l|}
\hline Aminosäure & Drei-Buchstaben-Kode & Ein-Buchstaben-Kode \\
\hline Alanin & Ala & A \\
\hline Arginin & Arg & R \\
\hline Asparagin & Asn & N \\
\hline Aspartat & Asp & D \\
\hline Cystein & Cys & C \\
\hline Glutamin & Gln & Q \\
\hline Glutamat & Glu & E \\
\hline Glycin & Gly & G \\
\hline Histidin & His & H \\
\hline Isoleucin & Ile & I \\
\hline Leucin & Leu & L \\
\hline Lysin & Lys & K \\
\hline Methionin & Met & M \\
\hline Phenylalanin & Phe & F \\
\hline Prolin & Pro & P \\
\hline Serin & Ser & S \\
\hline Threonin & Thr & T \\
\hline Tryptophan & Trp & W \\
\hline Tyrosin & Tyr & Y \\
\hline Valin & Val & V \\
\hline
\end{tabular}

\begin{tabular}{|l|l|}
\hline Nucleosid & Abkürzung \\
\hline Desoxyadenosin & A \\
\hline Desoxycytidin & $\mathrm{C}$ \\
\hline Desoxyguanosin & $\mathrm{G}$ \\
\hline Desoxythymidin & $\mathrm{T}$ \\
\hline
\end{tabular}

\begin{tabular}{|l|l|l|l|l|l|l|l|}
\hline \multicolumn{7}{|l|}{ Einheiten und Präfixe } \\
\hline $\mathbf{K}$ & kilo & min & Minute & A & Ampere & U & Unit/Enzymeinheit \\
\hline $\mathbf{m}$ & milli & sec & Sekunde & $\mathbf{F}$ & Farad & Da & Dalton \\
\hline $\mathbf{\mu}$ & micro & $\mathbf{m}$ & Meter & $\mathbf{V}$ & Volt & $\mathbf{A}$ & Angström \\
\hline $\mathbf{n}$ & nano & $\mathbf{I}$ & Liter & $\mathbf{g}$ & Erdbeschleunigung & ${ }^{\circ} \mathbf{C}$ & Grad Celsius \\
\hline & & $\mathbf{M}$ & molar & $\mathbf{r p m}$ & rounds per minute & & \\
\hline
\end{tabular}




\section{Einleitung}

\subsection{Das Immunsystem des Menschen}

Das Immunsystem des Menschen ist ein komplexes System, das sich aus einer Vielzahl von löslichen und zellulären Komponenten sowie verschiedenen lymphatischen Organen zusammensetzt. Zusammen sichern sie durch die Erkennung und Eliminierung von körperfremden Krankheitserregern das Überleben des Organismus. Das Immunsystem besteht aus einem angeborenen, unspezifischen und einem erworbenen, spezifischen Anteil (Murphy et al. 2008).

Das unspezifische Immunsystem stellt dabei die erste Verteidigungslinie gegen eindringende Krankheitserreger dar. Gelingt es einem Infektionserreger, die Barrieren von Haut oder Schleimhaut zu überwinden, wird dieser von der unspezifischen Abwehr mittels Rezeptoren für pathogen-spezifische Strukturen erkannt und über Mechanismen wie Phagozytose zum Teil auch eliminiert (Janeway und Medzhitov 2002). Außerdem ist das unspezifische Immunsystem an der Aktivierung des spezifischen Immunsystems beteiligt (Fearon und Locksley 1996).

Das spezifische Immunsystem besteht aus B- und T-Zellen. Kennzeichen der spezifischen Immunantwort ist die Expression von Rezeptoren, die gezielt gegen spezifische Antigene einzelner Pathogene gerichtet sind. B-Zellen exprimieren dafür den BZell-Antigen-Rezeptor (BZR). Über genetische Rekombinationsmechanismen können Antigen-Rezeptoren für ungefähr $10^{12}$ unterschiedliche Strukturen gebildet werden. Jede B-Zelle trägt dabei jeweils nur einen spezifischen Antigen-Rezeptor, der durch ein spezifisches Antigen-Epitop aktiviert werden kann (Davies und Cohen 1996).

\subsection{Die B-Zelle im Immunsystem}

B-Zellen sezernieren nach Aktivierung Antikörper, die bereits 1890 von Emil von Behring und Shibasaburo Kitasato als "Antitoxine" beschrieben wurden (von Behring und Kitasato 1890). B-Zellen, die noch keinen Kontakt zu einem Antigen hatten, sogenannte naive B-Zellen, exprimieren eine membranständige Form des Antikörpers als Teil des BZR, der Antigene erkennt und das Signal der Antigenerkennung in das Innere der Zelle übermittelt. Dadurch kommt es über Effekte auf Ebene der Transkription und der zytoskelettalen Organisation zur Aktivierung der B-Zelle (Tsubata und Wienands 2001). Da jede B-Zelle nur einen Antigen-Rezeptor exprimiert, ist für ein umfassendes Immunsystem die Existenz eines großen B-Zell-Bestandes essentiell. 
Die B-Zellen entwickeln sich im Knochenmark aus pluripotenten Stammzellen, in deren Genom die Informationen für die Antikörper liegen. Jeweils zwei schwere und zwei leichte Ketten bilden zusammen einen Antikörper. An beiden Ketten lassen sich eine konstante Region von einer hoch variablen, antigenbindenden Region, die jeweils von einem $\mathrm{V}$-, einem $\mathrm{J}$ - und bei der schweren Kette zusätzlich von einem DGensegment im Immunglobulinlokus kodiert werden, unterscheiden. Die Zusammensetzung verschiedener VDJ-Gensegmente wird als somatische Rekombination bezeichnet. Zusätzlich bildet bei der leichten und schweren Kette das C-Gensegment die konstante Region, welche bei der schweren Kette die Antikörperklasse definiert (Brack et al. 1978, Tonegawa et al. 1978).

Anhand des Status der somatischen Rekombination im Immunglobulinlokus und über die Expression von intrazellulären und membrangebundenen Proteinen lassen sich die verschiedenen Stadien der B-Zell-Entwicklung von der Pro- über die Prä- bis zur reifen B-Zelle unterscheiden. Pro-B-Zellen rekombinieren die Gensegmente der schweren Kette, die den auf Prä-B-Zellen exprimierten Prä-BZR bilden. Nur wenn dieser funktionsfähig ist, kommt es zur Rekombination der Segmente für die leichte Kette. Ist auch dies erfolgreich, wird der BZR auf der Oberfläche der nun unreifen BZelle auf seine Toleranz gegenüber körpereigenen Proteinen getestet. Dies wird als negative Selektion bezeichnet und soll die Anzahl selbst-reaktiver B-Zellen verringern. Die B-Zelle verlässt das Knochenmark als sogenannte reife, naive B-Zelle (Goodnow et al. 1995, Löffert et al. 1994).

Essentiell für die Entwicklung und das Überleben peripherer B-Zellen sind kontinuierliche Signale durch den BZR (Wang LD und Clark 2003). Da die genetische Inaktivierung des BZR in reifen B-Zellen zum Untergang der peripheren B-Zell-Population führt, wird die Existenz eines antigenunabhängigen BZR-Signals im Sinne eines tonisch schwach aktiven Signalweges vermutet (Lam et al. 1997).

Die reifen, naiven B-Zellen zirkulieren über die Blutbahn zwischen den peripheren lymphatischen Organen und können dort durch Antigene aktiviert werden. Diese werden als Komplex aus BZR und gebundenem Antigen durch Endozytose aufgenommen, das Antigen intrazellulär proteolytisch verdaut und die entstehenden Peptide auf der Oberfläche der B-Zelle mittels MHC-II-Molekülen präsentiert. Die B-Zelle benötigt danach ein zweites Signal zur vollständigen Aktivierung, das von einer THelferzelle über die Interaktion des T-Zell-Antigen-Rezeptors (TZR) mit dem MHC-II- 
gebundenen Peptid und des CD40-Liganden mit CD40 auf der B-Zelle vermittelt wird (Goodnow et al. 2010).

Die aktivierte B-Zelle entwickelt sich danach entweder zu einem IgM sezernierenden Plasmablasten oder migriert mit T-Helferzellen in einen primären Lymphfollikel. Die Plasmablasten haben eine erste protektive Wirkung auf den Organismus und sterben nach wenigen Tagen ab. Die von T-Helferzellen begleiteten B-Zellen proliferieren im Lymphfollikel weiter und formen schließlich ein Keimzentrum. Die zu Beginn stark teilungsaktiven B-Zellen werden Zentroblasten genannt, die sich zum Teil zu weniger teilungsaktiven Zentrozyten weiterentwickeln (Goodnow et al. 2010). Die proliferierenden Zellen des Keimzentrums durchlaufen dabei den Prozess der somatischen Hypermutation. Dabei werden durch Punktmutationen einzelne Aminosäuren der schweren und leichten Kette ausgetauscht. Die meisten dieser Mutationen werden die Bindung des BZR an das Antigen schwächen und die B-Zellen werden absterben (negative Selektion). Einige Mutationen werden die Affinität zum Antigen jedoch stärken und diese Zellen werden sich weiter vermehren (positive Selektion). Dadurch nimmt im Keimzentrum die Affinität des BZR zum Antigen zu, ein Prozess der als Affinitätsreifung bezeichnet wird. Die Signalstärke durch den BZR ist dabei einer der Hauptfaktoren (Jacob et al. 1991).

Zu Beginn einer Immunantwort werden vor allem IgM-Antikörper sezerniert, in den Keimzentren kommt es jedoch zum Isotypenwechsel, so dass neben IgM auch IgG, $\lg A$ und $\operatorname{lgE}$, die alle unterschiedliche biologische Eigenschaften haben, sezerniert werden können. Dabei kommt es durch erneute somatische Rekombination zur Auswahl eines neuen C-Segmentes in der für die schwere Kette kodierenden Region auf der DNA (Stavnezer et al. 2008). Am Ende der Keimzentrumsreaktion entstehen aus den B-Zellen entweder Plasmazellen oder B-Gedächtniszellen (Goodnow et al. 2010). Plasmazellen sekretieren die hochaffinen Antikörper, die an spezifische Antigene eines Pathogens binden, wodurch dieses neutralisiert oder für das unspezifische Immunsystem markiert und dadurch leichter beseitigt wird oder es kommt zur antikörperabhängigen Aktivierung des Komplementsystems (Cooper 1985, Karakawa et al. 1988). B-Gedächtniszellen haben die Fähigkeit, bei Reinfektion mit einem Erreger sehr schnell mit der Bildung von hochaffinen Antikörpern zu reagieren, so dass der Organismus vor bereits bekannten Erregern geschützt ist (McHeyzer-Williams et al. 2011). 


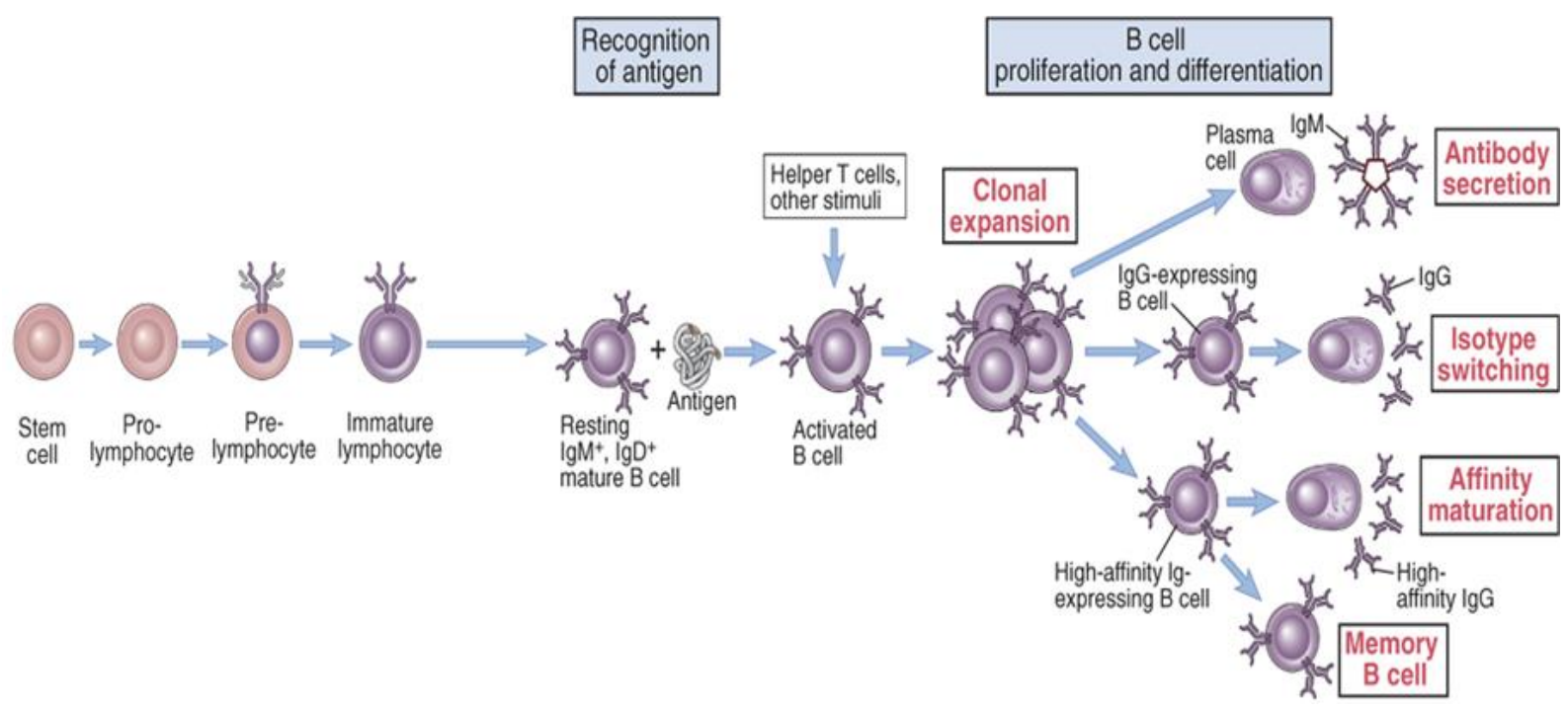

Abb. 1: Die Entwicklung der B-Zelle. Die Abbildung zeigt die Entwicklung der B-Zelle von der pluripotenten Stammzelle im Knochenmark bis zur antikörpersezernierenden Plasmazelle. Modifiziert nach Abbas et al. 2007, S. 154 und 216.

\subsection{Der BZR-Signalweg}

Der BZR enthält als Antigen-bindenden Teil eine membrangebundene Form des für diese B-Zelle spezifischen Antikörpers. Die Expression auf der Zelloberfläche wird durch die stabilisierende Funktion eines nicht kovalent assoziierten Heterodimeres, bestehend aus Ig- $\alpha$ (CD79a) und Ig- $\beta$ (CD79b), ermöglicht (Wienands 2000). Ig- $\alpha$ und $\lg -\beta$ sind der signalleitende Teil des BZR und enthalten im zytoplasmatischen Teil jeweils ein "Immunoreceptor tyrosine-based activation motif" (ITAM), dessen Konsensussequenz bereits 1989 als D/E X $X_{7}$ D/E X $\underline{Y}_{X_{2}} \mathrm{I} / L X_{7} \underline{Y} X_{2} \mathrm{I} / L$ (Aminosäuren im Ein-Buchstaben-Kode) identifiziert wurde (Reth 1989) und als für die signalübermittelnde Funktion des Heterodimers essentiell beschrieben wurde (Flaswinkel und Reth 1994, Sanchez et al. 1993).

Durch die Bindung eines passenden Antigens wird der BZR aktiviert (Sohn et al. 2006). Bereits in ruhenden B-Zellen sind Tyrosin-Kinasen der Src-Familie wie Lyn über eine phosphorylierungsunabhängige Interaktion mit lg- $\alpha$ assoziiert (Campbell und Sefton 1992). Nach Antigenbindung werden Tyrosine der ITAMs durch diese Src-Kinasen phosphoryliert (Saouaf et al. 1994) und die Tyrosin-Kinase Syk wird über die Bindung der Tandem-SH2-Domäne an die phosphorylierten Tyrosine der ITAM-Motive zum aktivierten BZR rekrutiert (Kurosaki et al. 1995). SH2-Domänen sind circa 100 Aminosäuren lang und binden spezifisch an Aminosäuresequenzen, die ein phosphoryliertes Tyrosin enthalten (Liu et al. 2006). Die Aktivierung von Syk 
erfolgt über die Bindung zu den ITAMs und durch Phosphorylierung durch Lyn und Syk selbst (Kurosaki et al. 1994, Tsang et al. 2008). Dabei kann Syk sowohl benachbarte Syk-Moleküle als auch sich selbst im Sinne einer Autophosphorylierung phosphorylieren. Des Weiteren kann Syk auch Tyrosine in ITAM-Motiven phosphorylieren und den gestarteten BZR-Signalweg damit verstärken (Rolli et al. 2002).

Ein Hauptsubstrat von Syk ist das B-Zell-spezifische Adapterprotein SLP65 (auch BLNK oder BASH genannt) (Fu et al. 1998, Goitsuka et al. 1998, Wienands et al. 1998). Nach Phosphorylierung rekrutiert SLP65 die Tyrosin-Kinase Btk und die Phospholipase PLC-ү2 und bildet den sogenannten Kalzium-Initiations-Komplex (Chiu et al. 2002). Dieser Komplex ermöglicht es Btk und Syk, PLC-y2 zu phosphorylieren und dadurch zu aktivieren. Außerdem rekrutiert SLP65 den Komplex an die Plasmamembran, wo PLC-y2 Zugang zu ihrem Substrat, dem Phospholipid Phosphatidyl-Inositol-4,5-Phosphat $\left[\mathrm{PIP}_{2}\right]$ erhält (Engelke et al. 2007). Die Details der Membranrekrutierung von SLP65 sind noch nicht abschließend geklärt, es zeigte sich jedoch, dass der N-Terminus (Köhler et al. 2005) und die SH2-Domäne von SLP65 (Abudula et al. 2007) sowie drei prolinreiche Motive, die an Cin85 binden (Oellerich et al. 2011), für die Rekrutierung nötig sind.

An der Membran hydrolysiert PLC-y2 $\mathrm{PIP}_{2}$ in der Zellmembran, wodurch Inositol1,4,5-Phosphat $\left(\mathrm{IP}_{3}\right)$ ins Zytosol freigesetzt wird und Diazylglyzerol (DAG) in der Plasmamembran verbleibt. $\mathrm{IP}_{3}$ aktiviert $\mathrm{IP}_{3}$-Rezeptoren im endoplasmatischen Retikulum, wodurch Kalziumionen in das Zytoplasma strömen (Kurosaki et al. 2000). Auf diesen Einstrom von Kalziumionen aus intrazellulären Speichern folgt ein Einstrom von Kalziumionen aus dem Extrazellulärraum (Engelke et al. 2007). Die erhöhte zytosolische Kalziumionenkonzentration beeinflusst eine Vielzahl zellulärer Prozesse, häufig über die Bindung an Calmodulin. Als Beispiel wird über die erhöhte Kalziumionenkonzentration die Phosphatase Calcineurin aktiviert, die den Transkriptionsfaktor NFAT, welcher in ruhenden Zellen durch konstitutive Phosphorylierung im Zytosol gehalten wird, dephosphoryliert und so in den Zellkern translozieren lässt (Crabtree und Olson 2002).

Ebenfalls durch die Aktivität der PLC-y2 kommt es über die Bindung an DAG zur Aktivierung der Serin/Threonin-Protein-Kinase C- $\beta$ (PKC- $\beta$ ). Diese aktiviert das Adapterprotein CARMA1 und den Guanosin-Austauschfaktor RasGRP3. Ersteres führt über die Bildung eines Multiproteinkomplexes zur Aktivierung der Kinase IKK, die 
über Phosphorylierung zum proteasomalen Abbau von IkB führt. NF-KB wird in ruhenden B-Zellen durch IkB im Zytosol gehalten und kann nun in den Zellkern translozieren und dort Transkriptionsfaktoren aktivieren (Shinohara und Kurosaki 2009). Die Aktivierung von RasGRP3 führt über die Aktivierung von Ras über eine Kaskade von MAP-Kinasen zur Aktivierung von Erk und weiteren Transkriptionsfaktoren, die wesentlich für das Überleben der B-Zellen sind (Coughlin et al. 2005, Rowland et al. 2010). Weitere MAP-Kinasen, die durch den BZR aktiviert werden, sind p38 und Jnk, die unter anderem durch SLP65 reguliert werden (Oellerich et al. 2009, Cook et al. 2007) und den Transkriptionsfaktor AP-1 regulieren. Dieser ist wichtig für den Zellzyklus und die Differenzierung der B-Zellen (Foletta et al. 1998).

Durch aktiviertes Syk wird außerdem eine PI3-Kinase aktiviert, die $\mathrm{PIP}_{2}$ phosphorylieren kann, so dass sich die Menge an $\mathrm{PI}(3,4,5) \mathrm{P}_{3}\left(\mathrm{PIP}_{3}\right)$ in der Membran erhöht (Marshall et al. 2000). Unter anderem binden die PH-Domänen von PLC-ү2 und Btk an $\mathrm{PIP}_{3}$ (Falasca et al. 1998, Saito et al. 2001). Ein weiteres Protein, das über $\mathrm{PIP}_{3}$ an die Plasmamembran rekrutiert und dort aktiviert wird, ist Akt, das in vielen Zellsystemen und so auch in der B-Zelle anti-apoptotisch wirkt (Pogue et al. 2000). Eine Übersicht über den BZR-Signalweg ist in Abb. 2 dargestellt.

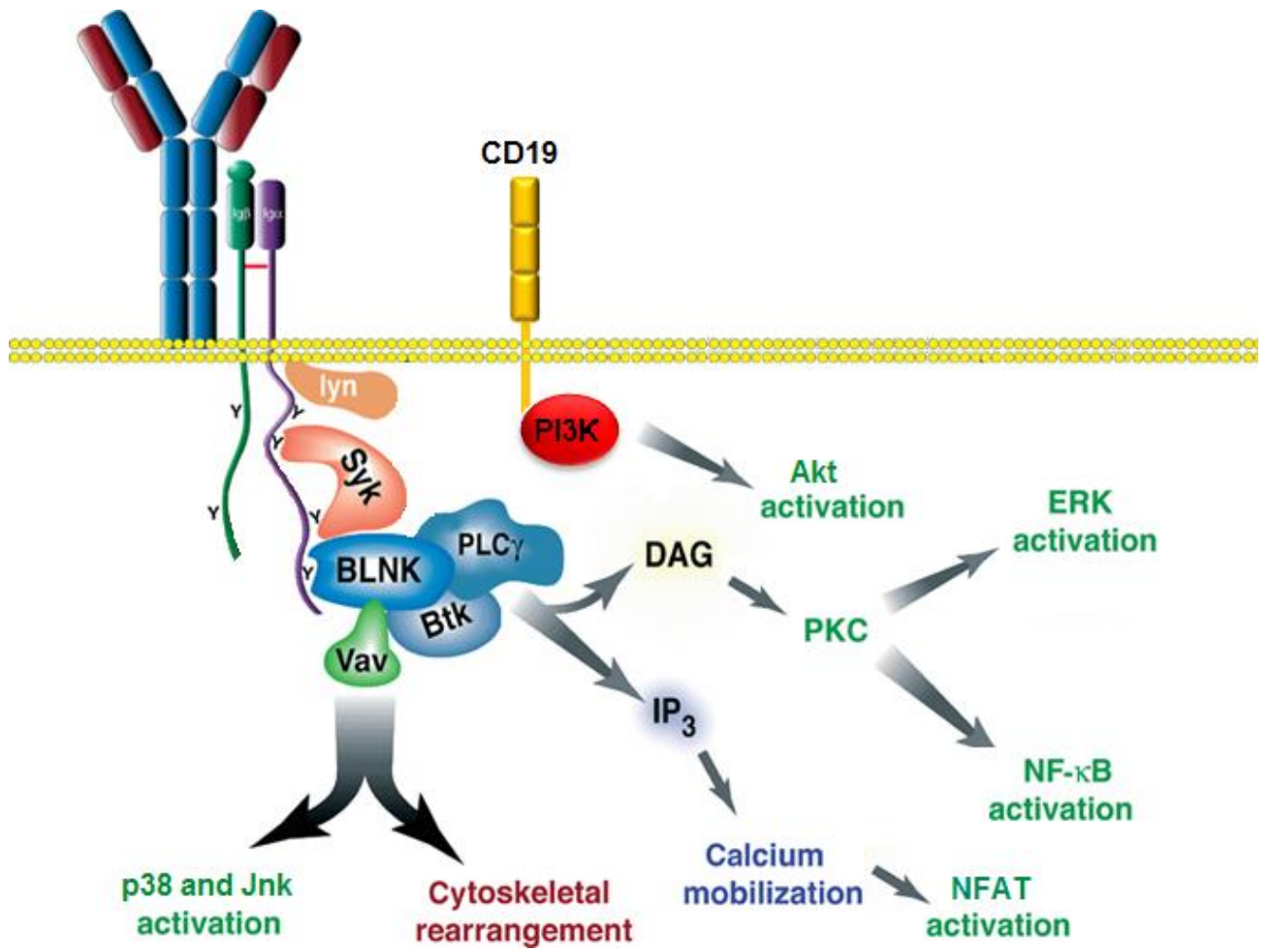

Abb. 2: Übersicht BZR-Signalweg. Nach Aktivierung des BZR durch ein Antigen kommt es zur Aktivierung und Rekrutierung von Syk an die ITAM-Motive in Ig- $\alpha$ und Ig- $\beta$. Dadurch wird eine Kette von intrazellulären Signalmolekülen und Transkriptionsfaktoren aktiviert, die in ihrer Gesamtheit die Reaktion der B-Zelle auf das Antigen bestimmen. Modifiziert nach Wang LD und Clark (2003, S.412). 


\subsection{Die „spleen tyrosine kinase“ Syk}

Ursprünglich wurde Syk 1986 aus bovinem Thymus als 40 kDa großes Fragment mit der Fähigkeit, ein synthetisches Peptid zu phosphorylieren, isoliert (Zioncheck et al. 1986). Später konnte Syk als 72 kDa große Kinase identifiziert (Zioncheck et al. 1988) und durch Analyse von Syk-defizienten DT40-B-Zellen die essenzielle Funktion von Syk im BZR-Signalweg gezeigt werden (Takata et al. 1994). Syk-defiziente Mäuse zeigen einen Block in der B-Zell-Entwicklung auf Ebene der Pro-B-Zellen (Turner et al. 1995, Cheng et al. 1995).

Syk wird jedoch auch in den meisten anderen hämatopoietischen Zellen und einer Vielzahl von nicht-hämatopoietischen Zellen exprimiert (Yanagi et al. 2001) und neben den beschriebenen Funktionen von Syk im BZR-Signalweg gibt es viele weitere Rezeptoren und Zellsysteme, die Syk als aktivierende Kinase benötigen (Mócsai et al. 2010). Auch für eine Reihe von pathologischen Prozessen konnte eine Beteiligung von Syk gezeigt werden. So konnte für viele Formen der Non-HodgkinLymphome wie die chronisch-lymphatische Leukämie (Buchner et al. 2009) oder das diffus-großzellige B-Zell-Lymphom (Chen et al. 2008) und für einige Formen der akuten lymphatischen Leukämie (Uckun et al. 2010 a) eine onkogene Funktion von Syk gezeigt werden. Die Inhibition von Syk durch Kinaseinhibitoren wie Fostamatinib konnte bei Patienten mit Non-Hodgkin-Lymphom-Rezidiv in einer klinischen Phase-IIStudie ein progressionsfreies Überleben von im Median 4,2 Monaten erzielen (Friedberg et al. 2010).

Syk besteht aus zwei $\mathrm{N}$-terminalen $\mathrm{SH} 2$-Domänen, die spezifisch an Phosphotyrosine binden können und durch die Interdomäne A getrennt sind, und einer Cterminalen Kinasedomäne, die von den SH2-Domänen durch die Interdomäne B getrennt ist (siehe Abb. 3) (Sada et al. 2001). In der Interdomäne B befindet sich ein 23 Aminosäuren langer Abschnitt genannt linker insert, der in einer Isoform von Syk, genannt Syk-B, durch alternatives Splicing fehlt (Rowley et al. 1995). Besonders in der Interdomäne B findet sich eine Vielzahl von Tyrosinen, die nach einem BZRStimulus phosphoryliert werden und für die Aktivierung und Regulation von Syk wichtig sind (Furlong et al. 1997). Aber auch für die Adapterfunktion von Syk ist unter anderem die Interdomäne $B$ entscheidend. Für eine Reihe von Proteinen, wie die regulatorische p85a-Untereinheit der PI3-Kinase (Moon et al. 2005), den Guanosin- 
Austauschfaktor VAV (Deckert et al. 1996) oder das Adapterprotein SLP65 (Kulathu et al. 2009) konnte eine Bindung an Syk gezeigt werden.

Syk ist größtenteils im Zytosol lokalisiert und wird nach einem BZR-Stimulus an die Plasmamembran rekrutiert (Ma et al. 2001). In T-Zellen wird die Funktion von Syk durch das Syk-ähnliche Protein Zap-70 übernommen. Zap-70 weist viele Homologien im Aufbau und in der Aminosäuresequenz auf, es fehlt jedoch das linker insert, so dass Zap-70 eher Syk-B gleicht (Chan et al. 1992).

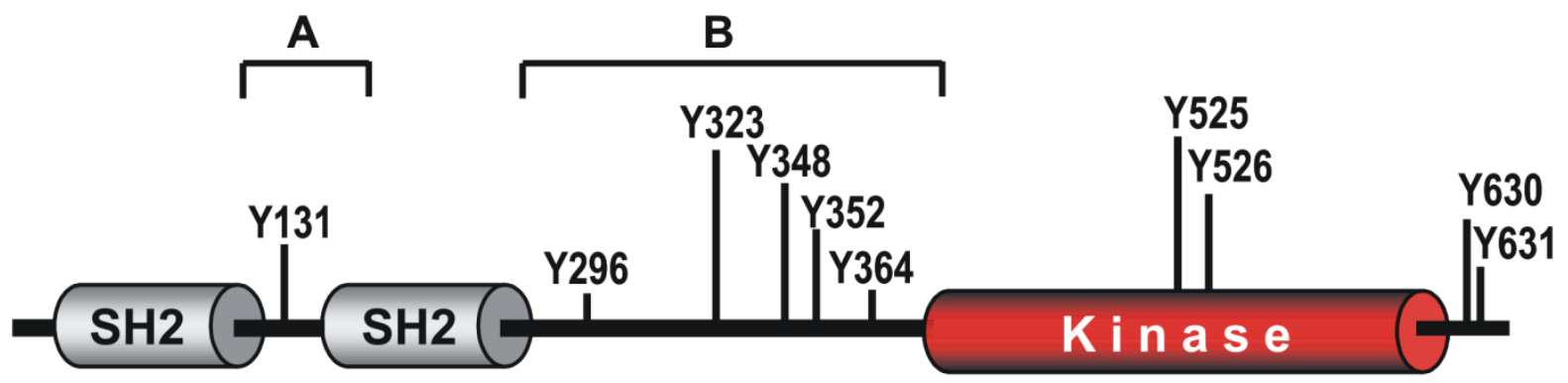

Abb. 3: Struktur von Syk. Eingezeichnet sind die Tandem-SH2-Domäne, die Kinasedomäne, die Interdomäne A und B sowie die bekannten Autophosphorylierungsstellen. Modifiziert nach Bohnenberger et al. (2011, S. 1552).

Wie die meisten Signalproteine weist Syk in unstimulierten B-Zellen nur eine geringe Aktivität auf, die nach einem BZR-Stimulus für einen begrenzten Zeitraum und an bestimmten subzellulären Lokalisationen in der B-Zelle stark ansteigt. Nach der Rekrutierung an die Plasmamembran und der Aktivierung durch Phosphorylierung und ITAM-Bindung phosphoryliert Syk eine Reihe von Zielproteinen und beeinflusst dadurch die Aktivität der Proteine oder schafft Bindemotive für Phosphotyrosinabhängige Bindedomänen wie SH2-Domänen (Geahlen 2009, Kulathu et al. 2009). Tatsächlich konnte gezeigt werden, dass Syk präferentiell Tyrosine in Aminosäuremotiven phosphoryliert, an die auch SH2-Domänen binden können (Brunati et al. 1995). Vergleicht man verschiedene von Syk phosphorylierte Motive, ergibt sich das Konsensusmotiv (Aminosäuren im Ein-Buchstaben-Kode) EXXDEEDY్YXPXEPX (Geahlen 2009).

Für viele Kinasen konnte gezeigt werden, dass sie sich in unstimulierten Zellen in einer autoinhibierten Konformation befinden, wobei die einzelnen Domänen sich gegenseitig in ihrer Funktion blockieren (Huse und Kuriyan 2002). Für Zap-70 konnte durch Analyse der kristallinen Struktur der molekulare Mechanismus dazu gezeigt werden. Dabei stabilisieren spezifische unphosphorylierte Tyrosin-Reste die autoin- 
hibierte Konformation. Durch Phosphorylierung dieser Tyrosin-Reste oder durch Interaktion der SH2-Domänen mit ITAM-Motiven werden diese intermolekularen Interaktionen gestört und Zap-70 geht in einen aktivierten Zustand über (Deindl et al. 2007). Für Syk konnte bisher keine hochauflösende Kristallstruktur erstellt werden, jedoch deuten verschiedene Studien, unter anderem auch eine niedrig aufgelöste dreidimensionale Struktur (Arias-Palomo et al. 2007 und 2009) darauf hin, dass Syk in ähnlicher Weise wie Zap-70 reguliert wird.

Es konnte gezeigt werden, dass Syk durch die Phosphorylierung von Tyrosin 348 und 352 (alle Aminosäureangaben beziehen sich auf humanes Syk) in der Interdomäne B aktiviert werden kann (Tsang et al. 2008). Diese Tyrosine können sowohl durch Syk selbst im Sinne einer Autophosphorylierung, als auch durch die SrcKinase Lyn phosphoryliert werden (Keshvara et al. 1998) und entsprechen den Tyrosinen in Zap-70, die für die Aufrechterhaltung der autoinhibierten Form wichtig sind. Syk kann aber genauso durch die Bindung der Tandem-SH2-Domänen an phosphorylierte ITAM-Motive aktiviert werden, so dass von einem Or-Gate gesprochen wird, da beide Aktivierungsalternativen zur vollen Aktivität von Syk führen (Tsang et al. 2008).

Ebenfalls zu einer Aktivierung führt die Phosphorylierung der drei C-terminalen Tyrosine (629, 630 und 631), die ein Bindemotiv für die SH2-Domäne von SLP65 darstellen. Es wird vermutet, dass Syk initial über den BZR an die Plasmamembran rekrutiert wird und nach der Internalisierung des gebundenen Antigens zusammen mit dem BZR Syk durch einen Komplex mit SLP65 als aktive Kinase an der Plasmamembran verbleibt (Kulathu et al. 2008, Abudula et al. 2007). Für Zap-70 konnte an homologen Tyrosinen eine Rolle bei der Stabilisierung der Autoinhibition gezeigt werden (Deindl et al. 2007).

Schließlich ist der BZR-abhängige Kalziumionen-Einstrom auch von der Phosphorylierung der Tyrosine 525 und 526 in der Aktivierungsschleife der Kinase-Domäne von Syk abhängig, wobei der genaue Mechanismus unklar bleibt, weil anders als bei vielen anderen Kinasen (Adams 2003) die Kinase-Aktivität von Syk dadurch nicht beeinflusst wird (Zhang et al. 1998).

Über die Inhibition von Syk ist weit weniger bekannt. Ein wichtiger Negativregulator scheint jedoch, nachdem es initial die Aktivierung von Syk bewirkt, Lyn zu sein, das über die Aktivierung von Phosphatasen wie SHP (DeFranco et al. 1998) die Dephos- 
phorylierung von Syk bewirkt. In der Interdomäne B von Syk befindet sich das von Lyn phosphorylierte, inhibitorisch wirksame Tyrosin 323, an das im phosphorylierten Zustand unter anderem die E3-Ubiquitinligase $\mathrm{Cbl}$ bindet und zur Ubiquitinylierung von Syk führen kann (Hong et al. 2002). Ubiquitinylierung führt häufig zur proteasomalen Degradierung von Proteinen (Salomons et al. 2010), jedoch konnte in B-Zellen kein BZR-abhängiger Abbau von Syk gemessen werden (Kitaura et al. 2007, siehe auch Abb. 10, Seite 49), so dass auch ein vom Proteasom unabhängiger Inhibitionsmechanismus von Syk durch $\mathrm{Cbl}$ in Frage kommt. Eine weitere Aufschlüsselung der inhibitorisch wirksamen Elemente des BZR-Signalweges ist angesichts der Relevanz von Syk als Onkogen in vielen Neoplasien ein wichtiger Schritt zum Verständnis dieser Erkrankungen.

Neben der Beeinflussung von Proteinen über die Phosphorylierung von TyrosinResten ist für viele Proteine auch eine Regulation durch die Phosphorylierung von Serin- und Threonin-Resten beschrieben (Weiel et al. 1990), die jedoch bisher für Syk weit weniger ausführlich erforscht ist. Für Threonin 530 konnte gezeigt werden, dass es durch PLK1 phosphoryliert und dadurch die Kinase-Aktivität von Syk beeinflusst wird (Uckun et al. 2010 b). Bei der Vielzahl an Serinen und Threoninen in Syk kann jedoch von weiteren Tyrosin-unabhängigen Regulationsmechanismen ausgegangen werden. Die genaue Kenntnis über die Gesamtheit der phosphorylierten Serine und Threonine und ihrer Phosphorylierungskinetik könnte Hinweise auf weitere Regulationsmechanismen von Syk liefern.

\subsection{Massenspektrometrische Analysen von Signalwegen}

Bei der Transduktion extrazellulärer Signale über intrazelluläre Signalketten wirkt eine schwer zu überblickende Anzahl von teils noch unbekannten Effektorproteinen in einem multipel verknüpften Netzwerk zusammen (Olsen et al. 2006). Bei der Vielzahl an möglichen Interaktionen der Effektorproteine und der Anzahl an möglichen Phosphorylierungsstellen sind Methoden wie die Massenspektrometrie Möglichkeiten zum weiteren Verständnis von Signalkaskaden. Die klassische Funktion eines Massenspektrometers ist die Bestimmung der Masse eines Moleküls. Massenspektrometrische Untersuchungen haben den Vorteil, dass eine unvoreingenommene und globale Untersuchung eines Proteins vorgenommen werden kann (Walther und Mann 2010, Choudhary und Mann 2010). Dazu müssen das zu untersuchende Proteinge- 
misch zunächst proteolytisch verdaut (Shevchenko et al. 2006) und die Peptide mittels Elektrospray-lonisierung (ESI) (Fenn et al. 1989) ionisiert werden. Zur Bestimmung der Masse stehen dann verschiedene Systeme zur Verfügung. Für diese Arbeit wurde ein Orbitrap-Massenspektrometer verwendet. In diesem oszillieren die Peptide in einer bestimmten, von Masse und Ladung des Peptides abhängigen Frequenz um eine lonenfalle. Dadurch kann die Masse im Verhältnis zur Ladung $(\mathrm{m} / \mathrm{z})$ und die Intensität jedes Peptides gemessen und als sogenanntes Spektrum mit $\mathrm{m} / \mathrm{z}$ auf der Abszisse und der Intensität auf der Ordinate angezeigt werden kann (Scigelova und Makarov 2006). Dieser erste Schritt der Peptiderkennung wird als MS-Analyse bezeichnet. Allein die Masse genügt jedoch in komplexen Peptid-Gemischen nicht, um ein Peptid sicher zu identifizieren. Deshalb wird in einem zweiten Messschritt die Sequenz des Peptides bestimmt, was als MS/MS-Analyse bezeichnet wird. Dazu werden die Peptide zunächst in eine Kollisionskammer überführt, wo sie fragmentiert werden. Durch die erneute Messung der Masse der Bruchstücke kann die Aminosäuresequenz des Peptides bestimmt werden (Steen und Mann 2004). Durch den Abgleich der resultierenden MS- und MS/MS-Daten mit einer Datenbank (Perkins et al. 1999) werden die dazugehörigen Proteine ermittelt (Sadygov et al. 2004). Mittels elektronischer Datenverarbeitungsprogramme wie MaxQuant (Cox und Mann 2008) oder MsQuant (Schulze und Mann 2004) sind weitere quantitative Auswertungen möglich.

Häufig ist jedoch wichtiger, in welchem Ausmaß sich die Menge eines Proteins in zwei unterschiedlichen Konditionen, zum Beispiel in einer stimulierten im Vergleich zu einer unstimulierten Zelle, unterscheidet (Walther und Mann 2010), als die bloße Anwesenheit eines Proteins nachzuweisen. Eine Möglichkeit, quantitative Messungen durchzuführen, ist das stable isotop labeling of amino acids in cell culture, kurz SILAC (Ong et al. 2002). Dabei werden die zu untersuchenden Zellen mit unterschiedlich schweren Aminosäuren kultiviert. Der Massenunterschied wird dabei durch den Einbau von stabilen, schweren Isotopen von Kohlen-, Stick- oder Wasserstoff in die Aminosäuren Arginin und Lysin erreicht (siehe Abb.4 unten). Da Arginin und Lysin als essentielle Aminosäuren in eukaryoten Zellen nicht synthetisiert werden können, werden alle Proteine in den Zellen mit diesen veränderten Aminosäuren markiert. 
Durch die Kultivierung einer Kontrollzelllinie mit leichten Aminosäuren kann ein relativer Vergleich von zwei verschiedenen Versuchsbedingungen erzielt werden, da sich die Peptide durch einen Massenunterschied im Massenspektrometer unterscheiden lassen (Ong et al. 2002). Es ergeben sich Peptid-Paare, die sich in ihrer Masse genau um die SILAC-Modifizierungen unterscheiden. Somit sind den aufgereinigten Peptiden der einen Zelle korrespondierende Peptide der anderen Zelle zuzuordnen. Ist die Intensität des Peptides aus beiden Zellen gleich groß, so ist das Peptid in beiden Versuchsbedingungen in gleicher Menge vorhanden. Wenn jedoch die Intensitäten der Peptide aus den schweren und leichten Zellen deutlich abweichen, so besteht ein quantifizierbarer Unterschied zwischen den Versuchsbedingungen (siehe Abb. 4 oben).

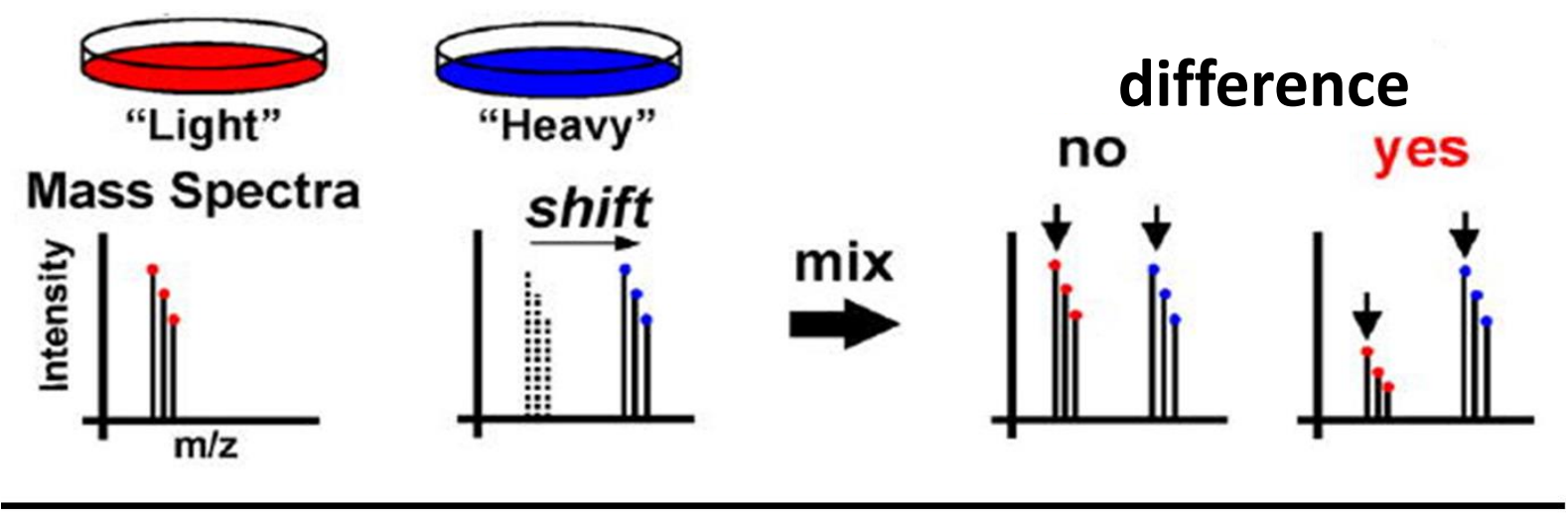

Mittelschwere Aminosäuren<smiles>NC(CCCC[CH2+][NH3+])C(=O)[O-]</smiles>

Lysin +4<smiles>[NH3+]C([NH3+])NCCCC([NH3+])C(=O)[O-]</smiles>

Arginin +6

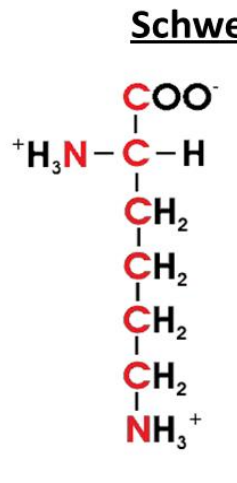

Lysin +8<smiles>NC(=[NH2+])NCCCC([NH3+])C(=O)[O-]</smiles>

Arginin +10

Abb. 4: Das SILAC-Prinzip. Der obere Abschnitt zeigt, wie sich die Spektren von leichten und schweren Peptiden zueinander verhalten, wenn die Peptide in unterschiedlichen Mengen vorliegen. Im unteren Abschnitt sind in Rot die Elemente der Aminosäuren dargestellt, die durch ein um eine Masseneineinheit schwereres Isotop $\left({ }^{2} \mathrm{D},{ }^{13} \mathrm{C}\right.$ oder $\left.{ }^{15} \mathrm{~N}\right)$ substituiert sind. Modifiziert nach Rinehart et al. (2009, S. 528).

Neben den Proteinmengen spielen posttranslationale Modifikationen (PTM) wie die Phosphorylierung eine wichtige Rolle bei allen zellulären Funktionen. Die Analyse 
von PTMs mittels Massenspektrometrie ist möglich, da jede zu einer definierten Massenänderung des Peptids führt. Dieser Massenunterschied kann im MS-Modus zunächst global für das Peptid bestimmt und dann im MS/MS-Modus einer spezifischen Aminosäure zugeordnet werden. Durch die Kombination der massenspektrometrischen Analyse phosphorylierter Peptide mit dem SILAC-Prinzip ist es über die reine Identifikation von Phosphorylierungsstellen hinaus auch möglich, Phosphorylierungskinetiken nach Rezeptorstimulation zu messen (Witze et al. 2007).

\subsection{Ziel der Studie}

Für das Verständnis der diversen Funktionen von Syk ist eine umfassende Kenntnis über die Regulation der Syk-Aktivität sowie der Interaktion von Syk mit spezifischen Effektorproteinen nötig. In den letzten Jahren sind in diesem Bereich große Fortschritte erzielt worden, insbesondere die Identifizierung von Phosphorylierungsstellen und die Untersuchung ihrer Funktion hat das Wissen über die Aktivierung von Syk stark vermehrt. Jedoch blieben viele Fragen, insbesondere zur Inhibition von Syk, bisher offen. Auch ist bisher wenig über die Phosphorylierung von Syk an Serinen und Threoninen bekannt.

Konventionelle Experimente wie die Ko-Immunopräzipitation einzelner Liganden haben den Nachteil, dass damit nur eine gezielte Überprüfung von Bindepartnern und Phosphorylierungsstellen möglich ist. Um dieses Problem zu überwinden, stellt die Massenspektrometrie in Kombination mit dem SILAC-Verfahren eine Möglichkeit dar, die Phosphorylierung und das Interaktom von Syk global und unvoreingenommen zu bestimmen.

Das Ziel dieser Studie soll die Analyse der BZR-abhängigen Phosphorylierungskinetik und des Interaktoms von Syk in B-Lymphozyten sein. Durch Mutationsanalysen der gefundenen Phosphorylierungsstellen und durch die Untersuchung der Konsequenzen einer solchen Mutation auf die Funktion von Syk im BZR-Signalweg sollen neue regulatorische Phosphorylierungsstellen und Interaktionspartner sowie deren Funktion identifiziert werden (siehe Abb. 5). 
Expression von Strep-Syk in Syk-defizienten DT40-B-Zellen

Aufreinigung von Strep-Syk mittels Streptaktin-Matrix

Massenspektrometrische Analyse des Phosphorylierungsprofils, der Phosphorylierungskinetik und des Interaktoms von Syk in BZR-aktivierten B-Zellen

Mutation von gefundenen Phosphorylierungsstellen in Syk und Expression in Syk-defizienten DT40-Zellen

Analyse der Auswirkungen der Mutationen mittels immunologischer, protein-biochemischer, massenspektrometrischer und durchflusszytometrischer Methoden und konfokaler Laser-Mikroskopie.

Identifizierung neuer Regulationsmechanismen von Syk im BZR-Signalweg

Abb. 5: Ziel der Studie. Die Abbildung zeigt zusammenfassend die Abfolge von Arbeitsschritten, die zur Identifizierung von neuen regulatorischen Elementen von Syk im BZR-Signalweg in dieser Arbeit erfolgt ist. 


\section{Material}

\subsection{Geräte}

\section{Autoklaven}

Bakterienbrutschrank Kelvitron

Blotwippe Duomax 1030

Blotapparatur T70/T77 semi-dry transfer unit

Bio-Photometer

Blotenwickler Optimax Typ TR

Durchflusszytometer FACS-Calibur

Elektrophoresekammer für DNA-Elektrophorese

Elektrophoresekammern für SDS-PAGE

Elektroporator Gene Pulser

ELISA-Auslesegerät Power Wave 340

Feinwaage R160P

Gel-Dokumentations-System Chemi Lux Imager

Konfokales Laser-Mikroskop TCS SP2

Kühlzentrifuge $5417 \mathrm{R}$

Kühlzentrifuge Sorvall RC 3B Plus

Massenspektrometer LTQ-Orbitrap XL Hybrid

Mikroskop DM IL

Multifuge 3 S-R

Nano-flow-LC-System 1100

PCR-Mastercycler EP Gradient

$\mathrm{pH}-$ Meter Level 1

Probenroller

Schüttelinkubator Unitron HT

Sicherheitswerkbank HeraSafe Typ H

Sonifier Cell Disruptor B-15

Spannungsquellen Electrophoresis Power Supply

Thermomixer Comfort

Water Purification System Milli-Q

Zellkultur-Inkubator Hera Cell 150
Integra Biosciences, Ruhberg

Heraeus, Hanau

Heidolph, Schwabach

Hoefer, Holliston, Massachusetts

Eppendorf, Hamburg

MS Laborgeräte, Dielheim

BD, Franklin Lakes, New Jersey

Peqlab, Erlangen

Biorad, München

Biorad, München

Biotek, Winooski, Vermont

Sartorius, Göttingen

Intas, Göttingen

Leica, Wetzlar

Eppendorf, Hamburg

MI-SS, Corona, California

Thermo, Waltham, Massachusetts

Leica, Wetzlar

Heraeus, Hanau

Agilent, Santa Clara, California

Eppendorf, Hamburg

inoLab, Weilheim

Fröbel Labor Technik, Lindau

Infors, Bottmingen, Schweiz

Heraeus, Hanau

Branson, Danbury, Connecticut

Amersham, München

Eppendorf, Hamburg

Millipore, Billerica, Massachusetts

Heraeus, Hanau 
2.2 Computersoftware und Internetadressen

\begin{tabular}{|c|c|}
\hline Beschreibung & Verwendung \\
\hline Photoshop CS2, Adobe, San Jose, Kalifornien & Bildbearbeitung \\
\hline CellQuest Pro, BD, Franklin Lakes, New Jersey & $\begin{array}{l}\text { Auswertung der Daten des } \\
\text { Durchflusszytometers }\end{array}$ \\
\hline Draw 10, Corel, Ottawa, Kanada & Bildbearbeitung \\
\hline CSX-1400M Kamera Controller, Intas, Göttingen & Westernblot-Fotografie \\
\hline FlowJo alias 3.5.3, Tree Star, Ashland, Oregon & $\begin{array}{l}\text { Auswertung der Daten des } \\
\text { Durchflusszytometers }\end{array}$ \\
\hline Gel-Dokumentations-Software GDS, Intas, Göttingen & Fotografie von Agarose-Gelen \\
\hline http://elm.eu.org/ & In-silico-Analyse von Syk \\
\hline http://frodo.wi.mit.edu/primer3/ & Primerdesign \\
\hline http://multalin.toulouse.inra.fr/multalin/multalin.html & Protein- und DNA-Vergleich \\
\hline http://scansite.mit.edu/ & In-silico-Analyse von Syk \\
\hline http://www.expasy.org/ & Protein-Datenbank \\
\hline http://www.ncbi.nlm.nih.gov & Pubmed \\
\hline ImageJ 1.42q, NIH, Bethesda, Maryland & $\begin{array}{l}\text { Auswertung der konfokalen } \\
\text { Laser-Mikroskopie }\end{array}$ \\
\hline IPI Chicken 3.47, EBI, Cambridge, Massachusetts & Peptid-Datenbank \\
\hline IPI Human 3.6, EBI, Cambridge, Massachusetts & Peptid-Datenbank \\
\hline SP2 System, Leica, Wetzlar & Konfokale Mikroskopie \\
\hline $\begin{array}{l}\text { MASCOT 2.2.04, Matrix Science, Boston, Massachu- } \\
\text { setts }\end{array}$ & $\begin{array}{l}\text { Suchmaschine für Peptidab- } \\
\text { gleich }\end{array}$ \\
\hline MaxQuant 1.0.12.31, MPI, München & $\begin{array}{l}\text { Auswertung Massenspektro- } \\
\text { metrischer Daten }\end{array}$ \\
\hline MsQuant 2.0b6, CEBI, Odense, Dänemark & $\begin{array}{l}\text { Auswertung Massenspektro- } \\
\text { metrischer Daten }\end{array}$ \\
\hline Excel 2010, Microsoft, Redmond, Washington & $\begin{array}{l}\text { Statistik, Erstellung von Dia- } \\
\text { grammen }\end{array}$ \\
\hline pDRAW 3.1, AcaClone Software & In-silico-DNA-Bearbeitung \\
\hline
\end{tabular}

Tabelle 1: Verwendete Software und Internetadressen 


\subsection{Materialien}

$1.5 \mathrm{ml}$ und $2 \mathrm{ml}$ Verschlussröhrchen Affinitätspräzipitations-Säulchen $5 \mathrm{ml}$ Akkupipettierhilfe Pipetboy

Blotting-Papier

Elektroporationsküvetten $4 \mathrm{~mm}$

Gekammerte Deckgläser Lab-Tek

NuPAGE Bis-Tris Gradientengel 4 - 12\%

HPLC C18 Säulen

Nitrocellulose (Hybond ${ }^{\mathrm{TM}} \mathrm{ECL}{ }^{\mathrm{TM}}$ )

PCR-Röhrchen

Pipetten $(2,5 ; 20 ; 100 ; 1.000 \mu l)$

Sterilfilter

Streptavidin-beschichtete ELISA-Platte

$\mathrm{TiO}_{2}$-Säulchen

Ultrafiltrations-Zentrifugen-Röhrchen Vivaspin

Zellkultur Plastikware

\subsection{Chemikalien und Reagenzien}

ABTS

Acetonitril

Acrylamid

Agarose

Agar

Ammoniumhydroxid

Ammoniumperoxidosulfat (APS)

Ampicillin

Azid $\left(\mathrm{NaN}_{3}\right)$

ATP

Biotinyliertes Gastrin-Vorläufer-Peptid (Tyr87)

Blasticidin

BSA

Bromphenolblau (BPB)

Coomassie Blue R250

Coomassie Plus 200 Bradford Reagenz

Desthiobiotin

Dimethylsulfoxid (DMSO)

DMEM-Medium

DNA-Marker GeneRuler ${ }^{\mathrm{TM}} 1 \mathrm{~kb}$

2,5-Dihydroxybenzoesäure

Dithiothreitol (DTT)

EDTA
Eppendorf, Hamburg

Thermo, Waltham, Massachusetts

Integra, Zizers, Schweiz

Whatman, Maidstone, UK

Peqlab, Erlangen

EMS, Hatfield, Pennsylvania

Invitrogen, Carlsbad, Kalifornien

Dr. Maisch, Ammerbuch-Entringen

Amersham, München

Thermo, Waltham, Massachusetts

Eppendorf, Hamburg

Roth, Karlsruhe

Millipore, Billerica, Massachusetts

GL Sciences Inc

Sartorius, Göttingen

Greiner, Nunc, Falcon

Sigma, St. Louis, Missouri

Merck, Darmstadt

Roth, Karlsruhe

Invitrogen, Carlsbad, Kalifornien

Sigma, St. Louis, Missouri

Sigma, St. Louis, Missouri

Merck, Darmstadt

Invitrogen, Carlsbad, Kalifornien

Sigma, St. Louis, Missouri

Sigma, St. Louis, Missouri

CST, Danvers, Massachusetts

Invitrogen, Carlsbad, Kalifornien

PAA, Pasching, Österreich

Roth, Karlsruhe

Roth, Karlsruhe

Thermo, Waltham, Massachusetts

IBA, Göttingen

Roth, Karlsruhe

Gibco, Darmstadt

Fermentas, St. Leon-Rot

Sigma, St. Louis, Missouri

Sigma, St. Louis, Missouri

Roth, Karlsruhe 


\section{EGTA}

Ethanol

Essigsäure

Ethidiumbromid

Fetales Kälberserum (FCS)

Ficoll

Dialysiertes fetales Kälberserum

L-Glutamin

Glutathione-Sepharose-Beads

Glutathion

Glycerin (87\%)

Glycin

IGEPAL CA-630 (NP40)

Glucose

Hefe-Extrakt

Hepes

Hühnchen-Serum (CS)

Indo-1

lodazetamid

Isopropanol

Isopropyl- $\beta$-D-thiogalactosid (IPTG)

Kaliumazetat

Kaliumchlorid

Kaliumhydroxid

Kaliumhydrogenphosphat

Kalziumchlorid

Kanamycin

L-Arginin

L-Arginin +6

L-Arginin +10

LDS

Luminol

L-Lysin

L-Lysin +4

L-Lysin +8

Magnesiumchlorid

Manganchlorid

$\beta$-Mercaptoethanol

Methanol

Methansäure

3-Morpholinopropansulfonsäure (MOPS)

Natriumazid

Natriumcarbonat
Roth, Karlsruhe

Roth, Karlsruhe

Roth, Karlsruhe

Sigma, St. Louis, Missouri

Gibco, Darmstadt

Sigma, St. Louis, Missouri

PAA, Pasching, Österreich

PAA, Pasching, Österreich

Amersham, München

Amersham, München

Roth, Karlsruhe

Sigma, St. Louis, Missouri

Sigma, St. Louis, Missouri

Roth, Karlsruhe

Roth, Karlsruhe

Roth, Karlsruhe

Gibco, Darmstadt

Molecular Probes, Eugene, Oregon

Sigma, St. Louis, Missouri

Merck, Darmstadt

AppliChem, Darmstadt

Roth, Karlsruhe

Roth, Karlsruhe

Roth, Karlsruhe

Merck, Darmstadt

Roth, Karlsruhe

Sigma, St. Louis, Missouri

Sigma, St. Louis, Missouri

Sigma, St. Louis, Missouri

Sigma, St. Louis, Missouri

Invitrogen, Carlsbad, Kalifornien

Sigma, St. Louis, Missouri

Sigma, St. Louis, Missouri

Cambridge Isotopes, Andover, Massa-

chusetts

Roth, Karlsruhe

Sigma, St. Louis, Missouri

Roth, Karlsruhe

Roth, Karlsruhe

Merck, Darmstadt

Roth, Karlsruhe

Sigma, St. Louis, Missouri

Roth, Karlsruhe 
Natriumchlorid

Natriumflorid

Natriumhydrogenphosphat

Natriumdodecylsulfat (SDS)

dNTPs

Orthovanadat $\left(\mathrm{Na}_{3} \mathrm{VO}_{4}\right)$

Para-Hydroxycoumarinsäure

Penicillin/Streptomycin

Peptone

Pluronic F-127

Polybrene (Hexadimethrinbromid)

Protease-Inhibitor-Cocktail (P 2714)

Protein-A/G-Plus-Agarose

Proteinmarker (vorgefärbt, 6.5-175 kDa)

Puromycin

Redox-Substanz

RPMI-1640-Medium

Salzsäure

SILAC-RPMI-1640-Medium

Sodium-Pyruvat

Streptaktin-Sepharose-Beads

Tetramethylethylendiamin (TEMED)

Transfektionsreagenz FuGENE

Trifluoressigsäure

Tris-(hydroximethyl)-aminomethan (Tris)

Triton X-100

Trypsin

Modifiziertes Trypsin

Tween-20

X-gal

Wasserstoffperoxid
Ridel-de Haën, Seelze

Sigma, St. Louis, Missouri

Merck, Darmstadt

Sigma, St. Louis, Missouri

NEB, Ipswich, Massachusetts

Sigma, St. Louis, Missouri

Sigma, St. Louis, Missouri

Sigma, St. Louis, Missouri

Roth, Karlsruhe

Molecular Probes, Eugene, Oregon

Sigma, St. Louis, Missouri

Sigma, St. Louis, Missouri

SCBT, Santa Cruz, Kalifornien

NEB, Ipswich, Massachusetts

Invitrogen, Carlsbad, Kalifornien

Invitrogen, Carlsbad, Kalifornien

Gibco, Darmstadt

Roth, Karlsruhe

Thermo, Waltham, Massachusetts

Biochrom, Berlin

IBA, Göttingen

Roth, Karlsruhe

Roche, Risch, Schweiz

Sigma, St. Louis, Missouri

Roth, Karlsruhe

Sigma, St. Louis, Missouri

Gibco, Darmstadt

Promega, Madison, Wisconsin

Roth, Karlsruhe

AppliChem, Darmstadt

Roth, Karlsruhe

\subsection{Puffer und Medien}

Sofern nichts anderes angegeben, wurden alle Puffer und Medien in doppelt deionisiertem Wasser $\left(\mathrm{ddH}_{2} \mathrm{O}\right)$ angesetzt. Medien für $\mathrm{E}$. coli wurden für 30 min bei $125^{\circ} \mathrm{C}$ autoklaviert und bei $4^{\circ} \mathrm{C}$ gelagert. FCS und CS wurden für 20 min bei $56^{\circ} \mathrm{C}$ hitzeinaktiviert und bei $-20^{\circ} \mathrm{C}$ gelagert. Alle Puffer und Medien wurden, wenn nicht anders angegeben, bei RT gelagert.

Blot-Transfer-Puffer

192 mM Glycin ; 25 mM Tris ; 0,1\% (w/v) SDS ; $20 \%(v / v)$ Methanol 
Agarose-Gel

Bakterien-Lysepuffer

Block-Puffer

DNA-Laufpuffer

ECL-Lösung

Einfriermedium

Glutathion-Elutionspuffer Indo-1

Kinase-Puffer

Kinase-ATP-Substrat-Lösung

Kinase-Stopp-Puffer

Kinase-ABTS-Puffer

Krebs-Ringer-Lösung

Laemmli-Puffer

LB-Medium

LB-Amp-Medium

LB-Kan-Medium

LB-Agar

PBS

PBS-T

Polybrene-Lösung
TAE-Puffer ; $1 \%(\mathrm{w} / \mathrm{v})$ Agarose ; 0,01\% (v/v) Ethidiumbromid ; aufkochen lassen und bei $60^{\circ} \mathrm{C}$ lagern $50 \mathrm{mM}$ Tris/HCl pH 7,4; 150 mM NaCl ; 5 mM DTT; $2 \%(\mathrm{v} / \mathrm{v})$ Protease Inhibitor Cocktail

TBS-T ; $5 \%$ BSA (w/v) $; 0.001 \% \mathrm{NaN}_{3}$

$10 \mathrm{mM}$ Tris/HCl pH 8,$0 ; 1 \mathrm{mM}$ EDTA ; 0,25\% (w/v) BPB ; $15 \%(w / v)$ Ficoll

4ml Lösung A: 0.1M Tris/HCl, $\mathrm{pH} 8.6 ; 250 \mathrm{mg} / \mathrm{ml}$ Luminol ; $4^{\circ} \mathrm{C} ; 400 \mu \mathrm{l}$ Lösung B: $1,1 \mathrm{~g} / \mathrm{l}$ parahydroxy-coumarin in DMSO ; $1,2 \mu \mathrm{l} 30 \% \mathrm{H}_{2} \mathrm{O}_{2}$

hitzeinaktiviertes FCS ; 10\% (v/v) DMSO ; $4^{\circ} \mathrm{C}$

$50 \mathrm{mM}$ Tris/HCl pH 8,0; $10 \mathrm{mM}$ Glutathion $1 \mathrm{mM}$ in DMSO

$120 \mathrm{mM}$ HEPES $\mathrm{pH} 7,5 ; 10 \mathrm{mM} \mathrm{MgCl}_{2} ; 10 \mathrm{mM}$ $\mathrm{MnCl}_{2} ; 6 \mu \mathrm{M} \mathrm{Na}_{3} \mathrm{VO}_{4} ; 1,25 \mathrm{mM}$ DTT

$40 \mu \mathrm{M}$ ATP ; $50 \%$ (v/v) Substrat-Peptid

50 mM EDTA, pH 8

ABTS ; $0,4 \%(v / v) \mathrm{H}_{2} \mathrm{O}_{2}$

$140 \mathrm{mM} \mathrm{NaCl} ; 4 \mathrm{mM} \mathrm{KCl} ; 1 \mathrm{mM} \mathrm{MgCl} 2 ; 10 \mathrm{mM}$;

Glukose ; 10 mM HEPES pH 7,4 ; autoklaviert, $4^{\circ} \mathrm{C}$;

entweder $0,5 \mathrm{mM}$ EGTA oder $1 \mathrm{mM} \mathrm{CaCl} 2$

125 mM Tris/HCl pH 6,8; 4\% (w/v) SDS ; 2 mM EDTA ; 20\% (v/v) Glycerin ; 0,02\% (w/v) Bromphenolblau ; $10 \%(\mathrm{v} / \mathrm{v}) \beta$-Mercaptoethanol

$10 \mathrm{~g} / \mathrm{l}$ Peptone; $5 \mathrm{~g} / \mathrm{l} \mathrm{Hefe}$ Extrakt ; $10 \mathrm{~g} / \mathrm{l} \mathrm{NaCl} ; 4^{\circ} \mathrm{C}$

LB-Medium ; $100 \mu \mathrm{g} / \mathrm{ml}$ Ampicillin ; $4^{\circ} \mathrm{C}$

LB-Medium ; $50 \mu \mathrm{g} / \mathrm{ml}$ Kanamycin ; $4^{\circ} \mathrm{C}$

LB-Medium ; 2\% (w/v) Agar ; $100 \mu \mathrm{g} / \mathrm{mL}$ Ampicillin oder $50 \mu \mathrm{g} / \mathrm{ml}$ Kanamycin ; $4^{\circ} \mathrm{C}$

$137,5 \mathrm{mM} \mathrm{NaCl} ; 2,7 \mathrm{mM} \mathrm{KCl} ; 1,5 \mathrm{mM} \mathrm{KH}_{2} \mathrm{PO}_{4}$; $8,6 \mathrm{mM} \mathrm{Na}_{2} \mathrm{HPO}_{4}$

PBS ; $0,1 \%(w / v)$ Tween-20

PBS ; 3 mg/ml Polybrene 
RPMI-Medium

DMEM-Medium

RPMI-SILAC-Medium

SDS-PAGE-Laufpuffer

SDS-PAGE-Trenngelpuffer

SDS-PAGE-Sammelgelpuffer

SDS-PAGE-Trenngel

SDS-PAGE-Sammelgel

TAE-Puffer

TBS-T

TFB-I-Puffer

TFB-II-Puffer

Trypsin/EDTA-Lösung

Zell-Lysepuffer
RPMI ; 10\% (v/v) hitzeinaktiviertes FCS ; $50 \mathrm{U} / \mathrm{ml}$ Penicillin ; 50 g/ml Streptomycin ; für DT40 zusätzlich $1 \%(\mathrm{v} / \mathrm{v}) \mathrm{CS}$

DMEM ; 10\% (v/v) hitzeinaktiviertes FCS ; $50 \mathrm{U} / \mathrm{ml}$ Penicillin ; $50 \mu \mathrm{g} / \mathrm{ml}$ Streptomycin

RPMI SILAC Medium ; 10\% (v/v) hitzeinaktiviertes, dialysiertes FCS ; $50 \mathrm{U} / \mathrm{ml}$ Penicillin ; $50 \mu \mathrm{g} / \mathrm{ml}$ Streptomycin ; 2 mg/ml Arginin $(+0 ;+6$ oder $+10 u)$; $4 \mathrm{mg} / \mathrm{ml}$ Lysin $(+0 ;+4$ oder $+8 \mathrm{u})$;

25 mM Tris ; 192 mM Glycin ; 3,5 mM SDS

$1,5 \mathrm{mM}$ Tris/HCl pH 8,$8 ; 0,4 \%$ (w/v) SDS

$500 \mathrm{mM}$ Tris/HCl pH 6,8;0,4\% (w/v) SDS

$375 \mathrm{mM}$ Tris/HCl, $\mathrm{pH} 8,8$; 0,1\% (w/v) SDS ; 10\% (w/v) Acrylamid ; 0,1\% TEMED ; 0,1\% APS (10\%)

$125 \mathrm{mM}$ Tris/HCl, $\mathrm{pH} 6,8 ; 0,1 \%$ (w/v) SDS ; 4,8\% (w/v) Acrylamid ; 0,1\% TEMED ; 0,1\% APS (10\%)

$40 \mathrm{mM}$ Tris/Essigsäure (HAc) $\mathrm{pH} 7,8 ; 1$ mM EDTA $\mathrm{pH} 8,0$

$10 \mathrm{mM}$ Tris/HCl pH 8,0; $100 \mathrm{mM} \mathrm{NaCl} ; 0,1 \%$ (v/v)

Tween-20

$50 \mathrm{mM} \mathrm{MnCl}_{2} ; 100 \mathrm{mM} \mathrm{KCl} ; 10 \mathrm{mM} \mathrm{CaCl}_{2} ; 30 \mathrm{mM}$ KOAc pH 6,8; 15\% (v/v) Glycerin ; mit Ethansäure auf $\mathrm{pH} 6,1$ einstellen; sterilfiltrieren; $4^{\circ} \mathrm{C}$

$75 \mathrm{mM} \mathrm{CaCl}_{2} ; 10 \mathrm{mM} \mathrm{KCl} ; 10 \mathrm{mM}$ MOPS ; 15\%

(v/v) Glycerin ; mit KOH auf pH 7,0 einstellen ; sterilfiltriert ; $4^{\circ} \mathrm{C}$

PBS; 0.05\% (w/v) Trypsin; 0.02\% (w/v) EDTA; $4^{\circ} \mathrm{C}$

$50 \mathrm{mM}$ Tris/HCl pH 8,0 ; $150 \mathrm{mM} \mathrm{NaCl} ; 5$ mM NaF; $1 \mathrm{mM} \mathrm{Na} \mathrm{VO}_{4} ; 2 \%(\mathrm{v} / \mathrm{v})$ Protease Inhibitor Cocktail; $0,5 \%$ NP40 


\subsection{Enzyme}

Alkaline Phosphatase (CIP)

Phusion-DNA-Polymerase

Restriktionsendonukleasen

T4-DNA-Ligase

Taq-DNA-Polymerase

\subsection{Kits}

Plasmidpräparation Mini

Plasmidpräparation Midi

DNA-Präparation Agarosegel

Klonierung in PCRII-TOPO
NEB, Ipswich, Massachusetts

Finnzyme, Vantaa, Finnland

NEB, Ipswich, Massachusetts

NEB, Ipswich, Massachusetts

NEB, Ipswich, Massachusetts

PureYield $^{\mathrm{TM}}$ Plasmid Miniprep System,

Promega, Madison, Wisconsin

PureYield ${ }^{\text {TM }}$ Plasmid Midiprep System,

Promega, Madison, Wisconsin

Wizard® Clean-Up System, Promega,

Madison, Wisconsin

TOPO ${ }^{\circledR}$ TA Cloning ${ }^{\circledR}$ Kit, Invitrogen,

Carlsbad, Kalifornien

\subsection{Vektoren}

\begin{tabular}{|l|l|l|}
\hline Vektor & Beschreibung & Herkunft \\
\hline pCRII-TOPO & $\begin{array}{l}\text { Zur Sicherung von PCR-Produkten } \\
\text { mittels T/A-Klonierung, Ampicillin- und } \\
\text { Kanamycinresistenz }\end{array}$ & $\begin{array}{l}\text { Invitrogen, Carls- } \\
\text { bad, Kalifornien }\end{array}$ \\
\hline pGEX & $\begin{array}{l}\text { Zur Expression von GST- } \\
\text { Fusionsproteinen in Bakterienzellen, } \\
\text { GST-Gen N-terminal des Polylinker, } \\
\text { Ampicillinresistenz }\end{array}$ & $\begin{array}{l}\text { Amersham, Mün- } \\
\text { chen }\end{array}$ \\
\hline pAbes-N-Strep & $\begin{array}{l}\text { Zur retroviralen Transfektion, } \beta \text {-Aktin } \\
\text { Promotor, STrEP-Tag-DNA (IBA, Göt- } \\
\text { tingen) N-terminal des Polylinkers, } \\
\text { Ampicillin- und Puromycinresistenz }\end{array}$ & $\begin{array}{l}\text { Takata et al., } \\
1994, \text { modifiziert } \\
\text { von Dr. T. Oelle- } \\
\text { rich, Göttingen }\end{array}$ \\
\hline pMSCV-Puro-N-Citrin & $\begin{array}{l}\text { Zur retroviralen Transfektion mittels } \\
\text { PlatE-Zellen, Citrin-Gen vor dem Poly- } \\
\text { linker, Ampicillin- und Puromycinresis- } \\
\text { tenz }\end{array}$ & $\begin{array}{l}\text { Clontech (Moun- } \\
\text { tain View, Kalifor- } \\
\text { nien), modifiziert } \\
\text { von Dr. M. Engel- } \\
\text { ke, Göttingen }\end{array}$ \\
\hline pHCMV-VSV-G & $\begin{array}{l}\text { Zur Expression von VSV-G in PlatE- } \\
\text { Zellen zur Pseudotypisierung rekombi- } \\
\text { nanter Retroviren }\end{array}$ & $\begin{array}{l}\text { Labor Dr. M. } \\
\text { Jücker, UKE } \\
\text { Hamburg }\end{array}$ \\
\hline
\end{tabular}

Tabelle 2: Verwendete Vektoren 


\section{9 cDNAs}

Die cDNA von humanem Syk lag bereits in der Arbeitsgruppe von Herrn Prof. Dr. Wienands vor. Die cDNA von humanem SLP76 wurde freundlicherweise von D. Yablonski (Haifa, Israel) bereitgestellt.

\subsection{Oligonukleotide (Primer)}

Alle Oligonukleotide wurden von Eurofins MWG Operon (Ebersberg) synthetisiert. Die Anlagerungstemperatur der Primer für die PCR wurde mit Hilfe von http://frodo.wi.mit.edu/primer3/ errechnet. Für die Mutagenese-Primer wurde generell eine Anlagerungstemperatur von $70^{\circ} \mathrm{C}$ gewählt.

\begin{tabular}{|c|c|c|}
\hline Primer & Sequenz $5^{‘} \rightarrow 3^{‘}$ & $\begin{array}{l}\text { Anlagerungs- } \\
\text { temperatur }\end{array}$ \\
\hline \multicolumn{3}{|c|}{ Syk für pAbes } \\
\hline Fw BamHI & AAAGGATCCACCATGGCCAGCAGCGG & $62^{\circ} \mathrm{C}$ \\
\hline Bw Xhol & $\begin{array}{l}\text { AAACTCGAGTTAGTTCACCACGTCATAGTAG- } \\
\text { TAATTG }\end{array}$ & $62^{\circ} \mathrm{C}$ \\
\hline \multicolumn{3}{|c|}{ Syk Mutagenese-Primer } \\
\hline S44A fw & $\begin{array}{l}\text { CTTTATTTGCTGCGCCAGGCCCGCAACTAC- } \\
\text { CTGGG } \\
\end{array}$ & Siehe Hinweis \\
\hline bw & $\begin{array}{l}\text { CCCAGGTAGTT- } \\
\text { GCGGGCCTGGCGCAGCAAATAAAG }\end{array}$ & Siehe Hinweis \\
\hline S44E fw & $\begin{array}{l}\text { CTTTATTTGCTGCGCCAGGAGCGCAACTAC- } \\
\text { CTGGG }\end{array}$ & Siehe Hinweis \\
\hline bw & $\begin{array}{l}\text { CCCAGGTAGTT- } \\
\text { GCGCTCCTGGCGCAGCAAATAAAG }\end{array}$ & Siehe Hinweis \\
\hline S202A fw & $\begin{array}{l}\text { CAGAGACAACAACGGCGCCTACGCCCTGTGCC } \\
\text { TG }\end{array}$ & Siehe Hinweis \\
\hline bw & $\begin{array}{l}\text { CAGGCACAGGGCGTAGGCGCCGTTGTT- } \\
\text { GTCTCTG }\end{array}$ & Siehe Hinweis \\
\hline S202E fw & $\begin{array}{l}\text { CAGAGACAACAACGGCGAG- } \\
\text { TACGCCCTGTGCCTG }\end{array}$ & Siehe Hinweis \\
\hline bw & $\begin{array}{l}\text { CAGGCACAGGGCGTACTCGCCGTTGTT- } \\
\text { GTCTCTG }\end{array}$ & Siehe Hinweis \\
\hline T256V fw & GGTTTGTTAAGAGTTCTTGTTGTCCCATGTC & Siehe Hinweis \\
\hline bw & GACATGGGACAACAAGAACTCTTAACAAACC & Siehe Hinweis \\
\hline
\end{tabular}




\begin{tabular}{|c|c|c|}
\hline S295A fw & CTCAAGAATCAAAGCATACTCСTTCCCAAAGC & Siehe Hinweis \\
\hline bw & GCTTTGGGAAGGAGTATGCTTTGATTCTTGAG & Siehe Hinweis \\
\hline S297A fw & GAATCAAATCATACGCCTTCCCAAAGCCTGGC & Siehe Hinweis \\
\hline bw & GCCAGGCTTTGGGAAGGCGTATGATTTGATTC & Siehe Hinweis \\
\hline S306A fw & $\begin{array}{l}\text { CCTGGCCACAGAAAGGCCTCCCCTGCCCAAGG } \\
\text { G }\end{array}$ & Siehe Hinweis \\
\hline bw & $\begin{array}{l}\text { CCCTTGGGCAGGGGAGGCCTTT- } \\
\text { CTGTGGCCAGG }\end{array}$ & Siehe Hinweis \\
\hline T317V fw & $\begin{array}{l}\text { GAACCGGCAAGAGAGTGTTGTGTCATTCA- } \\
\text { ATCCG }\end{array}$ & Siehe Hinweis \\
\hline bw & $\begin{array}{l}\text { CGGATTGAATGACACAACACTCTCTT- } \\
\text { GCCGGTTC }\end{array}$ & Siehe Hinweis \\
\hline Y323F fw & GTCATTCAATCCGTTTGAGCCAGAAC & Siehe Hinweis \\
\hline bw & GTTCTGGCTCAAACGGATTGAATGAC & Siehe Hinweis \\
\hline T371V fw & $\begin{array}{l}\text { GGACCGAAAGCTGCTGGTGCTG- } \\
\text { GAAGACAAAGAAC }\end{array}$ & Siehe Hinweis \\
\hline bw & $\begin{array}{l}\text { GTTCTTTGTCTTCCAGCACCAGCAGCTTT- } \\
\text { CGGTCC }\end{array}$ & Siehe Hinweis \\
\hline T530V fw & $\begin{array}{l}\text { CTACTACAAGGCCCAGGTCCATG- } \\
\text { GAAAGTGGCCTG }\end{array}$ & Siehe Hinweis \\
\hline bw & $\begin{array}{l}\text { CAGGCCACTTTCCATGGACCTGGGCCTTGTAG- } \\
\text { TAG }\end{array}$ & Siehe Hinweis \\
\hline \multicolumn{3}{|c|}{ Syk-B overlab extension für pMSCV } \\
\hline $\begin{array}{l}\text { 5‘ Teil-fw- } \\
\text { BamHI }\end{array}$ & AAAAGGATCCGAAGCATGGCCAGCAGC & $65^{\circ} \mathrm{C}$ \\
\hline 5‘ Teil-bw & GTGGCCAGGCTTTGGCAGGATGGGAACCTGGA & $65^{\circ} \mathrm{C}$ \\
\hline 3‘ Teil-fw & GTTCCCATCCTGCGTCCTCCCСTGCCCAAGG & $66^{\circ} \mathrm{C}$ \\
\hline $\begin{array}{r}\text { 3' Teil-bw- } \\
\text { Notl }\end{array}$ & AAAAGCGGCCGCGGAGCGGTTAGTTCACCACG & $67^{\circ} \mathrm{C}$ \\
\hline \multicolumn{3}{|c|}{ SLP76 für pMSCV } \\
\hline Fw-BamHI & AAAAGGATCCATGGCACTGAGGAATGTGCC & $66^{\circ} \mathrm{C}$ \\
\hline Bw-Notl & $\begin{array}{l}\text { AAAAGCGGCCGCCTATGGGTAC- } \\
\text { CCTGCAGCATG }\end{array}$ & $65^{\circ} \mathrm{C}$ \\
\hline
\end{tabular}




\begin{tabular}{|c|c|c|}
\hline \multicolumn{3}{|c|}{ SLP76 Mutagenese-Primer } \\
\hline $\mathrm{K} 85 \mathrm{P} \mathrm{fw}$ & $\begin{array}{l}\text { GAGCATCTTCACACGCCCAC- } \\
\text { CCCAAGTCCCGCGG }\end{array}$ & Siehe Hinweis \\
\hline bw & $\begin{array}{l}\text { CCGCGGGACTTGGGGTGGGCGTGTGAAGAT- } \\
\text { GCTC }\end{array}$ & Siehe Hinweis \\
\hline L334P fw & $\begin{array}{l}\text { CTTTGGCCCCAGCCAGCACCACTTCCTAT- } \\
\text { GAGCTCC }\end{array}$ & Siehe Hinweis \\
\hline bw & $\begin{array}{l}\text { GGAGCTCATAG- } \\
\text { GAAGTGGTGCTGGCTGGGGCAAAG }\end{array}$ & Siehe Hinweis \\
\hline $\begin{array}{l}\text { M337R + } \\
\text { L334P fw }\end{array}$ & CCAGCACCACTTCCTAGGAGCTCCAACACTTTC & Siehe Hinweis \\
\hline bw & $\begin{array}{l}\text { GAAAGTGTTGGAGCTCCTAG- } \\
\text { GAAGTGGTGCTGG }\end{array}$ & Siehe Hinweis \\
\hline N404R fw & СССTTGCCACTTCCAAGAAAACCTCGGCCCCC & Siehe Hinweis \\
\hline bw & GGGGGCCGAGGTTTTCTTGGAAGTGGCAAGGG & Siehe Hinweis \\
\hline
\end{tabular}

Tabelle 3: Verwendete Oligonukleotide

\subsection{Verwendete Konstrukte}

\begin{tabular}{|c|c|c|c|}
\hline Konstrukt & Einklonierte cDNA & Vektor & $\begin{array}{l}\text { Restriktionsstellen / } \\
\text { Herkunft }\end{array}$ \\
\hline $\begin{array}{l}\text { pAbes-Strep- } \\
\text { Syk }\end{array}$ & $\begin{array}{l}\text { Humanes Syk } \\
\text { Wildtyp und S297A }\end{array}$ & $\begin{array}{l}\text { pAbes-N- } \\
\text { Strep }\end{array}$ & BamHI / Xhol \\
\hline $\begin{array}{l}\text { pMSCV-Citrin- } \\
\text { Syk }\end{array}$ & $\begin{array}{l}\text { Humanes Syk: } \\
\text { Wildtyp, S44A, S44E, S202A, } \\
\text { S202E, S44+202A, } \\
\text { S44+202E, T256V, S295A, } \\
\text { S297A, S306A, T317V, } \\
\text { Y323F, S297A + Y323F, } \\
\text { T371V, T530V }\end{array}$ & $\begin{array}{l}\text { pMSCV- } \\
\text { Puro-N-Citrin }\end{array}$ & BamHI / Notl \\
\hline $\begin{array}{l}\text { pMSCV-Citrin- } \\
\text { SLP76 }\end{array}$ & $\begin{array}{l}\text { Humanes SLP76 } \\
\text { wildtyp und SLP76* }\end{array}$ & $\begin{array}{l}\text { pMSCV- } \\
\text { Puro-N-Citrin }\end{array}$ & BamHI / Notl \\
\hline $\begin{array}{l}\text { pMSCV-Citrin- } \\
\text { SLP65 }\end{array}$ & Humanes SLP65 & $\begin{array}{l}\text { pMSCV- } \\
\text { Puro-N-Citrin }\end{array}$ & $\begin{array}{l}\text { Dr. T. Oellerich, Göt- } \\
\text { tingen }\end{array}$ \\
\hline pGex-14-3-3y & Humanes 14-3-3y & pGex & $\begin{array}{l}\text { Dr. S. Beer-Hammer, } \\
\text { Düsseldorf }\end{array}$ \\
\hline
\end{tabular}

Tabelle 4: Verwendete Konstrukte 


\subsection{Antikörper}

Alle Antikörper wurden zur Westernblot-Analyse (WB) in TBS-T mit 5\% BSA und 0,001\% Azid in angegebener Konzentration eingesetzt.

\begin{tabular}{|c|c|c|c|}
\hline Antikörper & Spezies & Hersteller & $\begin{array}{l}\text { Anwendung und Verdün- } \\
\text { nung }\end{array}$ \\
\hline $\begin{array}{l}\text { anti-humanes-Syk } \\
\text { (4D10) }\end{array}$ & Maus & $\begin{array}{l}\text { SCBT, Santa Cruz, } \\
\text { Kalifornien }\end{array}$ & WB 1:1.000 ; IP: $2 \mu \mathrm{g} / \mathrm{ml}$ \\
\hline anti-Hühner-SLP65 & Kaninchen & T.Kurosaki & WB 1:2.000; IP: 1:1.000 \\
\hline anti-PLC-y2 (Q20) & Kaninchen & $\begin{array}{l}\text { SCBT, Santa Cruz, } \\
\text { Kalifornien }\end{array}$ & WB $1: 1.000 ; \mathrm{IP}: 2 \mu \mathrm{g} / \mathrm{ml}$ \\
\hline anti-GFP & Maus & $\begin{array}{l}\text { Roche, Risch, } \\
\text { Schweiz }\end{array}$ & WB $1: 1.000 ; \mathrm{IP}: 2 \mu \mathrm{g} / \mathrm{ml}$ \\
\hline anti-14-3-3y & Kaninchen & $\begin{array}{l}\text { CST, Danvers, } \\
\text { Massachusetts }\end{array}$ & WB 1:1.000 \\
\hline $\begin{array}{l}\text { anti-14-3-3-phospho- } \\
\text { Bindemotif }\end{array}$ & Kaninchen & $\begin{array}{l}\text { CST, Danvers, } \\
\text { Massachusetts }\end{array}$ & WB 1:1.000 \\
\hline anti-pTyr (4G10) & Maus & Biomol, Hamburg & WB 1:500 \\
\hline anti-GST & Kaninchen & $\begin{array}{l}\text { Molecular Probes, } \\
\text { Eugene, Oregon }\end{array}$ & WB 1:1.000 \\
\hline anti-Aktin & Kaninchen & $\begin{array}{l}\text { Sigma, St. Louis, } \\
\text { Missouri }\end{array}$ & WB 1:2.000 \\
\hline anti-Sek1 & Kaninchen & $\begin{array}{l}\text { CST, Danvers, } \\
\text { Massachusetts }\end{array}$ & WB 1:1.000 \\
\hline anti-Coronin1c & Maus & $\begin{array}{l}\text { SCBT, Santa Cruz, } \\
\text { Kalifornien }\end{array}$ & WB 1:200 \\
\hline anti-Ubiquitin & Kaninchen & $\begin{array}{l}\text { SCBT, Santa Cruz, } \\
\text { Kalifornien }\end{array}$ & WB 1:200 \\
\hline anti-Cin85 & Kaninchen & $\begin{array}{l}\text { Sigma, St. Louis, } \\
\text { Missouri }\end{array}$ & WB 1:1.000 \\
\hline $\begin{array}{l}\mathrm{F}(\mathrm{ab})_{2} \text {-Fragment anti- } \\
\text { humanes-IgM }\end{array}$ & Ziege & Dianova, Hamburg & $\begin{array}{l}\text { Stimulation von DG-75- und } \\
\text { Ramos-Zellen mit } 10 \mu \mathrm{g} / \mathrm{ml}\end{array}$ \\
\hline $\begin{array}{l}\text { anti-Hühner-IgM } \\
\text { (Klon M-4) }\end{array}$ & Maus & Biozol, Eching & $\begin{array}{l}\text { Stimulation von DT40- } \\
\text { Zellen mit } 0,2-2 \mu \mathrm{g} / \mathrm{ml}\end{array}$ \\
\hline $\begin{array}{l}\text { anti-Maus-IgG } \\
\text { HRPO-gekoppelt }\end{array}$ & Ziege & $\begin{array}{l}\text { Thermo, Waltham, } \\
\text { Massachusetts }\end{array}$ & $\begin{array}{l}\text { Sekundärer Antikörper, } \\
1: 10.000 \text { in TBS-T }\end{array}$ \\
\hline $\begin{array}{l}\text { anti-Kaninchen-IgG } \\
\text { HRPO-gekoppelt }\end{array}$ & Ziege & $\begin{array}{l}\text { Thermo, Waltham, } \\
\text { Massachusetts }\end{array}$ & $\begin{array}{l}\text { Sekundärer Antikörper, } \\
1: 10.000 \text { in TBS-T }\end{array}$ \\
\hline $\begin{array}{l}\mathrm{F}\left(\mathrm{ab}^{\prime}\right)_{2} \text {-Fragment anti- } \\
\text { Maus-IgM Cy-5- } \\
\text { gekoppelt }\end{array}$ & Esel & Dianova, Hamburg & $\begin{array}{l}\text { Bestimmung der Oberflä- } \\
\text { chenexpression von IgM } \\
\text { auf DT40-Zellen, } 1: 1.000\end{array}$ \\
\hline
\end{tabular}




\begin{tabular}{|l|l|l|l|}
\hline Isotypenkontrolle IgG & Maus & $\begin{array}{l}\text { BD, Franklin } \\
\text { Lakes, New Jersey }\end{array}$ & $\begin{array}{l}\text { Isotypenkontrolle bei Im- } \\
\text { munopräzipitationen mit } \\
\text { anti-GFP: } 2 \mu \mathrm{g} / \mathrm{ml}\end{array}$ \\
\hline Isotypenkontrolle $\mathrm{IgG}_{2 \mathrm{~A}}$ & Maus & $\begin{array}{l}\text { BD, Franklin } \\
\text { Lakes, New Jersey }\end{array}$ & $\begin{array}{l}\text { Isotypenkontrolle bei Im- } \\
\text { munopräzipitationen mit } \\
\text { anti-Syk: } 2 \mu \mathrm{m} / \mathrm{ml}\end{array}$ \\
\hline $\begin{array}{l}\text { Isotypenkontrolle Ka- } \\
\text { ninchen polyklonal }\end{array}$ & Kaninchen & $\begin{array}{l}\text { CST, Danvers, } \\
\text { Massachusetts }\end{array}$ & $\begin{array}{l}\text { Isotypenkontrolle bei Im- } \\
\text { munopräzipitationen mit } \\
\text { anti-SLP65 und anti-PLC- } \\
\text { Y2: 1:10.000 }\end{array}$ \\
\hline
\end{tabular}

Tabelle 5: Verwendete Antikörper

\subsection{Zelllinien}

\section{DT40 (ATCC CRL-2111)}

Diese Hühner-B-Lymphozyten-Zellinie ist durch die Infektion eines Hyline SC Huhns mit dem avian leukosis virus (ALV) und der Isolierung der Zellen aus einem bursalen Lymphom entstanden (Baba und Humphries 1984). DT40 exprimiert IgM auf der Oberfläche und eignet sich für die Etablierung von knock-out Zelllinien (Winding und Berchtold 2001). In dieser Arbeit wurden DT40-wildtyp-Zellen und DT40-Zellen, die entweder Syk oder SLP65 nicht exprimieren, als heterologes Expressionssystem verwendet.

\section{DG-75 (ATCC CRL-2625)}

Diese humane B-Lymphozyten-Zelllinie entstammt einem Burkitt-Lymphom, ist EBVnegativ und exprimiert auf der Zelloberfläche IgM (Ben-Bassat et al. 1977). Sie wurde in dieser Arbeit als heterologes Expressionssystem für Syk verwendet.

\section{Ramos (ATCC CRL-1596)}

Ramos ist eine weitere humane B-Lymphozyten-Zelllinie, die ebenfalls aus einem Burkitt-Lymphom entstammt, EBV-negativ ist und wiederum IgM auf der Zelloberfläche exprimiert (Klein et al. 1975). Sie wurde in dieser Arbeit für Immunopräzipitationsexperimente von Syk verwendet. 


\section{PlatE}

Die adhärente Zelllinie PlatE basiert auf der Zelllinie HEK293T und wurde mit dem gag-pol- und env-Gen des murinen Leukämievirus MMLV transfiziert (Morita et al. 2000). In dieser Arbeit wurden sie als Helferzelllinie zur Produktion von Retroviren zur retroviralen Transfektion von DT40- und DG-75-Zellen verwendet.

\section{Bakterienzelllinien}

E.coli Stamm Top10F- (Invitrogen, Carlsbad, Vermehrung von Plasmid-DNA Kalifornien)

E.coli Stamm BL21 (Novagen, Darmstadt) Expression von GST-

Fusionsproteinen 


\section{Methoden}

\subsection{Molekularbiologische Methoden}

\subsubsection{Polymerase-Kettenreaktion (PCR)}

Die Amplifizierung von cDNA erfolgte nach dem Prinzip der PolymeraseKettenreaktion (PCR), das erstmals 1986 von Mullis et al. beschrieben wurde. Die PCRs in dieser Arbeit wurden mit dem Phusion Kit von Finnzyme (Vantaa, Finnland) in dem PCR Mastercycler EP Gradient von Eppendorf, Hamburg durchgeführt. Dabei wurden stets folgender Standard-PCR-Ansatz und folgendes Standardprotokoll gewählt:

\begin{tabular}{|l|l|}
\hline Komponente & Konzentration / Menge \\
\hline DNA-Vorlage & $0,01 \mu \mathrm{g} / \mu \mathrm{l}$ \\
\hline 5 -Primer & $0,5 \mu \mathrm{M}$ \\
\hline 3'-Primer & $0,5 \mu \mathrm{M}$ \\
\hline dNTPs & $\mathrm{Je} 200 \mu \mathrm{M}$ \\
\hline Puffer & $1 \mathrm{x}$ \\
\hline Phusion-DNA-Polymerase & $0,015 \mathrm{U} / \mu \mathrm{l}$ \\
\hline $\mathrm{ddH}_{2} \mathrm{O}$ & Ansatz auf $20 \mu \mathrm{l}$ auffüllen \\
\hline
\end{tabular}

Tabelle 6: PCR-Standard-Ansatz

\begin{tabular}{|c|c|c|}
\hline Funktion & Temperatur und Zeit & $\begin{array}{l}\text { Anzahl } \\
\text { Zyklen }\end{array}$ \\
\hline Initiale Denaturierung & $98^{\circ} \mathrm{C}$ für $30 \mathrm{sec}$ & $1 \mathrm{x}$ \\
\hline Denaturierung & $98^{\circ} \mathrm{C}$ für $15 \mathrm{sec}$ & \multirow{3}{*}{$32 x$} \\
\hline Primer-Anlagerung & $\begin{array}{l}\text { Temperatur abhängig vom Primer } \\
\text { (siehe 2.10, Seite } 21-23 \text { ) für } 20 \mathrm{sec}\end{array}$ & \\
\hline Polymerisation & $\begin{array}{l}72^{\circ} \mathrm{C} \text { für } 20 \mathrm{sec} \text { je } \mathrm{kB} \text { des zu ampli- } \\
\text { fizierenden DNA-Abschnittes }\end{array}$ & \\
\hline Abschließende Polymerisation & $72^{\circ} \mathrm{C}$ für $10 \mathrm{~min}$ & $1 \mathrm{x}$ \\
\hline
\end{tabular}

Tabelle 7: PCR-Standard-Protokoll

\subsubsection{Mutagenese-Polymerase-Kettenreaktion}

Außer zur Amplifizierung von DNA-Abschnitten kann die PCR auch zur Mutagenese von einzelnen Basentriplets und daraus folgend zur Punktmutation von Proteinen eingesetzt werden. Dazu benötigt man einen zirkulären DNA-Vektor mit dem zu mutierenden DNA-Abschnitt. Die beiden Primer werden so gewählt, dass das zu mutierende Basentriplet von circa fünfzehn Basenpaaren flankiert wird. Das zu mutierende Basentriplet wird nicht komplementär zur Vorlage gewählt, sondern durch das ge- 
wünschte Triplet ausgetauscht. Die flankierenden Basenpaare sorgen dafür, dass sich die Primer dennoch an die DNA anlagern. Die Primer sind dabei direkt komplementär zueinander. Da die Vorlage zur Amplifizierung als zirkuläre DNA vorliegt, wird sie von nur einem Bereich ausgehend komplett amplifiziert, der Bereich des Primers jedoch dabei mutiert. Für den Ansatz zur PCR wurde dabei der gleiche Standard wie oben beschrieben gewählt, jedoch wurde das Cycling-Protokoll angepasst:

\begin{tabular}{|l|l|l|}
\hline Funktion & Temperatur und Zeit & Anzahl Zyklen \\
\hline Initiale Denaturierung & $98^{\circ} \mathrm{C}$ für $30 \mathrm{sec}$ & $1 \mathrm{x}$ \\
\hline Denaturierung & $98^{\circ} \mathrm{C}$ für $15 \mathrm{seC}$ & \multirow{2}{*}{} \\
\hline Primer-Anlagerung & $70^{\circ} \mathrm{C}$ für $30 \mathrm{sec}$ & $25 \mathrm{x}$ \\
\hline Polymerisation & $\begin{array}{l}72^{\circ} \mathrm{C} \text { für } 15 \mathrm{sec} \text { je kB des zu ampli- } \\
\text { fizierenden DNA-Abschnittes }\end{array}$ & $1 \mathrm{x}$ \\
\hline Abschließende Polymerisation & $72^{\circ} \mathrm{C}$ für 3 min & 20 \\
\hline
\end{tabular}

Tabelle 8: Mutagenese-PCR-Protokoll

Nach der Mutagenese-PCR wurde der Ansatz für $1 \mathrm{~h}$ bei $37^{\circ} \mathrm{C}$ mit $20 \mathrm{U}$ des Restriktionsenzyms DPNI inkubiert, das die Sequenz GATC schneidet, wenn Adenosin methyliert ist. Die Vorlage aus Bakterienzellen ist methyliert, die amplifizierte DNA jedoch nicht, so dass bei dem Verdau nur die mutierte DNA übrig bleibt. Die resultierende DNA wurde in kompetente Bakterien transformiert (siehe 3.1.8, S.31), ein PCR-Ansatz ohne Phusion-DNA-Polymerase diente als Negativkontrolle.

\subsubsection{Overlab extension PCR}

Eine dritte Anwendungsmöglichkeit der PCR besteht in der Deletion von einzelnen Basenabschnitten der DNA mittels der overlab extension PCR, die zur Klonierung der DNA von Syk-B, der kürzeren Isoform von Syk, verwendet wurde. Dabei wird in einer ersten PCR die DNA 5' und 3' des zu deletierenden Bereiches amplifiziert. Die Primer, die an dem zu deletierenden Bereich ansetzen, enthalten dabei auch eine Sequenz, die komplementär zur DNA auf der anderen Seite des zu deletierenden Bereiches liegt, so dass der Primer also diesen Bereich überspannt.

Der PCR-Ansatz und das PCR-Programm erfolgte dabei wie oben angegeben. Die DNA wurde mittels Agarose-Gelelektrophorese aufgetrennt und aus dem Gel extrahiert (siehe 3.1.4 und 3.1.5) und eine zweite PCR wurde angeschlossen. Dabei wurden Primer, die den gesamten DNA-Abschnitt umspannen und beide zuvor amplifizierten DNA-Fragmente hinzugegeben. Der PCR-Ansatz und das PCR-Programm erfolgten danach wie in 3.1.1 beschrieben. Die beiden zuvor amplifizierten DNA- 
Fragmente lagerten sich so im mittleren Bereich zusammen, so dass nun ein DNAFragment entsteht, das der Vorlage entspricht, jedoch nicht den Bereich, den die Primer der ersten PCR überspannt haben, enthält.

\subsubsection{Agarose-Gelelektrophorese}

Die Größenaufteilung von DNA-Fragmenten erfolgte mittels AgaroseGelelektrophorese. Dafür wurde 1\% Agarose in TAE-Puffer gegeben und in einer Mikrowelle aufgekocht, der Lösung wurde 0,01\% Ethidium-Bromid zugesetzt und in eine Form zum Abkühlen und Erstarren gegeben. In freigelassene Beladungstaschen wurde die aufzutrennende DNA vermischt mit DNA-Laufpuffer und ein DNAGrößenstandard pipettiert. Die Auftrennung der DNA erfolgte in einer mit TAE gefüllten Gelkammer bei $150 \mathrm{~V}$ angelegter Spannung. Das zugegebene Ethidiumbromid interkalierte in die aufgetrennte Doppelstrang-DNA, so dass diese mittels UV-Licht der Wellenlänge $302 \mathrm{~nm}$ sichtbar gemacht und fotografiert werden konnte.

\subsubsection{DNA-Extraktion aus Agarose-Gelen}

Zur Weiterverwendung der mittels Agarose-Gelelektrophorese aufgetrennten DNAFragmente wurden die entsprechenden Bereiche des Agarose-Gels ausgeschnitten und die DNA aus dem Gel mittels des Wizard® SV Clean-Up Kits von Promega, Madison, Wisconsin nach Anweisung des Herstellers extrahiert. Die DNA wurde in $\mathrm{dd}_{2} \mathrm{O}$ eluiert und bei $-20^{\circ} \mathrm{C}$ gelagert beziehungsweise weiterverarbeitet.

\subsubsection{Klonierung von PCR-Produkten in den pCRII-TOPO-Vektor}

Zur Sicherung von PCR-Produkten wurden diese zunächst mittels AgaroseGelelektrophorese isoliert, aus dem Gel extrahiert und anschließend in den pCRIITOPO-Vektor kloniert. Dazu wurde die extrahierte DNA in $17 \mu \mathrm{dd}_{2} \mathrm{O}$ eluiert und zunächst mit $2 \mu \mathrm{l}$ Taq-Puffer, $1 \mu \mathrm{l}$ dNTPs (Zielkonzentration je $500 \mu \mathrm{M}$ ) und $1 \mathrm{U}$ TaqDNA-Polymerase für $30 \mathrm{~min}$ bei $72^{\circ} \mathrm{C}$ inkubiert. Die Taq-DNA-Polymerase fügt an die 3'-Enden der PCR-Produkte ein zusätzliches Adenosin an. Diese A-Überhänge können dann für die Klonierung in den pCRII-TOPO-Vektor verwendet werden, da dieser an der Insertionsstelle für das zu klonierende DNA-Fragment, die von einer Topoisomerase offengehalten wird, T-Überhänge an den 5'-Enden hat. Für die Klonierung wurde das TOPO ${ }^{\circ}$ TA Cloning ${ }^{\circledR}$ Kit verwendet. 5,5 $\mu$ les DNA-Fragmentes mit A-Überhängen wurde mit $1 \mu \mathrm{l}$ Salzlösung (Bestandteil des Kits) und 0,5 $\mu \mathrm{l}$ des pCRII- 
TOPO-Vektors für 30 min bei Raumtemperatur inkubiert und danach in kompetente Bakterien transformiert (siehe 3.1.8).

\subsubsection{Herstellung kompetenter Bakterien}

Die Herstellung kompetenter E.coli-Bakterien erfolgte modifiziert nach Hanahan (1983). Dazu wurden diese in $150 \mathrm{ml}$ LB-Medium bei $37^{\circ} \mathrm{C}$ bis zu einer photometrischen Dichte von $\mathrm{OD}_{600} 0,45-0,55$ kultiviert und anschließend für 10 min bei $4^{\circ} \mathrm{C}$ und $2.000 \mathrm{~g}$ zentrifugiert. Das Bakterienpellet wurde in $30 \mathrm{ml}$ TFB-I-Puffer aufgelöst und für 10 min auf Eis inkubiert. Nach erneuter Zentrifugation wurde das Bakterienpellet in $6 \mathrm{ml}$ eiskaltem TFB-II-Puffer aufgelöst, jeweils $100 \mu \mathrm{l}$ aliquotiert, in flüssigem Stickstoff schockgefroren und bis zur Verwendung bei $-80^{\circ} \mathrm{C}$ gelagert.

\subsubsection{Transformation von kompetenten Bakterien}

$100 \mu \mathrm{l}$ chemisch kompetente E.coli-Top10F-Bakterien wurden mit 10 - 50 ng DNA für 10 min auf Eis inkubiert und anschließend einem Hitzeschock bei $42^{\circ} \mathrm{C}$ für $45 \mathrm{sec}$ ausgesetzt, bevor sie für weitere 2 min auf Eis und anschließend mit $800 \mu$ LBMedium für $30 \mathrm{~min}$ bei $37^{\circ} \mathrm{C}$ und $400 \mathrm{rpm}$ in einem Thermomixer inkubiert wurden. Nach Zentrifugation für $2 \mathrm{~min}$ bei $5.000 \mathrm{~g}$ wurde das Bakterienpellet in $200 \mu \mathrm{l}$ LBAmp- oder LB-Kan-Medium aufgelöst und auf vorgewärmte Bakterienplatten ausgestrichen. Die Bakterienplatten bestanden aus LB-Amp- oder LB-Kan-Medium mit 2\% Agar und wurden über Nacht bei $37^{\circ} \mathrm{C}$ inkubiert.

Bei der Transformation von pCRII-TOPO-Vektoren wurden die Bakterienplatten zusätzlich mit $40 \mu \mathrm{l}$ X-gal (40 mg/ml) und $40 \mu \mathrm{l}$ IPTG (100 mM) versetzt. Kommt es zur Ligation des Vektors ohne inseriertes DNA-Fragment, kann auf dem Vektor das Gen für eine Galaktosidase unter IPTG-Stimulation abgelesen werden, welches X-Gal zu Galactose und 5-Brom-4-chlor-indoxyl hydrolysiert. Letzteres sorgt dafür, dass sich die Kolonie von Bakterien blau verfärbt. Wird das zu klonierende DNA-Fragment jedoch in den pCRII-TOPO-Vektor integriert, kann keine Galaktosidase mehr exprimiert werden und die Bakterienkolonie bleibt weiß, so dass zwischen Bakterienklonen mit und ohne kloniertes DNA-Fragment unterschieden werden konnte.

\subsubsection{Kulturbedingungen der Bakterien}

Einzelne transformierte Bakterienkolonien einer Bakterienplatte wurden in $5 \mathrm{ml}$ LBAmp oder LB-Kan überführt und in einem Schüttelinkubator bei $37^{\circ} \mathrm{C}$ und $300 \mathrm{rpm}$ 
über Nacht vermehrt. Zur weiteren Vermehrung des Bakterienklons wurde $1 \mathrm{ml}$ dieser Übernachtkultur in 150 ml LB-Medium mit Antibiotikum überführt und erneut über Nacht bei $37^{\circ} \mathrm{C}$ und 300 rpm inkubiert.

\subsubsection{Präparation von Plasmiden}

Die Präparation der Plasmid-DNA aus transformierten Bakterienklonen wurde aus 4 $\mathrm{ml}$ beziehungsweise $150 \mathrm{ml}$ einer Übernachtkultur mit dem PureYield ${ }^{\mathrm{TM}}$ Plasmid Miniprep Kit beziehungsweise zur Isolierung größerer Mengen an Plasmid-DNA mit dem PureYield ${ }^{\mathrm{TM}}$ Plasmid Midiprep Kit (beide von Promega, Madison, Wisconsin) nach Anweisung des Herstellers durchgeführt und die DNA in dd $\mathrm{H}_{2} \mathrm{O}$ eluiert.

\subsubsection{Konzentrationsbestimmung von Nukleinsäure}

Zur Bestimmung der Konzentration von DNA wurde mit einem Photometer von Eppendorf, Hamburg die Absorption bei $260 \mathrm{~nm}$ Wellenlänge gemessen. Dabei entspricht bei einer Küvette mit $10 \mathrm{~mm}$ Schichtdicke eine $\mathrm{OD}_{260}$ von 1 in etwa einer DNA-Konzentration von $50 \mu \mathrm{g} / \mathrm{ml} \mathrm{H}_{2} \mathrm{O}$.

\subsubsection{Sequenzierung von DNA}

Die Sequenzierung zur Kontrolle von klonierten und mutierten DNA-Fragmenten erfolgte mittels der Didesoxy-Methode (Sanger et al. 1977) durch die Firmen MWG (Ebersberg), StarSEQ (Mainz) und SeqLab (Göttingen).

\subsubsection{Restriktionsverdau}

DNA wurde mit Restriktionsendonukleasen gespalten, um DNA-Fragmente aus einem Vektor zur weiteren Verwendung herauszuschneiden oder um klonierte Konstrukte zu kontrollieren. Die Restriktion erfolgte dabei in $15 \mu$ Ansätzen mit ein oder zwei Restriktionsenzymen von NEB (Ipswich, Massachusetts) nach Angaben des Herstellers. Die Restriktionsansätze wurden für $1-2 \mathrm{~h}$ bei $37^{\circ} \mathrm{C}$ inkubiert, die verdauten DNA-Fragmente mittels Agarose-Gelelektrophorese aufgetrennt und gegebenenfalls wurden aus dem Gel einzelne Fragmente zur Weiterverwendung isoliert.

\subsubsection{Ligation}

Die Ligation von DNA-Fragmenten und Vektoren, die mit den gleichen Restriktionsenzymen verdaut und nach Agarose-Gelelektrophorese isoliert wurden, erfolgte mit $0,5 \mu \mathrm{l}$ der T4 DNA-Ligase in $10 \mu \mathrm{l}$ Reaktionsansätzen über Nacht bei $15^{\circ} \mathrm{C}$. Der Vek- 
tor wurde vor der Ligation für 30 min mit $10 \mathrm{U}$ einer 5‘ DNA-Phosphatase (CIP von NEB, Ipswich, Massachusetts) bei $37^{\circ} \mathrm{C}$ inkubiert, um die Selbstligation des Vektors zu vermeiden. Der Ligationsansatz wurde in kompetente E.coli-Bakterien transformiert, die DNA aus den Bakterienklonen isoliert und mittels Restriktionsverdau und Sequenzierung kontrolliert.

\subsubsection{Linearisierung und Ethanolfällung von Vektoren}

Die Linearisierung von zirkulärer Plasmid-DNA zur Elektroporation von eukaryoten Zellen erfolgte in einem Restriktionsansatz mit $350 \mu$ l Volumen mit $30-40 \mu \mathrm{g}$ DNA und dem Restriktionsenzym PVUI (NEB, Ipswich, Massachusetts) nach Herstellerangaben über Nacht bei $37^{\circ} \mathrm{C}$. Zur Isolierung von linearisierten DNA-Vektoren wurde dem Restriktionsansatz ein Zehntel seines Volumens $5 \mathrm{M} \mathrm{NaCl-Lösung} \mathrm{und} \mathrm{danach}$ das 2,5-fache Volumen an eiskaltem 100\% Ethanol zugefügt und danach für 30 min bei $-80^{\circ} \mathrm{C}$ belassen. Die Proben wurden dann bei RT für $10 \mathrm{~min}$ mit $16.000 \mathrm{~g}$ zentrifugiert, der Überstand verworfen und das DNA-Pellet mit $1 \mathrm{ml}$ 70\% Ethanol gewaschen. Nach erneuter Zentrifugation wurde das DNA-Pellet für 15 min bei RT getrocknet und dann in $700 \mu$ l PBS-Puffer aufgelöst.

\subsection{Zellbiologische Methoden}

\subsubsection{Kulturbedingungen}

Alle verwendeten nicht-adhärenten Zelllinien wurden in RPMI-1640-Medium mit 10\% hitzeinaktiviertem FCS, 2 mM L-Glutamin, $50 \mathrm{U} / \mathrm{ml}$ Penicillin und 50 mg/ml Streptomycin bei $37^{\circ} \mathrm{C}, 5 \% \mathrm{CO}_{2}$ und $90 \%$ Luftfeuchtigkeit kultiviert. Das Medium für die Hühnerzelllinie DT40 enthielt außerdem 1\% hitzeinaktiviertes CS. Je nach Teilungsrate und Dichte der Zellen wurden alle ein bis zwei Tage ein Teil der Zellen verworfen und die restlichen Zellen mit neuem Medium verdünnt.

Die Zentrifugation erfolgte, sofern nicht anders angegeben, für $4 \mathrm{~min}$ bei $300 \mathrm{~g}$ und RT. Zur Bestimmung der Zelldichte wurde die Zellzahl in einer geeignet verdünnten Probe mit Hilfe einer Neubauer-Zählkammer bestimmt.

\subsubsection{Kultivierung von adhärenten Zellen}

Die adhärente Zellinie PlatE wurde in DMEM-Medium mit 10\% hitzeinaktiviertem FCS, $50 \mathrm{U} / \mathrm{ml}$ Penicillin, 50 $\mathrm{g} / \mathrm{ml}$ Streptomycin und unter Selektionsdruck durch 10 
$\mu \mathrm{g} / \mathrm{ml}$ Blasticidin und $2 \mu \mathrm{g} / \mathrm{ml}$ Puromycin bei $37^{\circ} \mathrm{C}, 5 \% \mathrm{CO}_{2}$ und $90 \%$ Luftfeuchtigkeit kultiviert.

Zur Verdünnung oder Expansion der Zellen auf weitere Zellkulturschalen wurde das Medium abgesaugt, einmal mit PBS gewaschen und die Zellen mit $2 \mathrm{ml}$ Trypsin/EDTA-Lösung für 2 min bei $37^{\circ} \mathrm{C}$ inkubiert, so dass sich die adhärenten Zellen lösten. Das Trypsin wurde mittels DMEM-Medium inaktiviert und die Zellen anschließend abzentrifugiert, der Überstand verworfen und die Zellen in frischem Medium aufgenommen und gegebenenfalls verdünnt oder auf mehrere Zellkulturschalen expandiert.

\subsubsection{Auftauen und Einfrieren von Zellen}

Zur längeren Einlagerung wurden circa $1 \times 10^{7}$ Zellen abzentrifugiert und die Zellen in $1 \mathrm{ml}$ hitzeinaktiviertem FCS mit 10\% DMSO aufgenommen, in Kryo-Röhrchen überführt und bei $-140^{\circ} \mathrm{C}$ eingefroren. Zur erneuten Verwendung wurden die Zellen in einem $37^{\circ} \mathrm{C}$ warmen Wasserbad aufgetaut und mit $10 \mathrm{ml}$ des entsprechenden Mediums verdünnt, abzentrifugiert und anschließend in frischem Medium aufgenommen und auf Zellkulturschalen gebracht.

\subsubsection{Transfektion durch Elektroporation}

Die Elektroporation von DT40- und DG-75-Zellen erfolgte nach Dower et al. (1988). Dazu wurden $1,5 \times 10^{7}$ Zellen abzentrifugiert und einmal mit $1 \mathrm{ml}$ PBS gewaschen. Nach erneuter Zentrifugation wurde das Zellpellet in PBS, das $30-40 \mu \mathrm{g}$ des zuvor linearisierten und durch Ethanolfällung isolierten Transfektionsvektors enthielt, aufgelöst und für 10 min in einer Elektroporationsküvette auf Eis inkubiert. Anschließend erfolgte die Elektroporation mit dem Elektroporationssystem GenePulser von Biorad, München mit $250 \mathrm{~V}$ Spannung bei $960 \mu \mathrm{F}$. Die Zellen wurden danach in $12 \mathrm{ml}$ vorgewärmten DT40- beziehungsweise DG-75-Medium aufgenommen und über Nacht kultiviert, bevor weitere $28 \mathrm{ml}$ Medium und zur Selektion der transfizierten Zellklone Puromycin mit einer Endkonzentration von $2 \mu \mathrm{g} / \mathrm{ml}$ zugefügt und die Zellen auf zwei 96-Kammer-Platten aufgeteilt wurden. Nach circa 10 Tagen waren die transfizierten Zellklone sichtbar und konnten auf separate Zellkulturplatten überführt werden. Mittels Westernblot-Analyse (siehe 3.3.3, Seite 40) wurden die Klone auf ihre Expression hin untersucht. Drei Klone wurden ausgewählt und vermischt, um klonale Besonderheiten der Einzelklone (klonale Effekte) zu vermeiden. 


\subsubsection{Retrovirale Transfektion}

Die Retroviren für die Transfektion von DT40- und DG-75-Zellen wurden mit Hilfe der Zelllinie PlatE nach Morita et al. (2000) hergestellt. Dazu wurden die PlatE-Zellen einen Tag vor der Transfektion auf $6 \mathrm{~cm}$ Zellkulturplatten aufgeteilt, so dass sie bei der Transfektion eine Dichte von 50 - 70\% erreicht haben. Zur Transfektion der PlatE-Zellen wurden nacheinander $200 \mu \mathrm{l}$ RPMI-Medium, 7,5 $\mu \mathrm{l}$ FuGENE (Roche, Risch, Schweiz), 1,9 $\mu \mathrm{g}$ des retroviralen Expressionsvektors pMSCVpuro und 0,7 $\mu \mathrm{g}$ von phCMV-VSV-G vermischt und für 30 min bei RT inkubiert. Ohne phCMV-VSV-G könnten die resultierenden Retroviren nur Zellen muriner Herkunft infizieren, phCMVVSV-G sorgt für eine Pseudotypisierung. Das PlatE Medium wurde abgesaugt und $4 \mathrm{ml}$ frisches DT40- beziehungsweise DG-75-Medium auf die PlatE-Zellen gegeben, bevor der Transfektionsansatz tropfenweise dazugegeben wurde. Die PlatE-Zellen wurden dann für $48 \mathrm{~h}$ unter Standard-Zellkultur-Bedingungen inkubiert und gaben in dieser Zeit die Retroviren in den Überstand ab. Dieser Überstand wurde dann zur Transfektion der DT40- beziehungsweise DG-75-Zellen verwendet und dafür zunächst steril in eine neue $6 \mathrm{~cm}$ Zellkulturschale durch einen Filter mit 0,45 $\mu \mathrm{m}$ Porengröße filtriert. $1 \times 10^{6}$ der zu transfizierenden Zellen wurden zentrifugiert und das Zellpellet in 1,5 ml frischen Medium aufgenommen und zu den Retroviren gegeben. Zusätzlich wurde Polybrene mit einer Zielkonzentration von $3 \mu \mathrm{g} / \mathrm{ml}$ hinzugefügt und die Zellen für $24 \mathrm{~h}$ unter Standard-Zellkultur-Bedingungen inkubiert. Die Zellen wurden dann erneut zentrifugiert, in $5 \mathrm{ml}$ frischem Medium aufgenommen und für weitere $24 \mathrm{~h}$ inkubiert, bevor $1 \mu \mathrm{g} / \mathrm{ml}$ Puromycin zur Selektion der transfizierten Zellen hinzugegeben wurde. Alle beschriebenen Arbeitsschritte mit pseudotypisierten Retroviren wurden nach den S2-Sicherheits- und Arbeitsvorschriften vorgenommen. Die retrovirale Transfektion von Zellen hat den Vorteil, dass dabei keine Zellklone entstehen, sondern stets eine Vielzahl von Zellen transfiziert wird. Klonale Effekte werden somit ausgeschlossen.

\subsubsection{Analyse der Citrin-Expression}

Zur Messung der Transfektionseffizienz von Citrin- oder GFP-gekoppelten Konstrukten wurden $1 \times 10^{6}$ Zellen abzentrifugiert, einmal mit $1 \mathrm{ml}$ PBS gewaschen, erneut zentrifugiert und das Zellpellet in $500 \mu \mathrm{PBS}$ aufgenommen. Anschließend wurde der Farbstoff in den Zellen im Durchflusszytometers FACS-Calibur (BD, Franklin Lakes, New Jersey) mit einem Laser der Wellenlänge $488 \mathrm{~nm}$ angeregt und die Emission bei 
500 - 560 nm detektiert. Als Kontrolle dienten untransfizierte DT40- oder DG-75Zellen. Die erzeugten Daten wurden mittels des Programms FlowJo (Tristar) ausgewertet.

\subsubsection{Analyse der Oberflächenexpression von IgM}

Zur Analyse der IgM-Expression nach BZR-Stimulus auf der Zelloberfläche von DT40-Zellen wurden $1 \times 10^{6}$ Zellen abzentrifugiert, der Überstand verworfen und die Zellen einmal mit $1 \mathrm{ml}$ PBS gewaschen. Nach erneuter Zentrifugation wurden die Zellen in $400 \mu \mathrm{l} \mathrm{RPMI}$ ohne Zusätze aufgenommen und mit $2 \mu \mathrm{g} / \mathrm{ml}$ des anti-lgMAntikörpers M4, ein muriner IgM-Antikörper, für gewünschte Stimulationszeiten bei $37^{\circ} \mathrm{C}$ inkubiert und $30 \mathrm{sec}$ vor Ende der Stimulationszeit für 10 min auf Eis abgekühlt, um die Stimulation zu stoppen. Die Zellen wurden erneut zentrifugiert, einmal mit 1 $\mathrm{ml}$ PBS gewaschen in $500 \mu \mathrm{l}$ PBS aufgenommen und mit 0,5 $\mu \mathrm{l}$ anti-Maus-IgM gekoppelt an den Farbstoff Cy-5 für 10 min auf Eis und in Dunkelheit inkubiert. Die Zellen wurden erneut mit $1 \mathrm{ml}$ PBS gewaschen und nach Zentrifugation in $500 \mu \mathrm{l}$ PBS aufgenommen und mittels Durchflusszytometrie analysiert. Dafür wurde der Farbstoff Cy-5 mit einem Laser mit $646 \mathrm{~nm}$ Wellenlänge angeregt und die Emission bei $664 \mathrm{~nm}$ gemessen. Als Kontrolle dienten DT40-Zellen, die nicht mit Anti-IgM, aber mit Cy-5 inkubiert wurden. Die Daten wurden mittels des Programms FlowJo (Tristar) ausgewertet.

\subsubsection{Analyse des BZR-abhängigen Kalziumionen-Einstroms}

Zur Bestimmung des BZR-abhängigen Kalziumionen-Einstroms wurden $1 \times 10^{6}$ DT40oder DG-75-Zellen abzentrifugiert und das Pellet in RPMI mit 5\% FCS aufgenommen. Zu den Zellen wurde der kalziumabhängige Farbstoff Indo-1-AM mit einer Zielkonzentration von $1 \mu \mathrm{M}$ und das Detergens Pluronic F-127 mit einer Zielkonzentration von $0,015 \%$ gegeben. Indo-1-AM ist ein ungeladenes Molekül, das die Zellmembran überwinden kann. Intrazellulär wird über unspezifische zytoplasmatische Esterasen eine Esterbindung gespalten und das resultierende geladene Indo-1 verbleibt intrazellulär. Die Zellen wurden bei $30^{\circ} \mathrm{C}$ und $500 \mathrm{rpm}$ für $25 \mathrm{~min}$ in einem Thermocycler inkubiert, bevor $700 \mu \mathrm{l}$ RPMI mit 10\% FCS zu den Zellen gegeben wurde und die Zellen für weitere $10 \mathrm{~min}$ bei $37^{\circ} \mathrm{C}$ und $500 \mathrm{rpm}$ inkubierten. Die Zellen wurden anschließend mit $1 \mathrm{ml}$ Krebs-Ringer-Lösung gewaschen und nach Zentrifugation in $700 \mu$ Krebs-Ringer-Lösung mit $1 \mathrm{mM} \mathrm{CaCl}_{2}$ aufgenommen. 
Der BZR-abhängige Kalziumionen-Einstrom wurde an dem Durchflusszytometer FACS-Calibur (BD, Franklin Lakes, New Jersey) bei RT gemessen. Dafür wurde nach Anregung des Farbstoffs mit einem Laser mit $350 \mathrm{~nm}$ Wellenlänge das Verhältnis der Emission von blauem Indo (ohne Kalzium) bei $530 \mathrm{~nm}$ zu violettem Indo (mit Kalzium) bei $405 \mathrm{~nm}$ gemessen. Nach Messung des Verhältnisses im unstimulierten Zustand wurden nach $25 \mathrm{sec}$ die DT40-Zellen mit 0,2 - $2 \mu \mathrm{g} / \mathrm{ml}$ Anti-Huhn-IgM (M4) und DG-75-Zellen mit $10 \mu \mathrm{g} / \mathrm{ml} \mathrm{F(ab')2-anti-Human-lgM} \mathrm{stimuliert} \mathrm{und} \mathrm{das} \mathrm{Verhältnis}$ 405/530 nm Emission für weitere 3 - 30 min gemessen.

Zur getrennten Betrachtung des Kalziumionen-Einstroms ins Zytosol aus intrazellulären Speichern und aus dem Extrazellulärraum wurde eine add-back Messung durchgeführt. Dafür wurden die Zellen vor der Messung in Krebs-Ringer-Lösung mit 0,5 mM EGTA aufgenommen, um extrazelluläre Kalziumionen zu chelatieren. Nach Stimulation der Zellen und Messung des Kalziumionenflusses aus intrazellulären Speichern wurde nach 5 min Messzeit $1 \mathrm{mM} \mathrm{CaCl} 2$ zu den Zellen gegeben, das nun als extrazelluläres Kalzium in die Zelle strömte und gemessen werden konnte.

Die Auswertung der Daten erfolgte mit dem Programm FlowJo und nach Export der Daten mit Microsoft Excel. Die Beladung der Zellen und die Messung am Durchflusszytometer erfolgte nach einem Protokoll von Dr. Michael Engelke (Engelke et al. 2002).

\subsubsection{Stimulation von Zellen}

Die zu stimulierenden Zellen wurden abzentrifugiert, in RPMI-Medium ohne Zusätze aufgenommen, die Zellzahl bestimmt und bei mehreren Zelllinien gegebenenfalls angepasst. Die Zellen wurden erneut zentrifugiert und pro Stimulationszeitpunkt in $1 \mathrm{ml}$ RPMI ohne Zusätze aufgenommen und für 30 min bei $37^{\circ} \mathrm{C}$ inkubiert, um Einflüsse durch FCS zu minimieren. Für die Stimulation durch den BZR wurden $2 \mu \mathrm{g} / \mathrm{ml}$ AntiHuhn-IgM (DT40) oder $10 \mu \mathrm{g} / \mathrm{ml} \mathrm{F(ab')2-anti-Human-IgM} \mathrm{(DG-75} \mathrm{oder} \mathrm{Ramos)} \mathrm{hin-}$ zugegeben und bis $30 \mathrm{sec}$ vor der gewollten Stimulationszeit bei $37^{\circ} \mathrm{C}$ inkubiert und dann für 10 min auf Eis abgekühlt, um die Stimulation zu stoppen.

\subsubsection{Zelllyse}

Zur Lyse von Zellen wurden diese für 4 min bei $4^{\circ} \mathrm{C}$ und $450 \mathrm{~g}$ abzentrifugiert, der Überstand verworfen, circa $20 \mu$ Lysepuffer pro $1 \times 10^{6}$ Zellen hinzugefügt und für 10 min bei $4^{\circ} \mathrm{C}$ inkubiert, bevor das Lysat für 10 min bei $4^{\circ} \mathrm{C}$ und $16.000 \mathrm{~g}$ zentrifugiert 
wurde. Der Überstand wurde in ein neues Gefäß überführt und als geklärtes zelluläres Lysat (CCL) je nach Verwendungszweck entweder mit 1/3 des bestehenden Volumens an $4 \mathrm{x}$ Laemmli Puffer für 5 min bei $95^{\circ} \mathrm{C}$ erhitzt oder weiterverwendet für Immuno- oder Affinitätspräzipitationen (siehe 3.3.6 und 3.3.7, Seite 42 - 43).

\subsubsection{Konfokale Laser-Mikroskopie von lebenden Zellen}

Die Analyse von DT40- und DG-75-Zellen mittels der konfokalen Laser-Mikroskopie erfolgte in Zusammenarbeit mit Dr. M. Engelke.

Um die Lokalisation von Citrin-Syk in DT40- und DG-75-Zellen und von Citrin-SLP76 in DT40-Zellen nach BZR-Stimulation zu bestimmen, wurden $0,5 \times 10^{6}$ Zellen mit $1 \mathrm{ml}$ Krebs-Ringer-Lösung gewaschen und nach Zentrifugation in $200 \mu \mathrm{l}$ Krebs-RingerLösung mit $1 \mathrm{mM} \mathrm{CaCl}_{2}$ aufgenommen und in einen 4-Kammer-Objektträger gegeben. Bis zur Messung wurden die Zellen bei $37^{\circ} \mathrm{C}$ gelagert. Am konfokalen LaserMikroskop wurde Citrin mit $514 \mathrm{~nm}$ angeregt und die Emission wurde bei 530 - 600 $\mathrm{nm}$ detektiert. DT40-Zellen wurden mit $2 \mu \mathrm{g} / \mathrm{ml}$ anti-Huhn-IgM (M4) und DG-75-Zellen

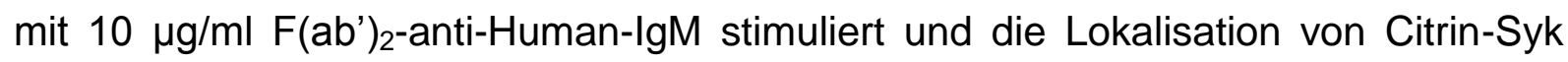
beziehungsweise Citrin-SLP76 alle 2 min fotografiert.

Die Auswertung der Bilder erfolgte mit dem Programm ImageJ. Dafür wurde die Ratio der Farbintensität eines zwei Pixel breiten Rings im Bereich der Zellmembran zur Farbintensität im intrazellulären Bereich bei $30-50$ Zellen pro Stimulationszeitpunkt gebildet, der Mittelwert errechnet und auf den unstimulierten Zustand der Zelle normiert. Der $\mathrm{p}$-Wert wurde durch Excel mit dem Student-T-Test bestimmt.

\subsection{Proteinbiochemische Methoden}

\subsubsection{SDS-Polyacrylamid-Gelelektrophorese}

Zur Auftrennung von Proteingemischen nach der Proteingröße mittels SDS-PAGE wurden die Proben durch Erhitzen auf $95^{\circ} \mathrm{C}$ für 5 min in Laemmli-Puffer denaturiert und anschließend in die Kammern eines Natriumdodecylsulfat-(SDS)-PolyacrylamidGels überführt (Laemmli 1970). Der obere Teil des Gels (Sammelgel) enthielt 4,8\% Polyacrylamid und wurde zur Konzentrierung der Probe am Übergang zum unteren Teil des Gels mit 10\% Polyacrylamid (Trenngel) verwendet. Für die Elektrophorese wurde in vertikalen Gelkammern (Biorad, München) ein Strom von $10 \mathrm{~mA}$ für $30 \mathrm{~min}$ zum Sammeln der Probe und für weitere $75 \mathrm{~min}$ von $25 \mathrm{~mA}$ zum Auftrennen angelegt. Als Größenvergleich wurde ein vorgefärbter Proteinmarker (7 - $175 \mathrm{kDa}$, Invit- 
rogen, Carlsbad, Kalifornien) verwendet. Die Gele mit den aufgetrennten Proteinen wurden entweder mittels Coomassie gefärbt oder einer Westernblot-Analyse zugeführt.

\subsubsection{Coomassie-Färbung}

Zur Anfärbung von SDS-PAGE-Gelen mit Coomassie wurden diese über Nacht mit $10 \mathrm{ml}$ Coomassie Blue R250 (Roth, Karlsruhe) bei RT inkubiert und anschließend wurde durch Waschen mit Wasser überschüssige Coomassie-Lösung entfernt und das gefärbte Gel fotografiert.

\subsubsection{Westernblot-Analyse}

Für die Westernblot-Analyse von Proteingemischen wurden diese mittels SDS-PAGE aufgetrennt und die Proteine auf Nitrocellulose-Membranen in semi dry BlotKammern von Hoefer, Holliston, Massachusetts übertragen. Dafür wurde eine mit Transferpuffer getränkte Filtermembran auf die Anode gelegt und darauf nacheinander die Nitrozellulosemembran, das SDS-Gel und eine weitere Filtermembran mit Transferpuffer geschichtet. Die Kathode wurde auf den beschrieben Stapel gedrückt und ein Strom von $200 \mathrm{~mA}$ und $16 \mathrm{~V}$ für $1 \mathrm{~h}$ angelegt. Nach dem Proteintransfer wurde die Zellulosemembran für $1 \mathrm{~h}$ mit Block-Puffer inkubiert, um unspezifische Bindungsstellen für Proteine zu blockieren, bevor die Membran über Nacht bei $4^{\circ} \mathrm{C}$ mit einem primären Antikörper gegen das zu detektierende Protein inkubiert wurde. Nach dreimaligem Waschen der Membran mit TBS-T für je 5 min wurde sie mit einem sekundären, an Meerschweinchen-Peroxidase (HRPO) gekoppelten und gegen den primären Antikörper gerichteten Antikörper für $1 \mathrm{~h}$ bei $4^{\circ} \mathrm{C}$ inkubiert. Die Membran wurde weitere drei Mal mit TBS-T für jeweils 10 min gewaschen, bevor sie mit ECLLösung inkubiert wurde. Die an den sekundären Antikörper gekoppelte Peroxidase führte bei Inkubation mit ECL zu einer lichtemittierenden Reaktion, die über das Chemi Lux Imager System von Intas (Göttingen) bei einer Beleuchtungszeit von 0,5 10 min digital fotografiert wurde. Die densitometrische Auswertung der Western-Blot Bilder erfolgte mit dem Programm ImageJ.

Sollte auf der gleichen Zellulosemembran ein zweites Protein detektiert werden, so wurde die Peroxidase des sekundären Antikörpers durch Inkubation mit 0,01\% $\mathrm{NaN}_{3}$ in TBS-T für $1 \mathrm{~h}$ inaktiviert. Die erneute Detektion eines Proteins in der Membran verlief wie bereits beschrieben. 


\subsubsection{Expression und Isolation von GST-Proteinen}

Die Expression von 14-3-3y-GST-Fusionsproteinen erfolgte nach Transformation der cDNA von 14-3-3y in dem Vektor pGEX, die freundlicherweise von S. Beer-Hammer, Düsseldorf bereitgestellt wurde, in den E.coli-Expressionsstamm BL21. Die resultierenden Klone wurden in eine $5 \mathrm{ml}$ Übernachtkultur überführt und diese mit weiteren $45 \mathrm{ml}$ LB-Amp-Medium bis zu einer photometrischen Bakteriendichte von $\mathrm{OD}_{600}$ von circa 0,8 bei $37^{\circ} \mathrm{C}$ und $300 \mathrm{rpm}$ inkubiert. Die Expression des GST-Fusionsproteins stand unter Kontrolle des tac-Promotors, der über 0,1 mM des Laktose-Analogon IPTG aktiviert wurde. Für die Bestimmung der optimalen Expressionsdauer wurde stündlich $1 \mathrm{ml}$ der Probe abgenommen, $50 \mu \mathrm{l}$ direkt mit $15 \mu \mathrm{l}$ 4x Laemmli für $5 \mathrm{~min}$ auf $95^{\circ} \mathrm{C}$ erhitzt, der Rest für $5 \mathrm{~min}$ bei $4.800 \mathrm{~g}$ zentrifugiert und das Pellet in $1 \mathrm{ml}$ Bakterienlysepuffer resuspendiert. Die Bakterien wurden mittels Ultraschall für $30 \mathrm{sec}$ lysiert, bevor zur zusätzlichen Lyse Triton-X100 mit einer Zielkonzentration von 1\% hinzugegeben wurde. Nach 10 min Inkubation auf Eis wurden die Proben für 20 min bei $4^{\circ} \mathrm{C}$ und $16.000 \mathrm{~g}$ zentrifugiert, der Überstand überführt und für 30 min mit $20 \mu \mathrm{l}$ Glutathion-Sepharose, das an GST bindet, bei $4^{\circ} \mathrm{C}$ auf einem Roller inkubiert. Die Proben wurden zwei Mal mit Bakterienlysepuffer und 1\% Triton-X100 gewaschen und für 3 min bei $400 \mathrm{~g}$ und $4^{\circ} \mathrm{C}$ zentrifugiert und das Pellet nach erneuter Zentrifugation in $25 \mu \mathrm{l} 4 \mathrm{x}$ Laemmli für 5 min auf $95^{\circ} \mathrm{C}$ erhitzt. Durch SDS-PAGE und Färbung des Gels mit Coomassie-Lösung konnte eine optimale Expressionsdauer von drei Stunden ermittelt werden (siehe Abb. 21, Seite 62).

Für die tatsächliche Expression wurden $50 \mathrm{ml}$ einer mit dem Vektor für 14-3-3y-GST transformierten Bakterienkultur mit einer photometrischen Dichte von $\mathrm{OD}_{600}$ von circa 0,8 für $3 \mathrm{~h}$ mit 0,1 mM IPTG inkubiert. Die Bakterien wurden für 15 min bei $3.000 \mathrm{~g}$ abzentrifugiert und in $20 \mathrm{ml}$ Bakterienlysepuffer aufgenommen, sechs Mal für $30 \mathrm{sec}$ mit Ultraschall lysiert und anschließend mit 1\% Triton-X100 für 10 min auf Eis inkubiert. Die Lysate wurden für $20 \mathrm{~min}$ bei $4^{\circ} \mathrm{C}$ und $6.000 \mathrm{~g}$ zentrifugiert, der Überstand wurde abgenommen und mit $1 \mathrm{ml}$ Glutathion-Sepharose über Nacht bei $4^{\circ} \mathrm{C}$ inkubiert. Anschließend wurden die Proben zwei Mal mit 5 ml Lysepuffer und 1\% Triton$\mathrm{X} 100 \mathrm{gewaschen}$ und für $3 \mathrm{~min}$ bei $3.000 \mathrm{~g}$ und $4^{\circ} \mathrm{C}$ zentrifugiert. Das resultierende Pellet wurde mit $1 \mathrm{ml}$ Glutathion-Elutionspuffer, der 14-3-3y-GST von den Bindestellen der Glutathion-Sepharose verdrängt, für 30 min bei $4^{\circ} \mathrm{C}$ auf einem Roller inkubiert. Die Proben wurden erneut zentrifugiert und der Überstand für die Far- 
Westernblot-Analyse verwendet oder zum Konzentrationsvergleich mit GST und einer BSA-Verdünnungsreihe mit $4 x$ Laemmli für 5 min auf $95^{\circ} \mathrm{C}$ erhitzt und einer SDSPAGE und anschließender Coomassie-Färbung zugeführt.

\subsubsection{Far-Westernblot}

Das aufgereinigte 14-3-3y-GST-Fusionsprotein wurde zur Far-Westernblot-Analyse der Bindung von 14-3-3y an Syk eingesetzt. Dafür wurde Citrin-Syk wt und S297A aus stimulierten und unstimulierten DT40-Zellen, wie in 3.3.6 beschrieben, mit einem Antikörper gegen Citrin immunopräzipitiert und mittels SDS-PAGE aufgetrennt und auf eine Westernblot-Membran übertragen. Als Kontrolle der IP dienten unspezifische Antikörper des gleichen Isotyps. Die Membran wurde zum Blocken für $30 \mathrm{~min}$ mit $2 \%$ BSA in PBS-T bei RT inkubiert und dann mit $1 \mu \mathrm{g} / \mathrm{ml} 14-3-3 \gamma$-GSTFusionsprotein oder GST-allein in $10 \mathrm{ml}$ PBS-T mit $2 \%$ BSA über Nacht bei $4^{\circ} \mathrm{C}$ inkubiert. Die Membran wurden 3 mal für 10 min mit PBS-T gewaschen, für $1 \mathrm{~h}$ bei $4^{\circ} \mathrm{C}$ mit anti-GST-Antikörper (Molecular Probes, Eugene, Oregon, 1:1.000 in 2\% BSA / PBS-T) inkubiert, erneut drei Mal für 10 min mit PBS-T gewaschen, für $1 \mathrm{~h}$ bei $4^{\circ} \mathrm{C}$ mit sekundären Antikörper inkubiert und anschließend wie in 3.3.3 beschrieben mit ECL entwickelt.

\subsubsection{Immunopräzipitation}

Zur Immunopräzipitation von Proteinen wurden $2 \times 10^{7}$ unstimulierte oder stimulierte Zellen lysiert und das resultierende geklärte zelluläre Lysat über Nacht mit $2 \mu \mathrm{g} / \mathrm{ml}$ des Präzipitations-Antiköper und danach für $1 \mathrm{~h}$ mit $20 \mu \mathrm{l}$ Protein-A/G-Agarose (SCBT, Santa Cruz, Kalifornien) bei $4^{\circ} \mathrm{C}$ auf einem Roller inkubiert. Als Kontrolle dienten unspezifische, isotypengleiche Antikörper. Die Proben wurden drei Mal für 3 min bei $300 \mathrm{~g}$ und $4^{\circ} \mathrm{C}$ zentrifugiert und das resultierende Pellet jeweils mit $1 \mathrm{ml} \mathrm{Ly}$ sepuffer gewaschen. Nach erneuter Zentrifugation wurden die Proben für das in vitro Kinase-Experiment (siehe 3.3.9) verwendet oder mit $15 \mu \mathrm{l}$ 4x Laemmli Puffer für 5 min bei $95^{\circ} \mathrm{C}$ erhitzt und einer Westernblot-Analyse zugeführt.

\subsubsection{Affinitätspräzipitation mittels Streptaktin-Matrix}

Zur Affinitätspräzipitation von STrEP-Tag gekoppeltem Syk aus DT40- oder DG-75Zellen wurden $3 \times 10^{8}$ Zellen abzentrifugiert, mit $25 \mathrm{ml}$ PBS gewaschen und nach erneuter Zentrifugation in $10 \mathrm{ml}$ RPMI ohne Zusätze für $15 \mathrm{~min}$ bei $37^{\circ} \mathrm{C}$ inkubiert, bevor sie mit $2 \mu \mathrm{g} / \mathrm{ml}$ (DT40) beziehungsweise $10 \mu \mathrm{g} / \mathrm{ml}$ (DG-75) anti-IgM stimuliert 
wurden. Nach erneuter Zentrifugation wurden die Zellen mit $5 \mathrm{ml}$ Lysepuffer für 10 min bei $4^{\circ} \mathrm{C}$ auf einem Roller lysiert und anschließend für $15 \mathrm{~min}$ bei $16.000 \mathrm{~g}$ und $4^{\circ} \mathrm{C}$ zentrifugiert. Das geklärte zelluläre Lysat wurde in eine Affinitätspräzipitationssäule (Thermo, Waltham, Massachusetts) überführt und mit $200 \mu \mathrm{l}$ Strep-TaktinMatrix für $1 \mathrm{~h}$ bei $4^{\circ} \mathrm{C}$ auf einem Roller inkubiert. Die Proben wurden anschließend über die Säule fünf Mal mit $1 \mathrm{ml}$ Lysepuffer und einmal mit $50 \mu \mathrm{l}$ Elutionspuffer (Desthiobiotin) gewaschen. Die Strep-gekoppelten Proteine und ihre Bindepartner wurden mit $500 \mu$ Elutionspuffer eluiert und mittels Ultrazentrifugationsröhrchen bei $10.000 \mathrm{~g}$ und $15^{\circ} \mathrm{C}$ für circa $15 \mathrm{~min}$ auf ein Zielvolumen von $50 \mu \mathrm{l}$ eingedickt bevor sie mit $18 \mu \mathrm{LLSS}$ und $7 \mu \mathrm{l}$ Redox-Agens bei $72^{\circ} \mathrm{C}$ für 10 min erhitzt wurden. Die Aufreinigung von Strep-gekoppeltem Syk erfolgte nach einem von Dr. Thomas Oellerich etablierten Protokoll (Oellerich et al. 2009).

\subsubsection{Bradfort-Methode zur Bestimmung von Proteinkonzentrationen}

Die Bestimmung der Proteinkonzentration in mittels Streptaktin-Matrix aufgereinigten Proben wurde benötigt, um diese für SILAC-Experimente in einer 1:1 Ration zu vermischen. Dazu wurden die Proben nach Bradford (1976) mit Coomassie Färbelösung gefärbt und die Absorption bei $595 \mathrm{~nm}$ photometrisch bestimmt und diese durch das Photometer in die Proteinkonzentration umgerechnet.

\subsubsection{In-vitro-Kinase-Experiment}

Zur Bestimmung der Syk-Kinase-Aktivität wurde Syk mittels eines Antikörpers gegen Citrin aus DT40-Zellen, die entweder wildtyp Syk (als Negativkontrolle) oder CitrinSyk wt oder S297A exprimieren und für 5 min stimuliert wurden, wie beschrieben immunopräzipitiert. Die Protein-A/G-Sepharose wurde dabei zwei Mal mit Lysepuffer und zwei Mal mit Kinasepuffer gewaschen und schließlich in $25 \mu$ Kinasepuffer aufgenommen. Dem immunopräzipitiertem Syk wurde $25 \mu$ ATP-Substrat-Lösungen zugesetzt und die Proben für 15 min bei Raumtemperatur oder auf Eis (Negativkontrolle) inkubiert und dabei alle 5 min gevortext, bevor $50 \mu$ Stopp-Puffer zugegeben und die Proben für 5 min auf Eis abgekühlt wurden. Als Substrat diente ein Biotingekoppeltes Peptid, das von Syk phosphoryliert werden kann. Je $50 \mu \mathrm{l}$ der Probe wurden in 4x Laemmli aufgekocht und zur Kontrolle der präzipitierten Menge an Syk einer Westernblot-Analyse mit anti-GFP-Antikörper zugeführt. Die restlichen $50 \mu \mathrm{l}$ wurden mit $50 \mu \mathrm{lddH} \mathrm{H}_{2} \mathrm{O}$ vermischt, in eine Kammer einer Streptavidin beschichteten 
ELISA-Platte gegeben und für 90 min bei RT inkubiert. Dadurch wurde das Biotingekoppelte phosphorylierte Substrat an die ELISA-Platten gekoppelt. Die ELISAPlatte wurde drei Mal mit $200 \mu$ PBS-T je Kammer gewaschen und dann mit $1 \mu \mathrm{g} / \mathrm{ml}$ Anti-Phosphotyrosin in $150 \mu \mathrm{l}$ PBS-T mit 1\% BSA je Kammer für 90 min bei RT inkubiert. Nach erneutem dreimaligen Waschen der Kammern mit je $200 \mu$ I PBS-T wurden die Proben mit sekundärem Antikörper mit einer Verdünnung von 1:500 in $100 \mu \mathrm{l}$ PBS-T mit 1\% BSA für 30 min bei RT inkubiert und die Kammern anschließend erneut fünf Mal mit je $200 \mu$ PBS-T gewaschen.

Zum Bestimmung der Phosphorylierung der Syk-Substrate und damit zur Bestimmung der Kinase-Aktivität von Syk wurde den Proben $100 \mu$ ABTS Lösung zugesetzt, wodurch eine peroxidaseabhängige Farbstoffreaktion gestartet wurde. Die Absorption wurde in einem ELISA-Auslesegerät nach 1 min bei $405 \mathrm{~nm}$ gemessen und der Mittelwert sowie der p-Wert mit dem Students-T-Test in Excel bestimmt.

Die Bestimmung der Kinase-Aktivität von Syk in vitro erfolgte nach einem von Dr. Marion Lösing etablierten Protokoll.

\subsection{Massenspektrometrische Methoden}

Alle massenspektrometrischen Analysen von aufgereinigten Proteinen sind in Kooperation mit der „Bioanalytical Mass Spectrometry“ Gruppe am MPI für Biophysikalische Chemie (Göttingen) unter Leitung von Prof. Dr. Henning Urlaub entstanden.

\subsubsection{Polyacrylamid-Gelelektrophorese und In-Gel-Verdau von Proteinen}

Die durch Affinitätspräzipitation mit Streptaktin-Matrix aufgereinigten Proteine aus DT40- oder DG-75-B-Zellen wurden zunächst mittels eindimensionaler PAGE (1DPAGE) in einem 4 - 12\%-haltigem Polyacrylamid-Gradienten-Gel (NuPAGE Bis-Tris Gel, Invitrogen, Carlsbad, Kalifornien) aufgetrennt und das Gel über Nacht mit Coomassie-Lösung gefärbt. Die entsprechende Spalte des Gels wurde ausgeschnitten und in 23 Teile zerschnitten. Jedes Teil wurde mit $10 \mathrm{mM}$ DTT für $55 \mathrm{~min}$ bei $56^{\circ} \mathrm{C}$ reduziert, anschließend mit $55 \mathrm{mM}$ IAA für $20 \mathrm{~min}$ bei $26^{\circ} \mathrm{C}$ alkyliert und schließlich über Nacht bei $37^{\circ} \mathrm{C}$ mit modifiziertem Trypsin (Promega, Madison, Wisconsin) verdaut. Trypsin spaltet Proteine C-terminal von Arginin und Lysin, so dass jedes Peptid eine positive Ladung am C-Terminus hatte. 


\subsubsection{Anreicherung von phosphorylierten Peptiden}

Eine Schwierigkeit bei der Identifikation von Phosphorylierungsstellen besteht in der geringen Menge von phosphorylierten im Vergleich zu unphosphorylierten Peptiden, so dass vor der eigentlichen Messung zusätzliche Anreicherungsschritte erfolgen müssen (Zhao und Jensen 2009). Die Anreicherung von Phosphopeptiden aus den verdauten Gel-Fragmenten erfolgte nach einem Protokoll von Larsen et al. (2005) über $\mathrm{TiO}_{2}$ Chromatographie (GL Sciences Inc). Dafür wurden die verdauten Peptide in $20 \mu \mathrm{l} 80 \%$ Acetonitril und $5 \%$ Trifluoressigsäure mit $200 \mathrm{mg}$ 2,5Dihydroxybenzoesäure aufgelöst und auf $\mathrm{TiO}_{2}$-Säulchen geladen, drei Mal mit $20 \mu \mathrm{l}$ der angegebenen Lösung und fünf Mal mit $20 \mu \mathrm{l} 80 \%$ Acetonitril und 5\% Trifluoressigsäure gewaschen. Danach wurde die Säule drei Mal mit $20 \mu \mathrm{NH}_{4} \mathrm{OH}(\mathrm{pH} 10,5)$ inkubiert, die gebundenen Phosphopeptide damit eluiert.

\subsubsection{Hochleistungsflüssigkeitschromatographie (HPLC)}

Die aus dem Trypsinverdau stammenden Peptide wurden, gegebenenfalls nach Anreicherung der Phosphopeptide, mittels Flüssigkeitschromatographie weiter aufgetrennt. Dafür wurden sie zunächst über eine C18-Vorsäule $(1,5 \mathrm{~cm}, 360 \mu \mathrm{m}$ äußerer

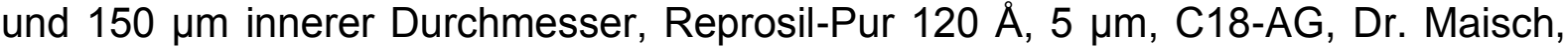
Ammerbuch-Entringen) mit einer Flussrate von $10 \mu \mathrm{l} / \mathrm{min}$ geleitet. Die gebundenen Peptide wurden eluiert und über eine C18-Kapillar-Säule $(15 \mathrm{~cm}, 360 \mu \mathrm{m}$ äußerer

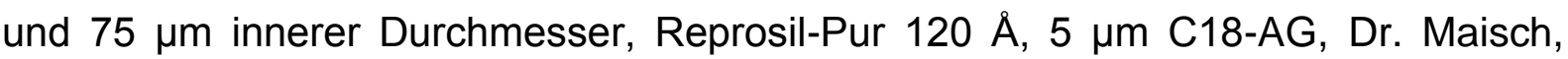
Ammerbuch-Entringen) mit einer Flussrate von $300 \mathrm{nl} / \mathrm{min}$ mit einem Gradienten von $7,5-37,5 \%$ Acetonitril in $0,1 \%$ Methansäure über 60 min mittels des Nano-flow-LCSystems 1100 (Agilent, Santa Clara, Kalifornien) geleitet.

\subsubsection{Massenspektrometrische Analyse}

Die durch HPLC aufgetrennten Peptide wurden in einen LTQ-Orbitrap XL Hybrid Massenspektrometer (Thermo, Waltham, Massachusetts) überführt. Zur Elektrospray-lonisierung (Fenn et al. 1989) der Peptide wurde eine Spannung von 1,8 kV bei einer Temperatur der Kapillare von $150^{\circ} \mathrm{C}$ angelegt. Das Massenspektrometer arbeitete im datenabhängigen Modus, so dass automatisch zwischen MS und MS/MS Modus gewechselt wurde. Nach der Bestimmung der Masse/Ladung der Peptide im MS-Modus wurden die fünf lonen mit der höchsten Intensität isoliert und zur MS/MS-Messung der kollisionsinduzierten Dissoziations-Fragmentierung mit ei- 
ner normalisierten Dissoziationsenergie von 37,5\% zugeführt. Anschließend wurde erneut die Masse/Ladung der Fragmente bestimmt.

\subsubsection{Auswertung der Daten mit MaxQuant und MsQuant}

Die von dem Massenspektrometer gelieferten Rohdaten über die Peptide und deren Fragmente wurden zunächst mit der MASCOT-Suchmaschine zur Peptid- und Proteinidentifikation (Version 2.2.04, Matrix Science) den entsprechenden Proteinen zugeordnet. Der internationale Proteinindex chicken (Version 3.47) und human (Version 3.6) wurde als Sequenz Datenbank verwendet (Kersey et al. 2004). Die MS/MSPeak-Listen wurden mit dem MASCOT-Server abgeglichen. Dabei wurde die Massentoleranz auf 7 ppm und die MS/MS-Toleranz auf 0,8 Da gesetzt. Als variable Modifikationen wurden oxidiertes Methionin und Cystein-Carbamidomethylierung angegeben. Bei der Phosphorylierungsanalyse wurden die Serin-, Threonin- und Tyrosinphosphorylierungs-Modifikationen hinzugefügt, so dass die phosphorylierten Peptide erkannt wurden. Außerdem wurden gegebenenfalls die Modifikationen, die durch mittelschwere oder schwere Arginine und Lysine hervorgerufen werden, angegeben, um SILAC Paare zu erkennen. Die minimale Peptidlänge wurde auf sechs Aminosäuren eingestellt.

Die weitere Auswertung der Daten der Interaktomanalyse erfolgte dann mit Hilfe der MaxQuant Software Version 1.0.12.31 (Cox et al. 2009), die Auswertung der Analyse der Phosphorylierungskinetik erfolgte mit dem Programm MsQuant Version 2.0b6 (Schulze und Mann 2004). 


\section{Ergebnisse}

\subsection{Expression von Strep-Syk in DT40- und DG-75-B-Lymphozyten}

Für eine umfassende massenspektrometrische Analyse der Phosphorylierung und der Proteininteraktionen von Syk in BZR-stimulierten B-Lymphozyten habe ich die DNA von humanem Syk in den pAbes-STrEP-Expressions-Vektor, der mir freundlicherweise von Dr. T. Oellerich zur Verfügung gestellt wurde, kloniert, so dass die DNA des „OneSTrEP-Tag“ (IBA, Göttingen) N-terminal an Syk gekoppelt wurde (im Folgenden als Strep-Syk bezeichnet). Mittels Elektroporation habe ich Sykdefiziente DT40-B-Zellen mit diesem Vektor rekonstituiert und zum Ausschluss von klonalen Effekten drei unabhängige Klone mit vergleichbarer Expression von StrepSyk ausgewählt und vermischt.

Die Expression von humanem Syk in DT40 ist vergleichbar mit der Expression von Syk in der humanen B-Zelllinie Ramos (siehe Abb. 6) und die Aktivierung des BZRSignalweges ist in den rekonstituierten DT40-B-Zellen vergleichbar zu DT40-wildtypZellen, wie ich mittels Westernblot-Analyse und durchflusszytometrischer Bestimmung des BZR-abhängigen Kalziumionen-Einstroms zeigen konnte (siehe Abb. 7).

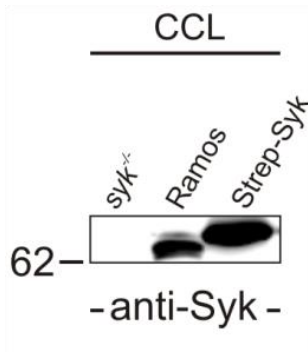

Abb. 6: Expression von Strep-Syk. Syk-defiziente DT40-BLymphozyten wurden mittels Elektroporation mit Konstrukten transfiziert, die für humanes Syk mit N-terminalem STrEP-Tag kodieren. Drei unabhängige Klone wurden ausgewählt und vermischt. Die gereinigten zellulären Lysate der untransfizierten Syk-defizienten DT40-Zellen (Reihe 1), der humanen B-Zelllinie Ramos (Reihe 2) und der Transfektanden (Reihe 3) wurden durch anti-Syk-Immunoblot auf ihre Expression von Syk hin untersucht. Als Ladekontrolle wurden die Lysate mit Antikörpern gegen Aktin analysiert. Relative molekulare Massen des Proteinmarkers sind links in $\mathrm{kDa}$ angegeben.

-anti-Aktin-

123

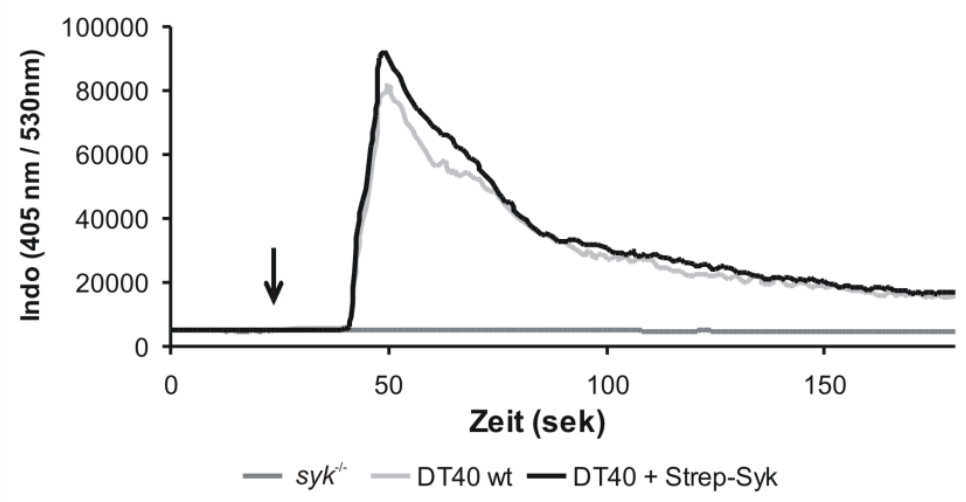

Abb. 7. Transfektion von StrepSyk stellt den KalziumionenEinstrom in Syk-defizienten DT40-B-Zellen wieder her. Die in Abb. 6 beschriebenen Transfektanden wurden mittels Indo-1 und Durchflusszytometrie auf ihren BZR-abhängigen Kalziumionen-Einstrom untersucht. Der Pfeil kennzeichnet den Beginn der BZR-Stimulation. Die Daten sind repräsentativ für drei unabhängige Experimente. 
Auch humane DG-75-B-Zellen habe ich mit Strep-Syk transfiziert und mittels Analyse des BZR-abhängigen Kalziumionen-Einstroms konnte ich wiederum die vergleichbare Aktivierung des BZR-Signalweges zeigen (siehe Abb. 8).

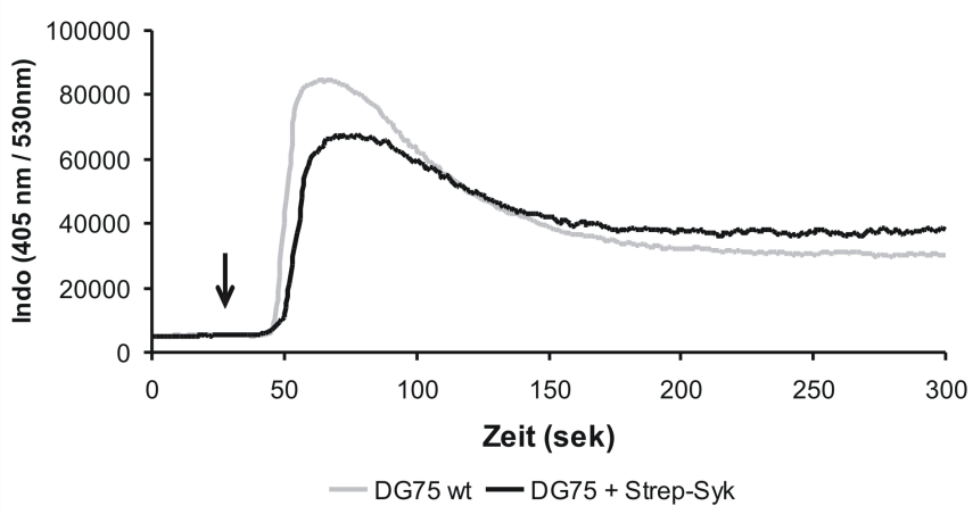

Abb. 8. DG-75-B-Zellen zeigen in Anund Abwesenheit von transfiziertem Strep-Syk einen vergleichbaren Kalziumionen-Einstrom. Humane DG-75-BLymphozyten wurden mittels Elektroporation mit Konstrukten transfiziert, die für Strep-Syk kodieren. Drei unabhängige Klone wurden ausgewählt und vermischt. Die Zellen wurden mittels Indo-1 und Durchflusszytometrie auf ihren BZRabhängigen Kalziumionen-Einstrom untersucht. Der Pfeil kennzeichnet den Beginn der BZR-Stimulation. Die Daten sind repräsentativ für drei unabhängige Experimente.

Zur Isolierung von Syk aus den transfizierten Zellen habe ich diese lysiert und nach einem Protokoll von Dr. T. Oellerich mit Streptaktin-Matrix inkubiert, die über die Interaktion mit dem „OneSTrEP-Tag“ zu einer Affinitätspräzipitation von Strep-Syk führte. Nach Elution mit Desthiobiotin konnte ich durch SDS-Page und anschließender Coomassie-Färbung die spezifische und effektive Aufreinigung von Strep-Syk aus DT40- und DG-75-Zellen zeigen (siehe Abb. 9).

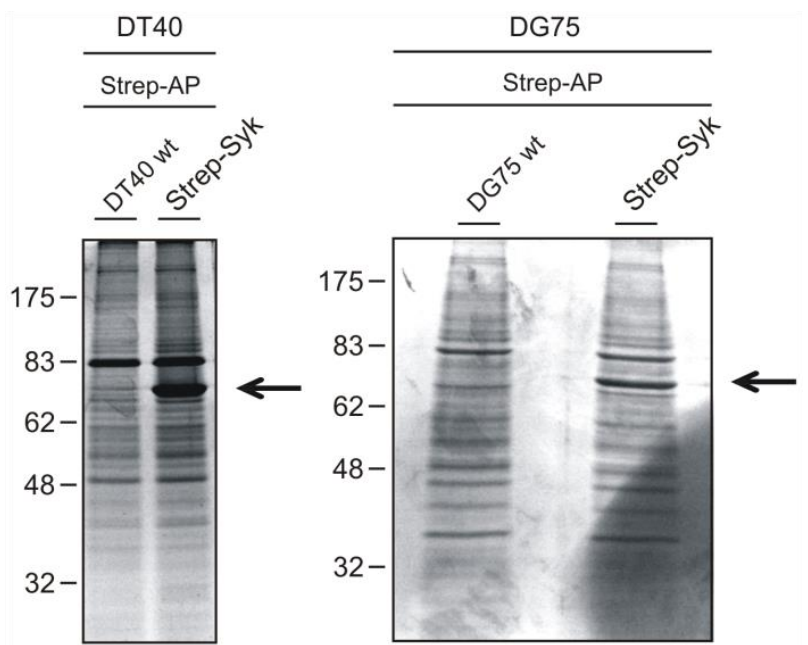

Abb. 9. Strep-Syk lässt sich effektiv aus DT40- und DG-75-B-Zellen isolieren. Die gereinigten zellulären Lysate der beschriebenen transfizierten DT40- (linke Seite) und DG-75(rechte Seite) B-Zellen wurden mit StreptaktinMatrix inkubiert und nach fünf Waschschritten wurde Strep-Syk mittels Desthiobiotin eluiert. Die resultierenden Eluate wurden mittels SDSPAGE aufgetrennt und mit Coomassie-Lösung gefärbt. Der Pfeil deutet auf das aufgereinigte Strep-Syk. Relative molekulare Massen des Proteinmarkers sind links in kDa angegeben.

Für Syk wurde eine Cbl-abhängige Ubiquitinylierung beschrieben (Hong et al. 2002). Ubiquitinylierung kann zur proteasomalen Degradation von Proteinen führen (Salomons et al. 2010). Zur Bestimmung des zeitlichen Verlaufes der Proteinmenge von Syk in BZR-stimulierten Zellen habe ich DT40- und DG-75-Zellen für verschiedene Zeiten stimuliert und durch Westernblot-Analyse konnte ich für beide Zelllinien eine konstante Expression von Syk über einen Stimulationszeitraum von 60 Min zeigen 
(siehe Abb. 10). Diese Ergebnisse stimmen auch mit Ergebnissen von Kitaura et al. (2007) überein. Eine mögliche Degradation von Syk konnte ich also in diesen Zellen ausschließen.
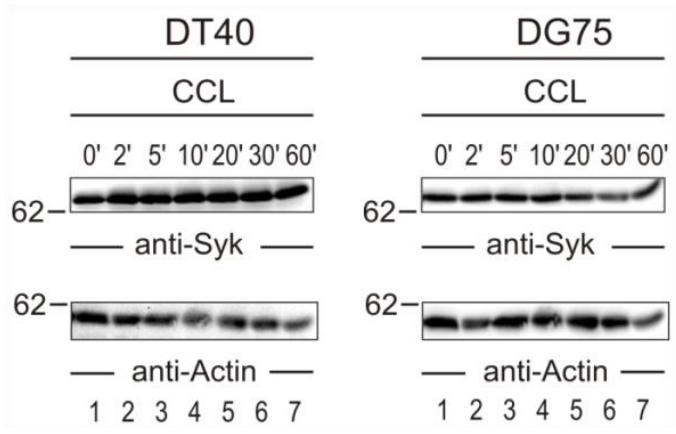

Abb. 10. Syk wird weder in DT40- noch in DG-75-BZellen nach BZR-Stimulation abgebaut. DT40- (linke Seite) und DG-75- (rechte Seite) B-Zellen wurden für angegebene Zeiten durch den BZR-Stimuliert und die gereinigten zellulären Lysate durch Immunoblot mit Antikörpern gegen humanes Syk auf den Zeitverlauf der Syk-Expression hin untersucht. Als Ladekontrolle wurden die Lysate mit Antikörpern gegen Aktin analysiert. Relative molekulare Massen des Proteinmarkers sind links in $\mathrm{kDa}$ angegeben. Die Daten sind repräsentativ für drei unabhängige Experimente.

\subsection{Das Phosphorylierungsprofil von Syk in aktivierten B-Zellen}

Zur massenspektrometrischen Bestimmung des Phosphorylierungsprofils von Syk in antigenstimulierten B-Zellen habe ich die in 4.1 beschriebenen DT40-Zellen für 1, 2, 3, 5, 10 oder 20 Minuten BZR-stimuliert und aus den zellulären Lysaten Syk wie in 3.3.7 (Seite 42) und 4.1 beschrieben affinitätspräzipitiert. In Zusammenarbeit mit der „Bioanalytical Mass Spectrometry Group“ am MPI für biophysikalische Chemie in Göttingen wurden die eluierten Proteine mittels 1D-PAGE aufgetrennt, mit Coomassie-Lösung angefärbt, die Bande bei 70 kDA herausgeschnitten und mit Trypsin verdaut. Nach einer Anreicherung der phosphorylierten Peptide über eine Titaniumdioxid-Säule wurden diese auf einem Orbitrap-Massenspektrometer auf Phosphorylierung hin analysiert. Die kovalente Verknüpfung eines Peptides mit einer Phosphatgruppe führt zu einer definierten Massenänderung des Peptides, welche durch das Massenspektrometer im MS-Modus zunächst global für das Peptid erfasst und nach Fragmentierung des Peptides im MS/MS-Modus einer spezifischen Aminosäure zugeordnet werden konnte.

Insgesamt konnten 32 Phosphorylierungsstellen, darunter 15 phosphorylierte Tyrosin-Reste, elf phosphorylierte Serin-Reste und sechs phosphorylierte ThreoninReste, in Syk identifiziert werden. Es konnten alle bisher bekannten Phosphorylierungsstellen bestätigt werden (in Abb. 11 schwarz dargestellt) sowie 19 neue Phosphorylierungsstellen (rot dargestellt) gezeigt werden. Eine Phosphorylierungsstelle in der regulatorisch wichtigen Interdomäne B ist Serin 297, das nach einer Stimulationszeit von fünf Minuten die dominante Phosphorylierungsstelle zu sein scheint, da es die größte Anzahl an gefundenen Phosphopeptiden aufweist (siehe Tabelle 9). 


\section{Phosphorylierungsstelle}

Serin 297

Tyrosin 352

Tyrosin 525 / 526

Tyrosin $630 / 631$

Tyrosin 296
Peptidanzahl

IKSYSFPKPGHR 25

EALPMDTEVYESPYADPEEIRPK 10

ALRADENYYK 16

LRNYYYDVVN

SYYSFPKPGHR 5

Tabelle 9. Phosphopeptidanzahl nach 5 min BZR-Stimulation. Modifiziert nach Bohnenberger et al. (2011, S. 1553).

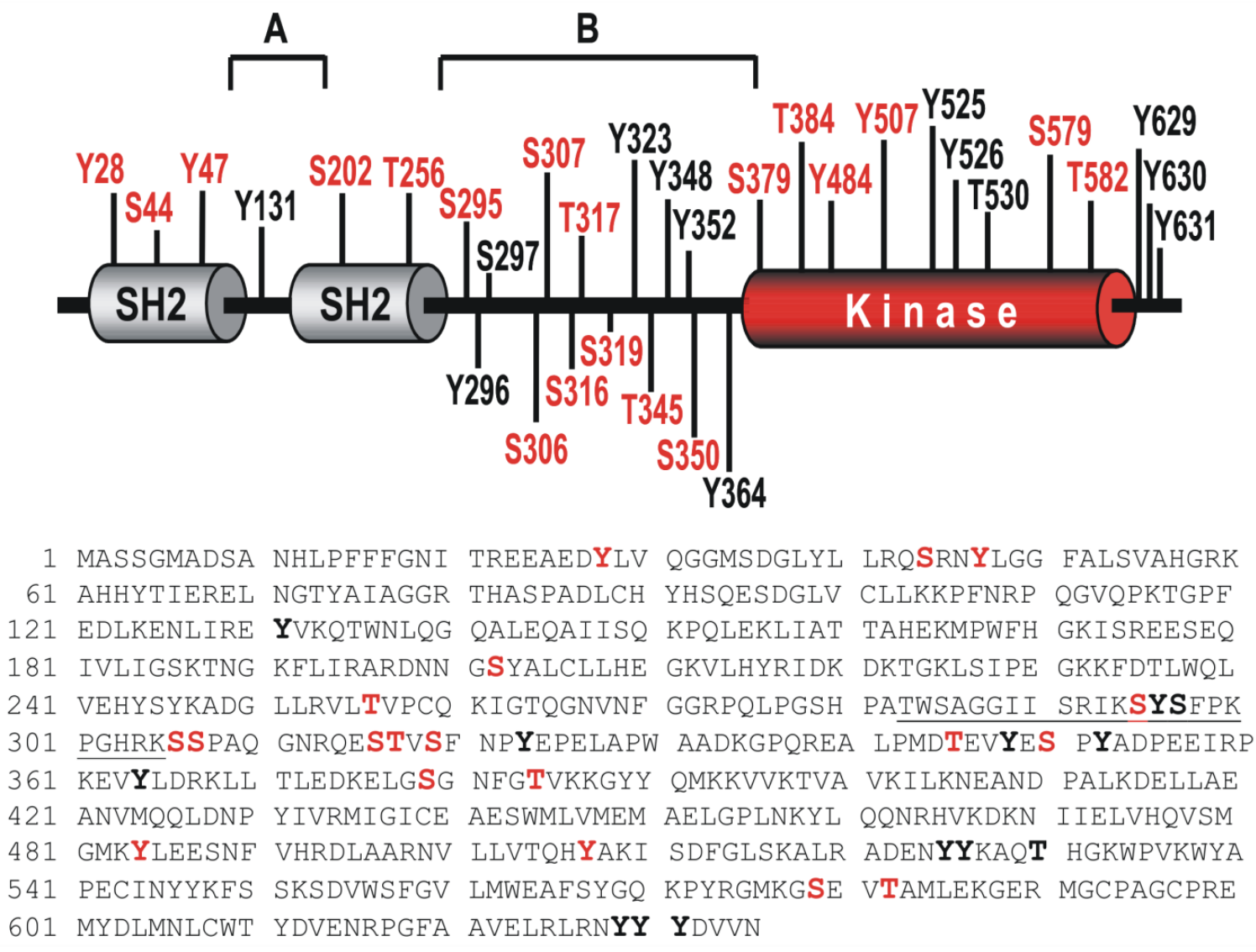

Abb. 11. Das Phosphorylierungsprofil von humanem Syk in BZR-stimulierten DT40-B-Zellen. Strep-Syk wurde aus DT40-B-Zellen, die für 1, 2, 3, 5, 10 oder 20 min durch den BZR stimuliert wurden, mittels Streptaktin isoliert, mit Trypsin verdaut und die resultierenden Phosphopeptide nach $\mathrm{TiO}_{2}-$ Anreicherung mittels LC-MS/MS Massenspektrometrie analysiert. Der obere Anteil zeigt die Domänen-Struktur von Syk mit der Lokalisation der gefundenen Phosphorylierungsstellen. Der untere Anteil zeigt die Aminosäuresequenz von humanem Syk mit den gefundenen Phosphorylierungsstellen fettgedruckt. Das linker insert, das die Isoformen von Syk unterscheidet, ist unterstrichen. Neu gefundene Phosphorylierungsstellen sind in Rot dargestellt. Modifiziert nach Bohnenberger et al. (2011, S.1552).

Durch Wiederholung der beschriebenen Versuche mit der in 4.1 beschriebenen, transfizierten humanen B-Zelllinien DG-75 konnten, da sich die Aufreinigung als insgesamt weniger effektiv herausstellte, elf der in der Literatur beschriebenen und sechs der in DT40 neu gefunden Phosphorylierungsstellen bestätigt werden (siehe Abb. 12). Auch Serin 297 konnte erneut als phosphoryliert gezeigt werden. Zusätzlich 
wurde Tyrosin 203 als Phosphorylierungsstelle identifiziert, das bei der Analyse der DT40-Zellen nicht auftauchte.

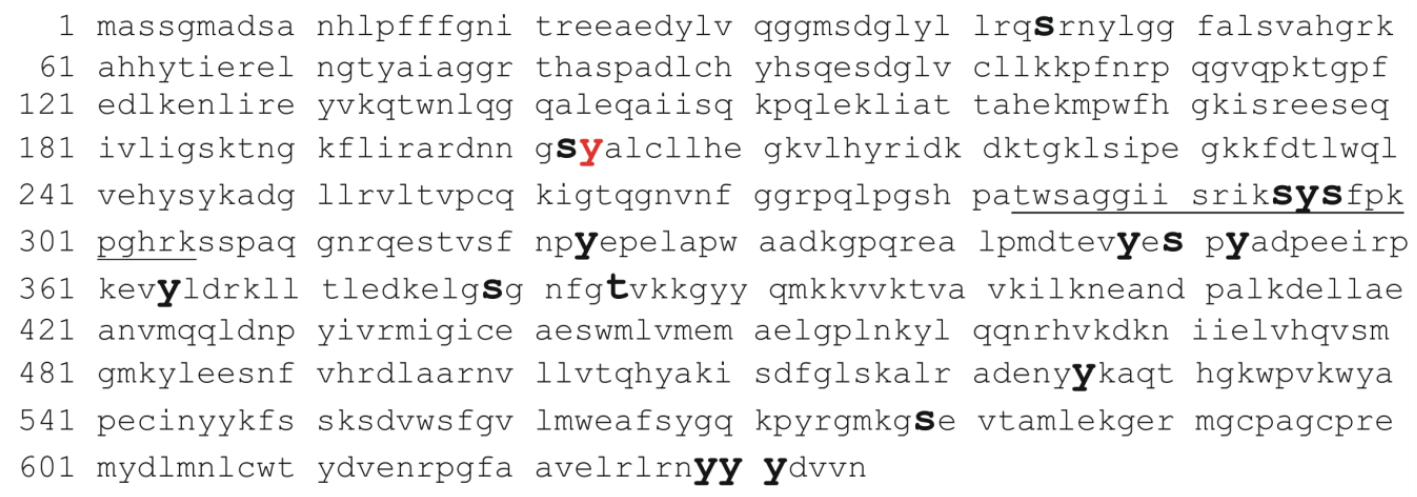

$\begin{array}{llllll}\text { Ser44 } & \text { Ser202 } & \text { Tyr203 } & \text { Ser295 } & \text { Tyr296 } & \text { Ser297 } \\ \text { Tyr323 } & \text { Tyr348 } & \text { Ser350 } & \text { Tyr352 } & \text { Tyr364 } & \text { Ser379 } \\ \text { Thr384 } & \text { Tyr525 } & \text { Tyr526 } & \text { Ser579 } & \text { Tyr629 } & \text { Tyr630 }\end{array}$

Abb. 12. Das Phosphorylierungsprofil von humanem Syk in BZR-Stimulierten DG-75-B-Zellen. Strep-Syk wurde aus DG-75-Zellen, die für 1, 2, 3, 5, 10, 20 min durch den BZR-Stimuliert wurden, mit Streptaktin isoliert und massenspektrometrisch analysiert. In der Aminosäuresequenz von humanem Syk sind die gefundenen Phosphorylierungsstellen fett gedruckt. Das linker insert ist unterstrichen. Phosphoryliertes Tyrosin 203, das in DT40 nicht gefundenen wurde, ist in Rot dargestellt. Unter der Sequenz sind die in DG-75 gefundenen Phosphorylierungsstellen zusammengefasst.

\subsection{Die BZR-induzierte Phosphorylierungskinetik von Syk}

Nach Stimulation eines Rezeptors kommt es häufig zur dynamischen Phosphorylierung einer Vielzahl von Proteinen und damit zur Aktivierung und Regulation eines intrazellulären Signalweges (Olsen et al. 2006). Auch beim Signalweg des BZR spielt Phosphorylierung eine entscheidende Rolle, jedoch liegen bisher keine umfassenden massenspektrometrischen Analysen der Phosphorylierungskinetik aller beteiligten Proteine vor (Oellerich et al. 2009).

Zur Untersuchung der Phosphorylierungskinetik von individuellen Phosphorylierungsstellen von Syk wurde ein SILAC-basierter, massenspektrometrischer Versuch durchgeführt. Strep-Syk-exprimierende DT40-Zellen wurden metabolisch markiert, in dem sie in drei verschiedenen Medien für mindestens zehn Zellteilungen kultiviert wurden, die jeweils Arginin und Lysin mit schweren oder leichten Isotopen von Kohlenstoff, Stickstoff und Wasserstoff in unterschiedlichen Kombinationen enthielten. "Leichtes Medium“ enthielt dabei unmodifiziertes Lysin $(+0)$ und Arginin $(+0)$, „mittelschweres Medium" enthielt die Kombination aus ${ }^{2} \mathrm{D}_{4},{ }^{12} \mathrm{C}_{6},{ }^{14} \mathrm{~N}_{2}$-Lysin $(+4)$ und ${ }^{13} \mathrm{C}_{6},{ }^{14} \mathrm{~N}_{4}$-Arginin (+6) und "schweres Medium “ ${ }^{13} \mathrm{C}_{6},{ }^{15} \mathrm{~N}_{2}$-Lysin (+8) und ${ }^{13} \mathrm{C}_{6},{ }^{15} \mathrm{~N}_{4}$ Arginin (+10). Die leichten Zellen blieben unstimuliert, während die mittelschweren 
für zwei oder fünf und die schweren Zellen für 10 oder 20 min durch den BZRStimuliert wurden. Die Peptide der unterschiedlich markierten Zellen konnten von dem Massenspektrometer auf Grund ihrer unterschiedlichen absoluten molekularen Masse voneinander unterschieden und somit einer der drei Zelllinien, die unterschiedlich stimuliert wurden, zugeordnet werden.

Strep-Syk habe ich aus den Zellen mittels Streptaktin aufgereinigt, die resultierenden Eluate in einem Verhältnis von 1:1:1 gemischt, so dass sich in einer Probe jeweils Syk aus unstimulierten und BZR-stimulierten ( 2 und 10 beziehungsweise 5 und 20 min) DT40-B-Zellen befanden. Die Proben wurden nach 1D-PAGE mit Trypsin, das Proteine nach Arginin oder Lysin spaltet, verdaut, so dass jedes Peptid mindestens ein Arginin oder Lysin enthält. Die phosphorylierten Peptide wurden wie in 3.4.2 (Seite 45 ) beschrieben angereichert, mittels LC-MS/MS untersucht und die Daten anschließend mit der MsQuant-Software ausgewertet. Durch Vergleich der PeakIntensitäten konnte der Verlauf der Phosphorylierung der einzelnen Phosphorylierungsstellen nach BZR-Stimulus bestimmt werden. Durch den Vergleich zum unstimulierten Zustand konnte eine Kinetik über fünf Zeitpunkte ermittelt werden. Insgesamt konnte so die Phosphorylierungskinetik von 15 Phosphopeptiden über fünf Zeitpunkte (siehe Abb. 13) und die Phosphorylierungskinetik von weiteren elf Phosphopeptiden über jeweils drei der fünf Zeitpunkte ermittelt werden (siehe Abb. 14). In Tabelle 10 sind die Ergebnisse zusammengefasst.

Bei der Phosphorylierungskinetik der Tyrosine (siehe Abb. 13, oben) fällt auf, dass die Phosphorylierung bei allen Phosphopeptiden bereits nach zwei Minuten ein Maximum erreicht und danach bei den meisten (z.B. Y526) sehr rasch wieder abfällt. Diese Kinetik wird auch als "frühe und rasche Kinetik" bezeichnet. Bei einigen Phosphorylierungsstellen bleibt die Phosphorylierung jedoch auch über einen längeren Zeitraum bestehen (z.B. Y348 + 352). Dies wird als „frühe und bleibende Kinetik" bezeichnet wird (Olsen et al. 2006).

Die Phosphorylierungskinetik der Serine und Threonine (siehe Abb. 13, unten) hingegen ist weniger homogen. Serin 297 zeigt eine ähnliche Kinetik wie die meisten Tyrosine mit einem deutlichen Anstieg in der Phosphorylierung nach Stimulation und einem raschen Abfall danach, jedoch wird das Maximum der Phosphorylierung etwas später erreicht. Serin 579 scheint eine noch stärker verzögerte Kinetik zu haben mit einem Anstieg der Phosphorylierung erst nach zehn Minuten (siehe Abb. 13). Dies 
wird als „späte Kinetik“ bezeichnet (Olsen et al. 2006). Serin 202 hingehen zeigt einen Rückgang der Phosphorylierung nach Stimulation, wodurch die BZR-abhängige Dephosphorylierung von Syk durch Phosphatasen an definierten Phosphorylierungsstellen anzunehmen ist. Auf Serin 379 scheint der BZR kaum Einfluss zu nehmen, da die Phosphorylierung über den gesamten Stimulationszeitraum konstant bleibt.

Syk zeigte also nach BZR-Stimulation eine dynamische und differenzierte Phosphorylierung unterschiedlicher Tyrosin-, Serin- und Threonin-Reste.
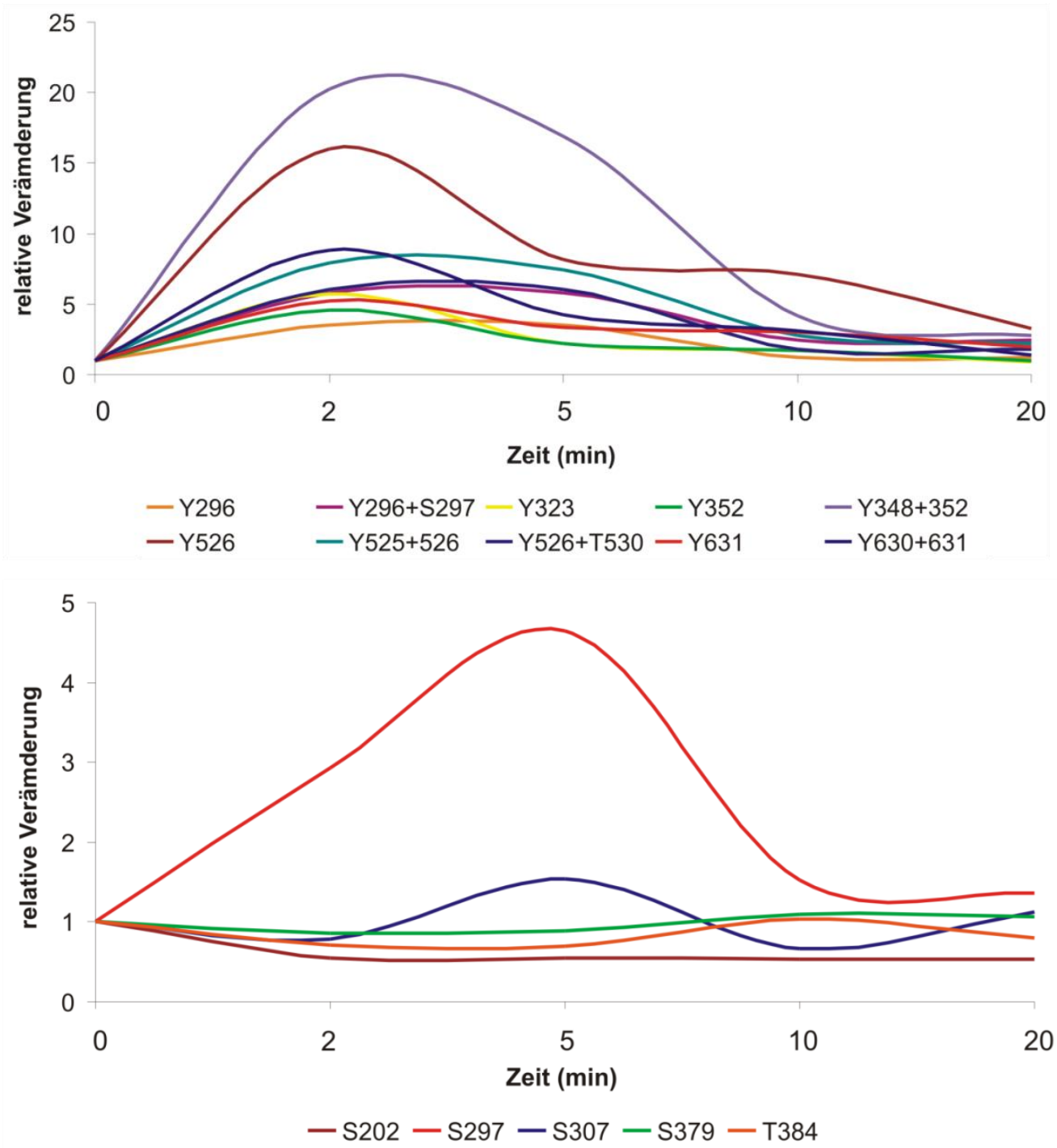

Abb. 13. Die Phosphorylierungskinetik von humanem Syk nach BZR-Stimulation. DT40-BZellen, die Strep-Syk exprimieren, wurden in drei verschiedenen SILAC-Medien (leicht, mittelschwer und schwer) kultiviert und dadurch metabolisch markiert. Die Zellen wurden für 0, 2, 10 min beziehungsweise 0, 5, 20 min stimuliert und aus den gereinigten zellulären Lysaten wurde Strep-Syk wie beschrieben isoliert, die Eluate im Verhältnis 1:1:1 vermischt und massenspektrometrisch analysiert. Der Status aus unstimulierten Zellen wurde zur Normalisierung der beiden Messungen verwendet. Die relative Änderung der Phosphorylierung stellt den Vergleich von leichten mit mittelschweren und schweren Phosphopeptiden dar. Der obere Anteil zeigt die Phosphorylierungskinetik der Tyrosine, der untere die der Serine und Threonine. Die Daten sind repräsentativ für zwei unabhängige Experimente. 


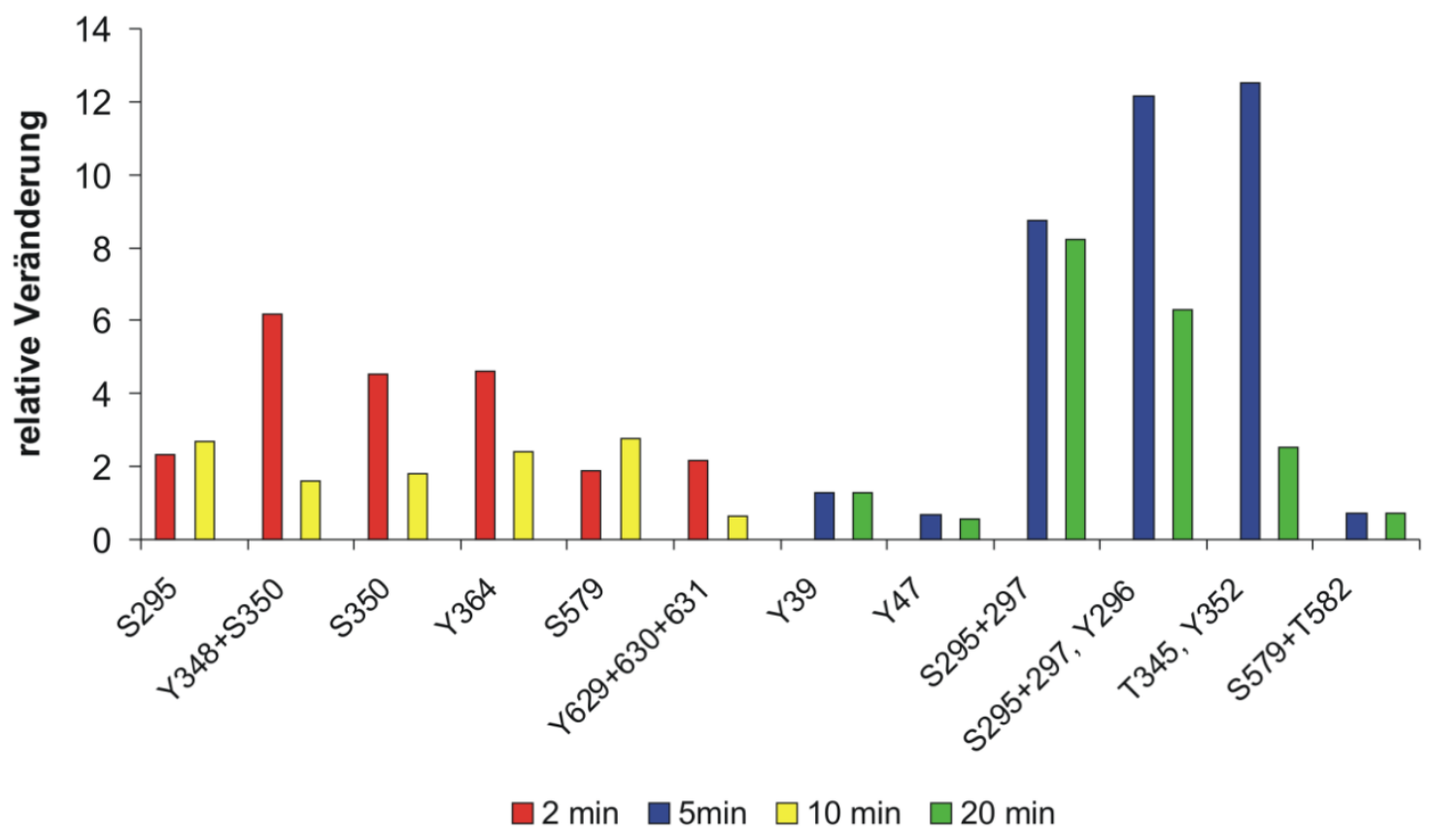

Abb. 14. Kinetik weiterer Phosphorylierungsstellen in humanem Syk nach BZR-Stimulation. Der Versuchsablauf ist identisch wie bereits für Abb. 13 beschrieben. Für einige Phosphorylierungsstellen konnte nur eine unvollständige Phosphorylierungskinetik erstellt werden, da sie nur bei der Messung mit 0, 2 und 10 min Stimulationszeit (linke Seite in Rot und Gelb) oder nur bei der mit 0, 5 und 20 min Stimulationszeit (rechte Seite in Blau und Grün) identifiziert wurden.

\begin{tabular}{|c|c|c|c|c|c|c|}
\hline Sequenz & Phosphorylierungsstelle & $2 \mathrm{~min}$ & $\begin{array}{r}\text { Std. } \\
\text { Abw. }\end{array}$ & $10 \mathrm{~min}$ & Normalisiert & $\begin{array}{r}\text { Std. } \\
\text { Abw. }\end{array}$ \\
\hline spleen tyrosine kinase (unphos) & & 1,000 & & 0,780 & & \\
\hline SYSFPKPGHR & Y296 & 3,500 & 0,670 & 1,190 & 1,526 & 0,230 \\
\hline SYSFPKPGHR & S297 & 2,930 & 0,620 & 1,520 & 1,949 & 0,550 \\
\hline IKSYSFPKPGHR & Y296+S297 & 5,830 & 1,440 & 2,450 & 3,141 & 0,570 \\
\hline QESTVSFNPYEPELAPWAADKGPQR & Y323 & 5,730 & 1,270 & 1,700 & 2,179 & 0,240 \\
\hline EALPMDTEVYESPYADPEEIRPK & Y352 & 4,580 & 0,740 & 1,700 & 2,179 & 0,270 \\
\hline EALPMDTEVYESPYADPEEIRPK & Y348+352 & 20,280 & 2,860 & 4,150 & 5,321 & 0,680 \\
\hline ADENYYKAQTHGK & Y526 & 16,020 & 2,160 & 7,130 & 9,141 & 2,180 \\
\hline ALRADENYYKAQTHGK & pY525+526 & 7,920 & 2,310 & 2,770 & 3,551 & 0,950 \\
\hline ALRADENYYKAQTHGK & Y526+T530 & 6,080 & 2,280 & 1,790 & 2,295 & 0,590 \\
\hline LRNYYYDVVN & Y631 & 5,260 & 1,740 & 3,000 & 3,846 & 1,160 \\
\hline LRNYYYDVVN & $Y 630+631$ & 8,820 & 1,640 & 3,110 & 3,987 & 0,550 \\
\hline IKSYSFPKPGHR & S295 & 2,320 & 0,350 & 2,100 & 2,692 & 0,430 \\
\hline ELGSGNFGTVK & S379 & 0,860 & 0,230 & 1,100 & 1,410 & 0,340 \\
\hline LLTLEDKELGSGNFGTVKK & T384 & 0,710 & 0,100 & 1,040 & 1,333 & 0,230 \\
\hline GMKGSEVTAMLEK & S579 & 1,900 & 0,600 & 2,170 & 2,782 & 0,690 \\
\hline DNNGSYALCLLHEGK & S202 & 0,550 & 0,230 & 0,530 & 0,679 & 0,180 \\
\hline KSSPAQGNR & S307 & 0,790 & 0,260 & 0,670 & 0,859 & 0,250 \\
\hline EALPMDTEVYESPYADPEEIRPK & Y348+S350 & 6,190 & "---" & 1,264 & 1,620 & "---" \\
\hline EALPMDTEVYESPYADPEEIRPK & S350 & 4,540 & 0,72 & 1,396 & 1,790 & 0,26 \\
\hline EVYLDRK & Y364 & 4,620 & 0,85 & 1,880 & 2,410 & 0,44 \\
\hline GMKGSEVTAMLEK & S579 & 1,900 & 0,6 & 1,693 & 2,170 & 0,69 \\
\hline LRNYYYDVVN & $Y 629+630+631$ & 2,180 & 0,32 & 0,515 & 0,660 & 0,14 \\
\hline
\end{tabular}




\begin{tabular}{|r|r|r|r|r|r|}
\hline Sequenz & Phosphorylierungsstelle & $\mathbf{5 m i n}$ & $\begin{array}{r}\text { Std. } \\
\text { Abw. }\end{array}$ & 20min & Std. Abw. \\
\hline spleen tyrosine kinase (unphos) & & 1,000 & & 1,000 & \\
\hline SYSFPKPGHR & Y296 & 3,500 & 0,670 & 1,190 & 0,23 \\
\hline SYSFPKPGHR & S297 & 4,650 & 0,460 & 1,360 & 0,55 \\
\hline IKSYSFPKPGHR & Y296+S297 & 5,830 & 1,440 & 2,450 & 0,57 \\
\hline QESTVSFNPYEPELAPWAADKGPQR & Y323 & 2,180 & 0,090 & 0,900 & 0,17 \\
\hline EALPMDTEVYESPYADPEEIRPK & Y352 & 2,200 & 0,160 & 1,000 & 0,09 \\
\hline EALPMDTEVYESPYADPEEIRPK & Y348+352 & 16,910 & 1,810 & 2,760 & 1,11 \\
\hline ADENYYKAQTHGK & Y526 & 8,180 & 2,100 & 3,290 & 0,92 \\
\hline ALRADENYYKAQTHGK & Y525+526 & 7,450 & 0,280 & 2,190 & 0,49 \\
\hline ALRADENYYKAQTHGK & Y526+T530 & 6,080 & 2,200 & 1,790 & 0,59 \\
\hline LRNYYYDVVN & Y631 & 3,350 & 0,470 & 1,920 & 0,34 \\
\hline LRNYYYDVVN & Y630+631 & 4,240 & 0,900 & 1,380 & 0,18 \\
\hline ELGSGNFGTVK & S379 & 0,890 & 0,34 & 1,060 & 0,36 \\
\hline T384 & 0,690 & 0,16 & 0,800 & 0,11 \\
\hline LLTLEDKELGSGNFGTVKK & S202 & 0,550 & 0,23 & 0,530 & 0,18 \\
\hline DNNGSYALCLLHEGK & S307 & 1,540 & 0,41 & 1,120 & 0,41 \\
\hline KSSPAQGNR & Y47 & 0,690 & 0,28 & 0,560 & 0,3 \\
\hline NYLGGFALSVAHGR & S295+297 & 8,730 & 1,43 & 8,220 & 1,7 \\
\hline IKSYSFPKPGHR & S295+297, Y296 & 12,150 & 2,45 & 6,280 & 1,44 \\
\hline IKSYSFPKPGHR & T345, Y352 & 12,530 & 2,98 & 2,530 & 0,7 \\
\hline S579+T582 & 0,710 & 0,22 & 0,710 & 0,27 \\
\hline GMLPMSEVVTAMLEK & & & & & \\
\hline & & &
\end{tabular}

Tabelle 10. Phosphorylierungskinetik von humanem Syk in BZR-stimulierten DT40-B-Zellen. In dieser Tabelle sind die in Abb. 13 und 13 dargestellten Ergebnisse zusammengefasst. Der obere Anteil zeigt die Daten der Kinetik 0, 2, 10 min. Nach 10 min wurde eine Abweichung der aufgereinigten Syk-Menge festgestellt und deshalb die Kinetik auf diesen Wert normalisiert. Der untere Anteil zeigt die Ergebnisse der Kinetik 0, 5, 20 min. Die phosphorylierte Aminosäure ist fett gedruckt. Die Daten sind repräsentativ für zwei unabhängige Experimente.

\subsection{Das Interaktom von Syk in ruhenden und aktivierten B-Zellen}

Die Phosphorylierung von bestimmten Tyrosinen, Serinen oder Threoninen ist häufig eine Voraussetzung für die Interaktion mit anderen Proteinen. Für Syk konnte bereits gezeigt werden, dass neben der Kinase-Aktivität auch die Interaktion mit anderen Proteinen wichtig für den BZR-Signalweg ist (Kulathu et al. 2009).

Mit dem Ziel, neben der Analyse der Phosphorylierung auch das Interaktom von Syk in B-Lymphozyten zu bestimmen, habe ich Strep-Syk aus unstimulierten und stimulierten (1, 2, 5, 10, $20 \mathrm{~min})$ DT40-Zellen, die Strep-Syk exprimieren und in schwerem SILAC-Medium kultiviert wurden, mit Streptaktin-Matrix aufgereinigt. Als Negativkontrolle habe ich die gleiche Aufreinigung mit unstimulierten oder für die oben angegebenen Zeiten stimulierten DT40-Zellen, die wildtyp Syk ohne STrEP-Tag exprimieren und in leichtem Medium kultiviert wurden, durchgeführt. Die Eluate wurden im Verhältnis 1:1 vermischt und nach 1-D Page und Verdau mit Trypsin massenspektrometrisch analysiert und anschließend durch die MaxQuant Software ausgewertet. Dabei 
erkennt MaxQuant durch den Massenunterschied die Peptide, in die schweres Arginin oder Lysin integriert ist, identifiziert somit Peptid-Paare, die sich in ihrer Masse genau um die SILAC-Modifizierungen unterscheiden und kann so den aufgereinigten Peptiden der einen Zelle korrespondierende Peptide der anderen Zelle zuordnen. Waren die beiden Signale des Peptid-Paares von ähnlich starker Intensität, so ist das entsprechende Protein als unspezifischer Hintergrund aufgereinigt worden (siehe Abb. 15 oben). Ist jedoch das schwere Peptid, das aus der Zellkultur mit Strep-Syk stammt, mindestens um den Faktor fünf stärker aufgereinigt als das leichte Peptid aus der Negativkontrolle, so hat das entsprechende Protein als Interaktionsprotein spezifisch an Syk gebunden und ist deshalb in der Probe angereichert (siehe Abb. 15 Mitte). Der Grenzwert von Faktor fünf wird durch die Tatsache unterstützt, dass alle bekannten Interaktionspartner, die durch diese Messungen gefunden wurden, oberhalb dieser Grenze liegen.

In Abbildung 15 ist außerdem das MS-Spektrum eines Peptides von Syk zu sehen. Da Strep-Syk nur in den DT40-Zellen, die in schwerem Medium kultiviert wurden, exprimiert wurde, konnte es somit auch nur aus diesen Zellen aufgereinigt werden. Aus dem Fehlen eines leichten Peptides in dem Spektrum ergibt sich somit, dass die Proteine der DT40-Strep-Syk-Zellen vollständig mit schweren Aminosäuren markiert wurden (siehe Abb. 15 unten).

In unstimulierten B-Lymphozyten assoziiert Syk nur mit wenigen Proteinen (Tabelle 11, oberer Teil). In Übereinstimmung mit der ursprünglichen Entdeckung von Syk als BZR-assoziierte Kinase erscheinen die membrangebundene Form des Immunglobulin $M$ sowie die assoziierten Proteine Ig- $\alpha$ (CD79a) und Ig- $\beta$ (CD79b) als Interaktionsproteine von Syk bereits in unstimulierten B-Zellen.

Nach BZR-Stimulation erhöht sich die Anzahl der Interaktionsproteine von Syk auf über 20 (Tabelle 11, unterer Teil). Zusätzlich zu bekannten Bindepartnern wie dem BZR, dem Guanosin-Austauschfaktor VAV3 oder dem Adapterprotein SLP65 konnten mehr als 15 neue Bindepartner aus unterschiedlichen funktionellen Kategorien bestimmt werden. Neben der MAP-Kinase Sek1 und dem aus T-Zellen bekannten Adapterprotein RhoH konnten verschiedene Proteine aus der Gruppe des Zytoskeletts wie Aktin, Coronin1c und Dynein und verschiedene Isoformen des Adapterproteins 14-3-3 als Bindepartner von Syk ermittelt werden. 

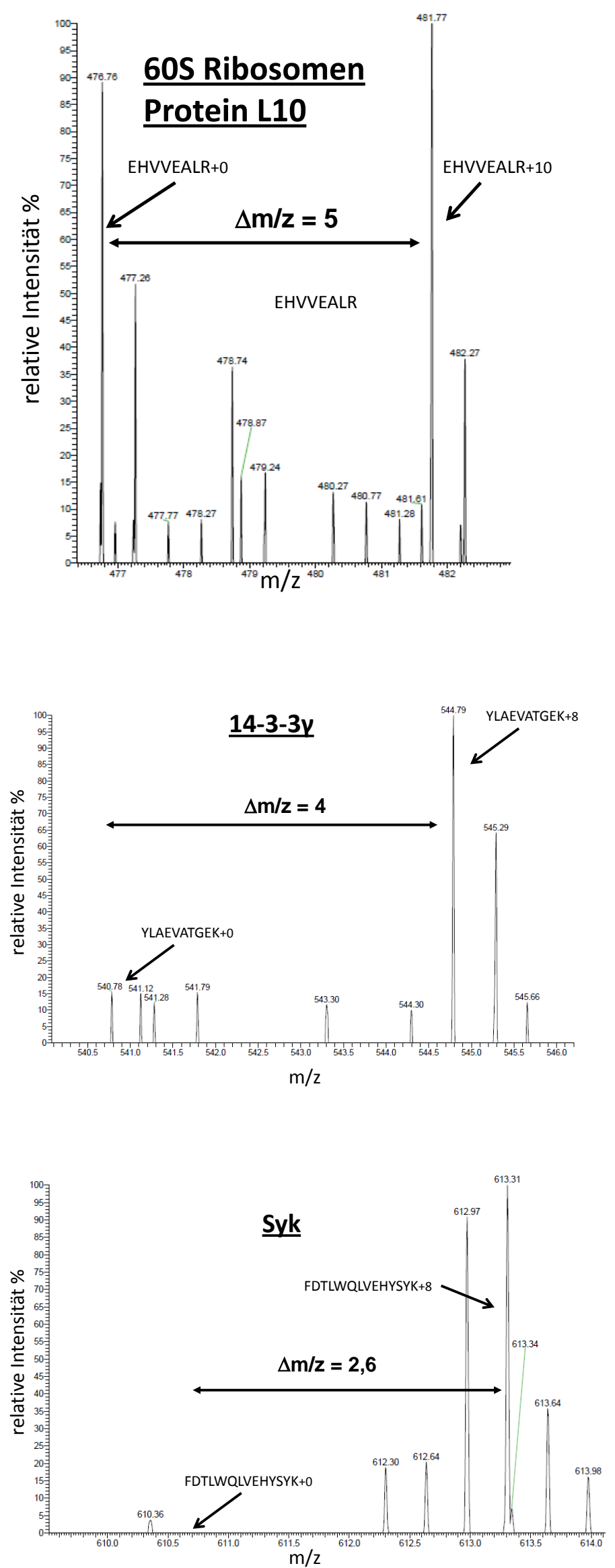

Abb. 15. SILAC-basierte massenspektrometrische Analyse des Interaktoms von Syk aus DT40-BLymphozyten. Dargestellt sind die MSSpektren der Peptide des Hintergrundproteins „60S Ribosomen Protein L10“, Ladung $=2$ (oben), des Bindepartners von Syk 14-3-3y, Ladung = 2 (mitte) und von Syk selbst, Ladung $=3$ (unten). Eingezeichnet ist der $\mathrm{m} / \mathrm{z}$-Unterschied, der sich aus der Ladung des Peptides und der Anzahl der Arginine und Lysine und damit der schweren Isotope ergibt. Anzumerken ist, dass die meisten Peptide, aufgrund des natürlichen Vorkommens von schweren Isotopen, ein oder zwei zusätzliche schwere Isotope beinhalten und sich somit ein Peak-Triplet ergibt, bei dem der zweite und dritte Peak jeweils um eine atomare Masseneinheit geteilt durch die Ladung des Peptides, verschoben ist. 


\begin{tabular}{|c|c|c|c|c|}
\hline Bindepartner & IPI & Peptide & Funktion & Referenz \\
\hline \multicolumn{5}{|c|}{ ruhende B-Zellen } \\
\hline IgM schwere und leichte Kette & 00591488 & 16 & Membrangebundenes IgM & (Hutchcroft et al. 1992) \\
\hline $\lg -\alpha(C D 79 a) / \lg -\beta$ (CD79b) & 00589784 & 10 & Bestandteil des BZR & (Wienands et al. 1995) \\
\hline $\begin{aligned} \text { PLK2 }\end{aligned}$ & 00601339 & 1 & Serin-/Threonin-Kinase & (Uckun et al. 2010 b) \\
\hline Ig-schwere-Kette-Bindeprotein & 00590375 & 8 & Hitzeschockprotein & diese Arbeit \\
\hline $\mathrm{Hsp} 90 \alpha / \beta$ & 00596586 & 136 & Hitzeschockprotein & diese Arbeit \\
\hline Hsp90 ko-chaperone Cdc37 & 00582638 & 26 & Hitzeschockprotein & diese Arbeit \\
\hline TRAP1 & 00584168 & 3 & Hitzeschockprotein & diese Arbeit \\
\hline \multicolumn{5}{|c|}{ aktivierte B-Zellen } \\
\hline IgM schwere und leichte Kette & 00591488 & 72 & membrangebundenes IgM & (Hutchcroft et al. 1992) \\
\hline $\lg -\alpha(C D 79 a) / \lg -\beta$ (CD79b) & 00589784 & 41 & Bestandteil des BZR & (Wienands et al. 1995) \\
\hline SLP65 & 00601644 & 17 & Adapterprotein & (Abudula et al. 2007) \\
\hline VAV3 & 00578220 & 8 & GTP-Austauschfaktor & (Deckert et al. 1996) \\
\hline p85- $\beta$ & 00575992 & 3 & Untereinheit der PI3K & (Moon et. al 2005) \\
\hline PLK2 & 00601339 & 3 & Serin-/Threonin-Kinase & (Uckun et al. 2010 b) \\
\hline Sek1 & 00594829 & 1 & MAP-Kinase & diese Arbeit \\
\hline $\mathrm{RhoH}$ & 00581726 & 14 & GTP-Bindeprotein & diese Arbeit \\
\hline TRAP1 & 00584168 & 7 & Hitzeschockprotein & diese Arbeit \\
\hline 14-3-3 $\alpha, \gamma, \varepsilon, \eta$ & 00587444 & 78 & Adapterprotein & $\begin{array}{l}\text { diese Arbeit, (Paris et al. } \\
\text { 2010) }\end{array}$ \\
\hline Aktin $\alpha 2$ & 00579460 & 10 & Zytoskelett & diese Arbeit \\
\hline Coronin1c & 00576513 & 22 & aktinassoziiertes Protein & diese Arbeit \\
\hline Dynein schwere Kette 2 & 00589956 & 1 & intrazellulärer Transport & diese Arbeit \\
\hline TOM1L1 & 00604337 & 2 & intrazellulärer Transport & diese Arbeit \\
\hline Ubiquitin & 00819877 & 34 & Proteinmodifikation & (Rao et al. 2001) \\
\hline Ig-schwere-Kette-Bindeprotein & 00590375 & 100 & Hitzeschockprotein & diese Arbeit \\
\hline Hsp $90 \alpha / \beta$ & 00596586 & 700 & Hitzeschockprotein & diese Arbeit \\
\hline Hsp70 & 00818704 & 30 & Hitzeschockprotein & diese Arbeit \\
\hline Hsp90 ko-chaperone Cdc37 & 00582638 & 112 & Hitzeschockprotein & diese Arbeit \\
\hline DNA-J-Homolog B6 & 00584191 & 6 & Hitzeschockprotein & diese Arbeit \\
\hline Sec7-Domän- Familie & 00571847 & 2 & unbekannt & diese Arbeit \\
\hline LOC423772 & 00588286 & 2 & unbekannt & diese Arbeit \\
\hline Leucinreich mit $\mathrm{CH}$-Domäne 3 & 00581388 & 1 & unbekannt & diese Arbeit \\
\hline PH-Domäne enthaltend G4B & 00570901 & 1 & unbekannt & diese Arbeit \\
\hline
\end{tabular}

Tabelle 11. Das B-Zell Interaktom von Syk aus ruhenden und BZR-aktivierten DT40-B-Zellen. Strep-Syk wurde mittels Streptaktin-Matrix aus unstimulierten oder BZR-stimulierten (1, 2, 5, 10, 20 min) DT40-B-Zellen die entweder Strep-Syk oder wildtyp Syk (als Negativkontrolle) exprimieren und in schwerem oder leichtem SILAC-Medium kultiviert wurden, isoliert, die Eluate im Verhältnis 1:1 vermischt und massenspektrometrisch analysiert. Die Tabelle zeigt alle Proteine, die mindestens eine fünffache Anreicherung schwerer gegenüber leichter Peptide zeigten. Pro Zeitpunkt wurden zwei unabhängige Experimente durchgeführt. Modifiziert nach Bohnenberger et al. (2011, S.1554).

Die Interaktion von Syk mit Sek1, Aktin und Coronin1c konnte ich durch KoImmunopräzipitation von Syk aus der humanen B-Zelllinie Ramos mittels Westernblot-Analyse verifizieren (siehe Abb. 16). Für 14-3-3y konnte ich die Interaktion durch 
Ko-Immunopräzipitation von Syk sowohl aus der humanen B-Zelllinie Ramos und DG-75 als auch aus der Zelllinie DT40 zeigen (siehe Abb. 19, Seite 61).

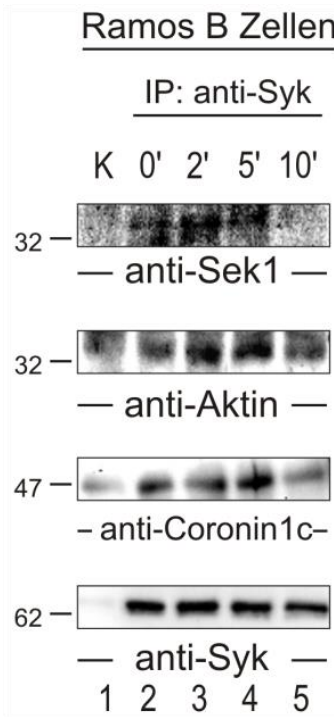

\begin{abstract}
Abb. 16. Immunopräzipitation neuer Syk-Bindepartner aus humanen Ramos-B-Lymphozyten. Ramos-B-Zellen wurden unstimuliert gelassen oder durch den BZR für angegebene Zeiten stimuliert und Syk aus den geklärten zellulären Lysaten immunopräzipitiert und einer Immunblotanalyse mit Antikörpern gegen Sek1, Aktin und Coronin1c zugeführt. Als Immunopräzipitationskontrolle dienten isotypengleiche Antikörper. Immunoblot mit Antikörpern gegen Syk diente als Ladekontrolle. Relative molekulare Massen des Proteinmarkers sind links in kDa angegeben. Die Daten sind repräsentativ für drei unabhängige Experimente.
\end{abstract}

Zusammenfassend zeigt sich also, dass Syk bereits in unstimulierten B-Zellen mit bestimmten Proteinen interagiert und dass sich dieser Komplex BZR-abhängig zu einem Multiproteinkomplex ausweitet. Dabei passt eine stimulationsabhängige Veränderung des Interaktoms von Syk zu der ermittelten, verstärkten Phosphorylierung von Syk nach BZR-Stimulus.

\title{
4.5 14-3-3y bindet an phosphoryliertes Serin 297 in humanem Syk
}

Als neuer Interaktionspartner von Syk wurde 14-3-3 identifiziert. Für diese Gruppe von Adapterproteinen sind viele Funktionen in der Signaltransduktion verschiedener Rezeptorsysteme beschrieben. Sie binden an spezifische Motive mit einem phosphorylierten Serin oder Threonin (Yaffe et al. 1997). Eine Funktion im proximalen BZRSignalweg war bisher nicht bekannt. Da bei der Phosphorylierungsanalyse neben vielen Tyrosinen auch viele Serine und Threonine als phosphoryliert gefunden wurden, ist zu vermuten, dass 14-3-3 an eines oder mehrere dieser Motive bindet.

Mit Hilfe der Proteinanalyseprogramme von ScanSite (Obenauer et al. 2003) und ELM (Diella et al. 2008) konnte ich sieben potentielle Binde-Motive für 14-3-3 in humanem Syk ermitteln, von denen fünf über verschiedene Säugetierspezies konserviert sind (siehe Abb. 17). 


\begin{tabular}{|c|c|c|c|c|c|c|c|}
\hline & T256 & S295 & S297 & S306 & T317 & T371 & T530 \\
\hline Human & \multicolumn{7}{|c|}{ 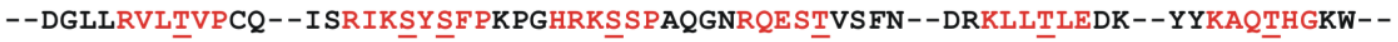 } \\
\hline Maus & \multicolumn{7}{|c|}{ 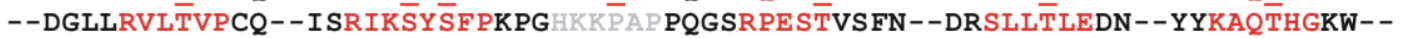 } \\
\hline Ratte & \multicolumn{7}{|c|}{--DGLLRVLTVPCQ--ISRIKSYSF PKPGHKKP P PQQGRPESTVSFN--DRKLLTLEDN--YYKAQTHGKW- - } \\
\hline Schwein & \multicolumn{7}{|c|}{--DGLLRVLTVPCQ- -ISRIKSYSFPKPGHRKASS PQGNRPE SLVSFN--DRKLLTLEDK--YYKAQTHGKW-- } \\
\hline Scansite & mittel & mittel & mittel & schwach & nein & nein & schwach \\
\hline Elm & ja & nein & ja & nein & ja & ja & nein \\
\hline Phosohoryliert & ja & ja & ja & ja & ja & nein & ja \\
\hline
\end{tabular}

Abb. 17. In-siliko-Suche nach potentiellen 14-3-3-Bindestellen in humanem Syk. Gezeigt ist ein Vergleich der Aminosäuresequenz von Syk aus verschiedenen Spezies. Rote Schrift bedeutet Übereinstimmung, graue Schrift Abweichung. Humanes Syk wurde mit den Online-Programmen ScanSite und Elm auf potentielle 14-3-3-Bindemotive untersucht. ScanSite unterscheidet zusätzlich noch zwischen hoch, mittel und niedrig wahrscheinlichen Bindemotiven. Zusätzlich ist der massenspektrometrisch ermittelte Phosphorylierungszustand nach BZR-Stimulation angegeben. Modifiziert nach Bohnenberger et al. (2011, S.1556).

Mit dem Ziel, die Bedeutung dieser Aminosäuren auf die Bindung von Syk zu untersuchen, habe ich durch zielgerichtete Mutagenese-PCRs Varianten der humanen Syk-DNA hergestellt, die an Stelle des Serins für Alanin beziehungsweise an Stelle des Threonin für Valin kodieren. Die mutierte DNA habe ich an die DNA für den Farbstoff Citrin gekoppelt und retroviral in Syk-defiziente DT40-Zellen transduziert, so dass diese jeweils eine $\mathrm{N}$-terminal Citrin-gekoppelte Variante von Syk stabil exprimieren (im Folgenden als Citrin-Syk bezeichnet). Durch retrovirale Transduktion können klonale Effekte ausgeschlossen werden. Die Vergleichbarkeit der Expression der Syk-Varianten habe ich mittels Durchflusszytometrie überprüft (siehe Abb. 18).

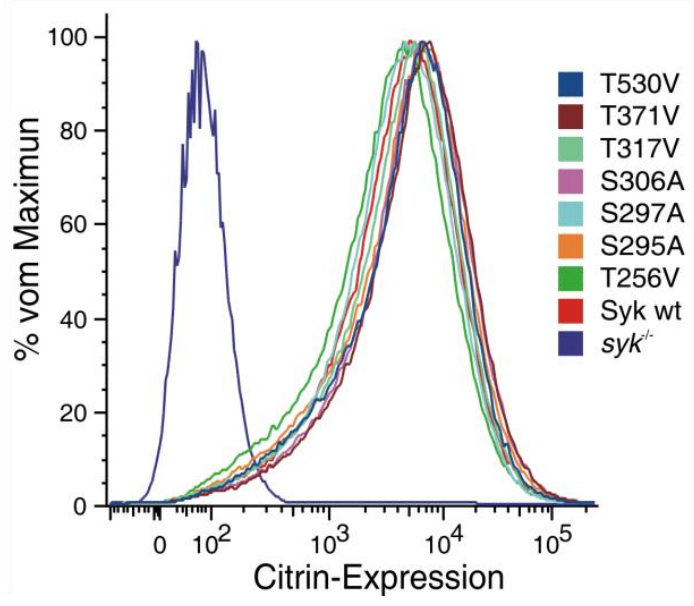

Abb. 18. Expression von Citrin-Syk Varianten in DT40-Zellen. Syk-defiziente DT40-B-Lymphozyten wurden retroviral mit angegebenen Varianten von Citrin-Syk transfiziert. Die resultierenden Zellen wurden mittels Durchflusszytometrie auf die Expression von Citrin-Syk hin analysiert. Modifiziert nach Bohnenberger et al. (2011, S.1557).

In der massenspektrometrischen Analysen der Syk-Phosphorylierung konnten nur vier der fünf konservierten Serine / Threonine als phosphoryliert gezeigt werden: Threonin 256, Serin 295, Serin 297 und Threonin 530, jedoch nur Threonin 256 und Serin 297 wurden in beiden Suchmaschinen als potentielle Bindemotive erkannt. Da 
Serin 297 das am häufigsten gefundene Phosphopeptid nach fünf Minuten BZRStimulation darstellt, erfolgten alle weiteren Experimente zunächst mit der S297A Variante von Citrin-Syk.

Durch Ko-Immunopräzipitation von Syk aus DT40-, DG-75- und Ramos-Zellen konnte ich mittels Westernblot-Analyse zeigen, dass 14-3-3y durch BZR-Stimulation induzierbar nach fünf Minuten BZR-Stimulation an Syk bindet und dass diese Bindung durch die Mutation von S297A aufgehoben werden kann (siehe Abb. 19).
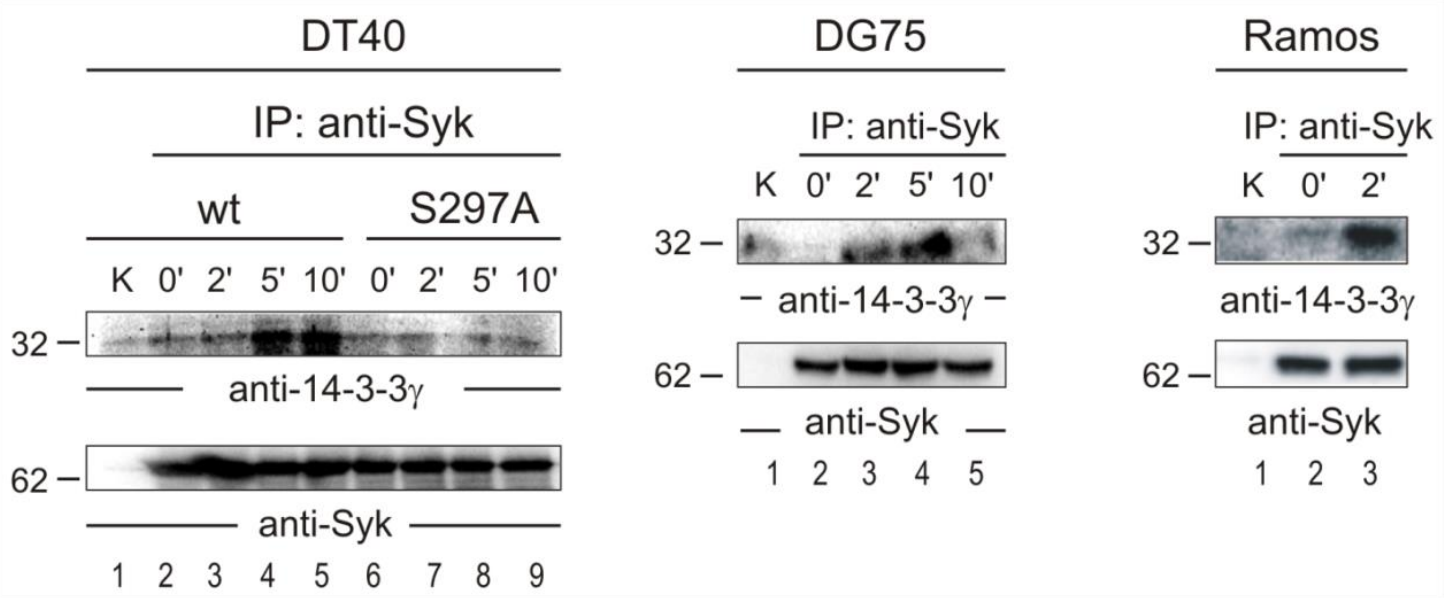

Abb. 19. Interaktion von Syk und 14-3-3y. Syk wurde aus DT40-Zellen, die Citrin-Syk wildtyp beziehungsweise die Variante S297A exprimieren (links), aus DG-75-Zellen (Mitte) und aus RamosZellen (rechts), die jeweils unstimuliert belassen oder für angegebene Zeiten durch den BZR stimuliert wurden, immunopräzipitiert und einer Immunblotanalyse mit einem Antikörper gegen 14-3-3y zugeführt. Als Immunopräzipitationskontrolle dienten isotypengleiche Antikörper. Immunoblot mit Antikörpern gegen Syk diente als Ladekontrolle. Relative molekulare Massen des Proteinmarkers sind links in $\mathrm{kDa}$ angegeben. Die Daten sind jeweils repräsentativ für drei unabhängige Experimente. Modifiziert nach Bohnenberger et al. (2011, S.1556).

Des Weiteren konnte ich durch Westernblot-Analyse von Lysaten aus Sykdefizienten DT40-Zellen, die Citrin-Syk wt oder S297A exprimieren, sowie den humanen Zellen DG-75 und Ramos unter Verwendung eines phosphospezifischen Antikörpers gegen das phosphorylierte Typ-I-Bindemotiv für 14-3-3 (R/KXXpSX), die Existenz eines phosphorylierten 14-3-3-Bindemotivs in Syk in BZR-stimulierten BZellen nachweisen (siehe Abb. 20). In Lysaten von Zellen, die die S297A-Variante von Syk exprimieren, konnte kein Signal festgestellt werden. Somit scheint die Aminosäuresequenz um Serin 297 das einzige phosphorylierte Typ-I-Bindemotiv für 143-3 in Syk zu sein. 

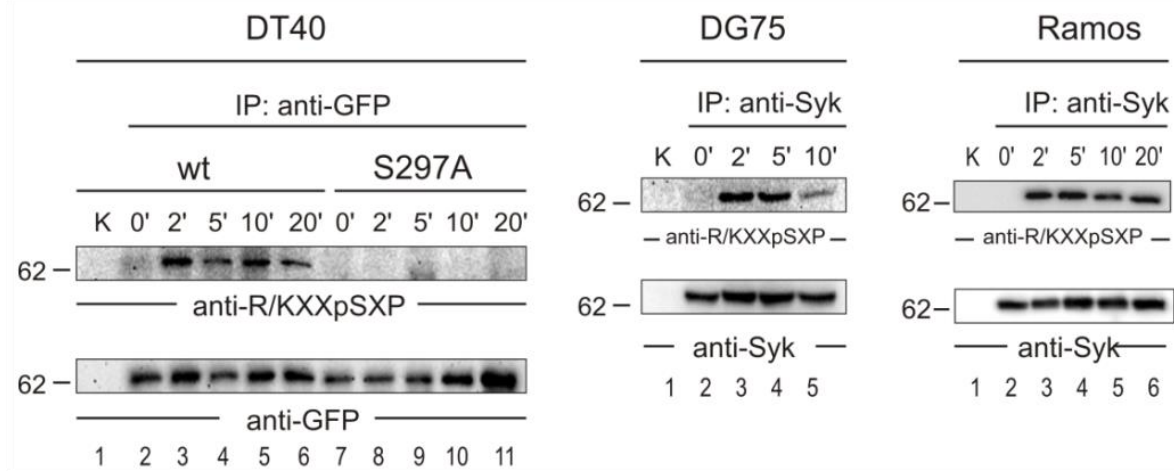

Abb. 20. Die Aminosäuresequenz um Serin 297 ist das einzige phosphorylierte 14-3-3Bindemotiv in humanem Syk. Syk wurde aus beschriebenen DT40- (links), DG-75- (Mitte) und Ramos-Zellen (rechts), die jeweils unstimuliert belassen oder für angegebene Zeiten durch den BZ stimuliert wurden, immunopräzipitiert und einer Immunblotanalyse mit einem Antikörper gegen das phosphorylierte Typ-I-Bindemotiv für 14-3-3 (R/KXXpSXP) zugeführt. Als Immunopräzipitationskontrolle dienten isotypengleiche Antikörper. Immunoblot mit Antikörpern gegen Syk und GFP diente als Ladekontrolle. Relative molekulare Massen des Proteinmarkers sind links in kDa angegeben. Die Daten sind jeweils repräsentativ für drei unabhängige Experimente. Modifiziert nach Bohnenberger et al. (2011, S.1556).

\subsection{4-3-3y bindet direkt an phosphoryliertes Serin 297}

Als Nächstes sollte mittels Far-Westernblot-Analyse untersucht werden, ob es sich bei der Bindung von 14-3-3y an Syk um eine direkte oder indirekte Interaktion handelt. Zu diesem Zwecke habe ich das Fusionsprotein von GST-14-3-3y und als Negativkontrolle GST aus IPTG-stimulierten Lysaten von BL21 E.coli Bakterien aufgereinigt. Testexpressionen ergaben eine maximale Expression der Proteine nach drei Stunden IPTG-Stimulation (siehe Abb. 21, oberer Abschnitt). Zur Bestimmung der Proteinmenge wurde eine BSA-Vergleichsreihe verwendet (siehe Abb. 21, unterer Abschnitt).

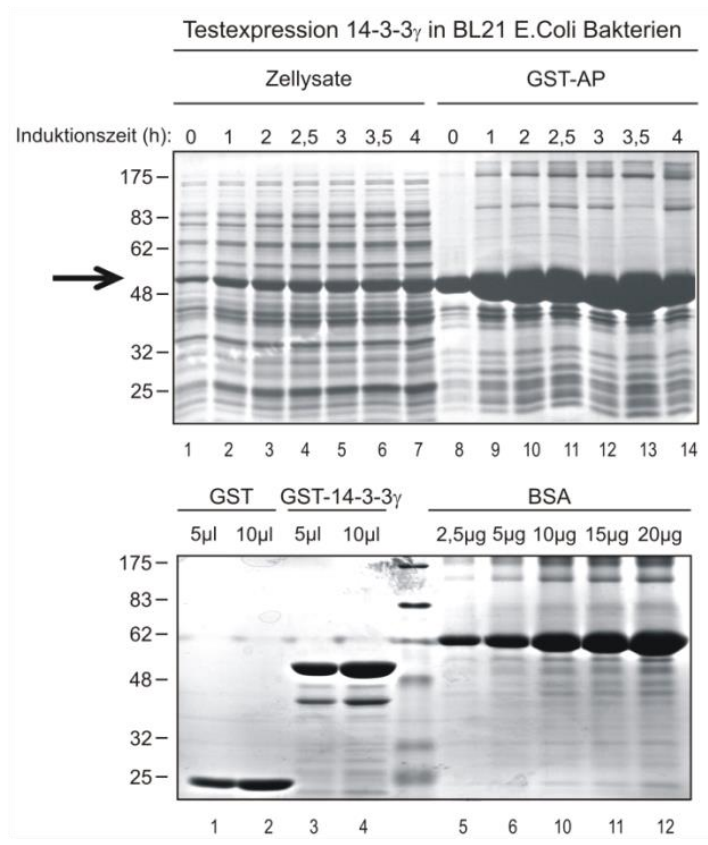

Abb. 21. Testexpression von GST-14-3-3y. BL21 E.coli Bakterien wurden mit der DNA von 14-3-3y im pGEXGST-Expressionsvektor transformiert. Die Expression von GST-14-3-3y wurde durch die Zugabe von IPTG gestartet und Proben wurden jeweils nach angegebenen Zeiten entnommen. Durch Inkubation mit Glutathion-Matrix konnte GST-14-3-3y isoliert werden. Der obere Bildabschnitt zeigt die unaufgereinigten Zelllysate (linke Seite) und die aufgereinigten Proben (rechte Seite), die mittels Gelelektrophorese aufgetrennt und mit Coomassie gefärbt wurden. Der Pfeil zeigt auf GST-14-3-3y. Der untere Bildabschnitt zeigt aufgereinigtes und eluiertes GST (Spalte 1+2) und GST-14-3-3y (Spalte 3+4), das mittels Gelelektrophorese aufgetrennt und mit Coomassie gefärbt wurde, wobei jeweils 5 beziehungsweise $10 \mu \mathrm{l}$ des Eluats aufgetragen wurden. Um die enthaltenen Proteinmenge abzuschätzen wurde eine BSA-Verdünnungsreihe aufgetragen (Spalten 5 - 9). Relative molekulare Massen des Proteinmarkers sind links in $\mathrm{kDa}$ angegeben. 
Syk wurde von mir aus den in 4.5 beschriebenen DT40-Zellen aufgereinigt und nach Westernblot der Proteine die resultierende Membran mit $10 \mu \mathrm{g}$ GST-14-3-3y beziehungsweise GST inkubiert. Durch Entwicklung mit einem Antikörper gegen GST konnte eine direkte und induzierbare Interaktion von Syk mit 14-3-3y gezeigt werden, die aufgehoben ist, wenn Serin 297 zu Alanin mutiert ist (siehe Abb. 22, oberste Spalte). Eine unspezifische Bindung von GST allein konnte ausgeschlossen werden (siehe Abb. 22, mittlere Spalte).

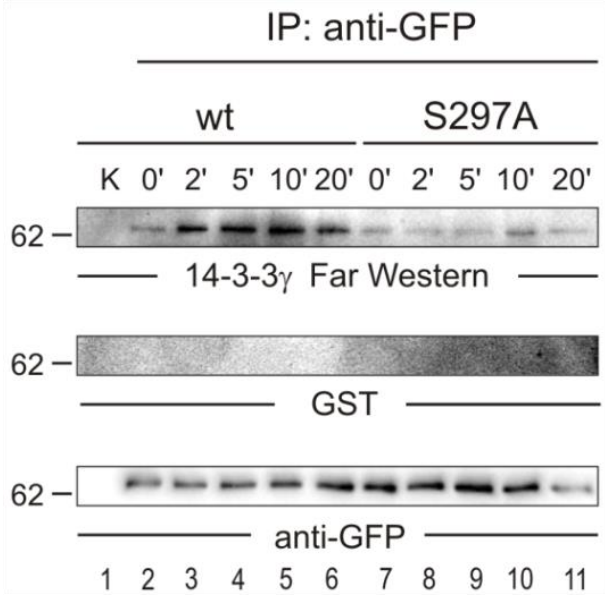

\begin{abstract}
Abb. 22. 14-3-3y interagiert direkt mit phosphoryliertem Serin 297. Syk wurde aus beschriebenen unstimulierten oder BZR-stimulierten DT40-Zellen immunopräzipitiert, die resultierenden Proben mittels Gelelektrophorese aufgetrennt und geblottet. Die Blottingmembranen wurden mit gleichen Mengen GST-14-3-3y (oben) oder GST (Mitte) inkubiert (Far-Westernblot). Anschließend wurden die Membranen mit Antikörpern gegen GST und Peroxidasegekoppeltem sekundären Antikörpern inkubiert und die Bindung mittels Chemilumineszenz nachgewiesen. Als Immunopräzipitationskontrolle dienten isotypengleiche Antikörper. Immunoblot mit Antikörpern gegen GFP diente als Ladekontrolle. Relative molekulare Massen des Proteinmarkers sind links in $\mathrm{kDa}$ angegeben. Die Daten sind repräsentativ für drei unabhängige Experimente. Modifiziert nach Bohnenberger et al. (2011, S.1556).
\end{abstract}

Die Mutation eines der anderen sechs Serine beziehungsweise Threonine vermochte die direkte Bindung von 14-3-3y an Syk nicht aufzuheben, wie mittels Immunopräzipitation von Syk aus den beschriebenen rekonstituierten DT40-Zellen und anschlieBender Far-Westernblot-Analyse gezeigt werden konnte (siehe Abb. 23). Somit konnte das Motiv KSYpSFP um das phosphorylierte Serin 297 als hauptsächliches Bindemotiv für 14-3-3y bestimmt werden.

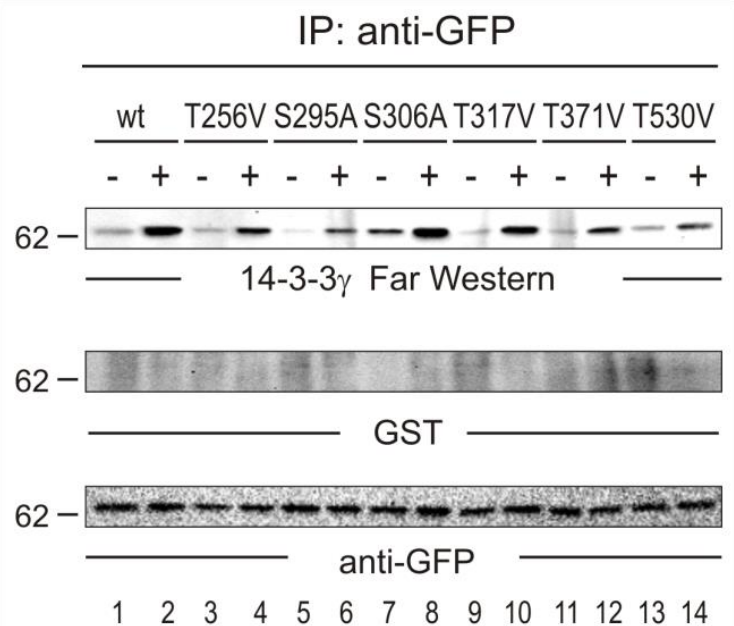

Abb. 23. 14-3-3y interagiert nur mit phosphoryliertem Serin 297 in humanem Syk. Der in Abb. 22 beschriebene Versuchsaufbau wurde mit den sechs anderen Mutanten von Syk, in denen jeweils ein potentielles Bindemotiv für 14-3-3 mutiert ist, wiederholt. Die Zellen wurden dabei entweder unstimuliert belassen (-) oder für 5 min stimuliert (+). Als Immunopräzipitationskontrolle dienten isotypengleiche Antikörper. Immunoblot mit Antikörpern gegen GFP diente als Ladekontrolle. Relative molekulare Massen des Proteinmarkers sind links in $\mathrm{kDa}$ angegeben. Die Daten sind repräsentativ für drei unabhängige Experimente. Modifiziert nach Bohnenberger et al. (2011, S.1556). 


\title{
4.7 Das Interaktom von Syk S297A
}

Mittels eines SILAC-basierten, massenspektrometrischen Versuches wurde quantitativ das Interaktom von wildtypischem Syk und der S297A Variante verglichen, um die Auswirkungen des Austausches von Serin 297 zu Alanin auf das Gesamt-Interaktom von Syk zu zeigen und damit Hinweise auf die Funktion der Bindung von 14-3-3 an Syk zu bekommen.

Dazu habe ich die Syk-Mutante, die für Syk S297A kodiert, an den beschriebenen "OneSTrEP-Tag" gekoppelt und mittels Elektroporation in Syk-defiziente DT40-BZellen transfiziert. Wiederum wurden, um klonale Effekte auszuschließen, drei Klone mit vergleichbarer Expression von Strep-Syk S297A vermischt. Eine vergleichbare Expression von wt und S297A Strep-Syk wurde mittels Immunoblotting und Coomassie-Färbung einer Testaufreinigung gesichert (siehe Abb. 24, unterer Anteil).

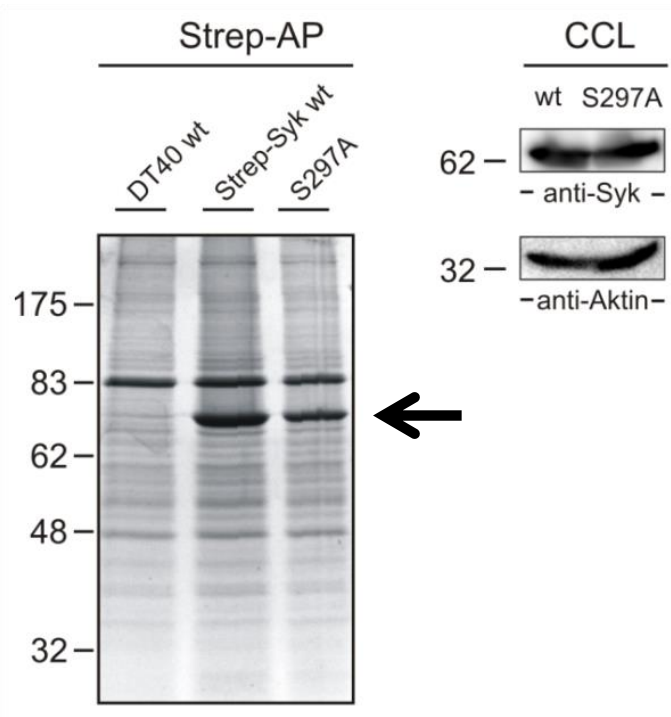

\begin{abstract}
Abb. 24. Expression von Strep-Syk wt und S297A in Syk-defizienten DT40-B-Lymphozyten. Syk defiziente DT40-Zellen wurden mit Strep-Syk S297A transfiziert, drei unabhängige Klone wurden vermischt und Strep-Syk wurde aus DT40-wildtypZellen und DT40-Zellen, die entweder Strep-Syk wt oder S297A stabil exprimieren, mit StreptaktinMatrix aufgereinigt. Die resultierenden Eluate wurden mittels Gelelektrophorese aufgetrennt und mit Coomassie-Lösung gefärbt (linke Seite). Der Pfeil kennzeichnet das aufgereinigte Strep-Syk.

Die gereinigten zellulären Lysate von DT40-Zellen, die stabil Strep-Syk wt beziehungsweise S297A exprimieren, wurden durch Immunoblot mit Antikörpern gegen humanes Syk auf ihre Expression von Syk hin untersucht. Als Ladekontrolle wurden die Lysate mit Antikörpern gegen Aktin analysiert (rechte Seite).
\end{abstract}

Die beschriebenen DT40-Zellen, die Strep-Syk S297A exprimieren, wurden in schwerem Medium und die Strep-Syk-wildtyp-exprimierenden in leichtem Medium kultiviert. Nach fünf Minuten BZR-Stimulation habe ich Strep-Syk aus den geklärten zellulären Lysaten mittels Streptaktin-Matrix aufgereinigt und die Eluate im Verhältnis 1:1 vermischt. Die Proben wurden massenspektrometrisch analysiert und durch MaxQuant ausgewertet. Nun ergaben sich Unterschiede in der Intensität der schweren und leichten Peptide nur bei Proteinen, die durch die Punktmutation verstärkt oder vermindert aufgereinigt wurden. Ratios der Intensitäten von $<1$ bedeuten dabei eine schwächere Assoziation und Ratios $>1$ eine verstärkte Assoziation des entsprechenden Bindepartners mit der Syk S297A-Variante. Es zeigte sich, dass der S297A Aus- 
tausch zu einem fast kompletten Verlust der Bindung von 14-3-3 y und $\varepsilon$ führt. Darüber hinaus zeigten die Daten, dass $\lg -\beta$ und Ubiquitin um den Faktor zwei effizienter mit der S97A-Variante aufgereinigt wurden (siehe Abb. 25).

Insgesamt bestätigt dieser Versuch also die bedeutsame Rolle von Serin 297 für die Bindung von 14-3-3 an Syk und deutet darauf hin, dass dieser Komplex die Bindung von Ubiquitin und $\lg -\beta$ an Syk inhibiert.

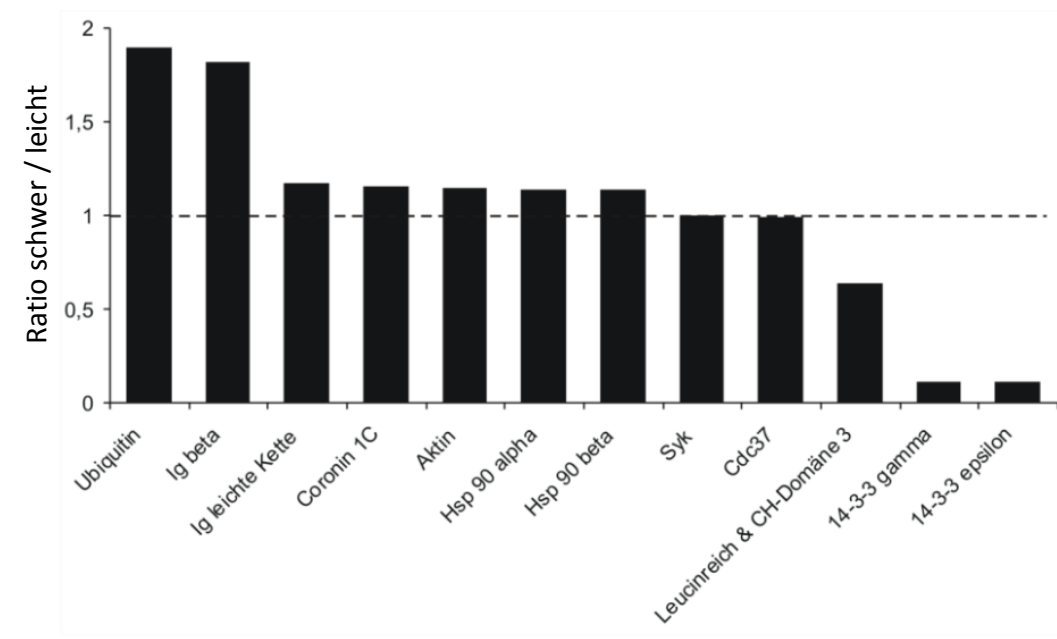

Abb. 25. Das Interaktom von Syk S297A. Die in Abb. 25 beschriebenen Zellen wurden in leichtem oder schwerem SILAC-Medium kultiviert und Strep-Syk wt oder die S297A-Variante wurde mittels Streptaktinmatrix aufgereinigt. Die resultierenden Eluate wurden 1:1 gemischt und massenspektrometrisch analysiert. Durch den Vergleich von korrespondierenden schweren und leichten Peptiden konnten die Interaktome relativ verglichen werden. Die Ratio von schweren zu leichten Peptiden gibt an, wie sich das Interaktom von Syk S297A im Vergleich zu Syk wildtyp zusammensetzt. Modifiziert nach Bohnenberger et al. (2011, S.1556).

\subsection{4-3-3 inhibiert die Bildung des Kalzium-Initiations-Komplexes}

Zur Untersuchung der Bedeutung der Bindung von 14-3-3 an Syk auf den BZRSignalweg wurde der Einfluss auf den Kalzium-Initiations-Komplex untersucht. Dazu habe ich SLP65 und PLC-y2 aus DT40-Zellen, die entweder die wildtyp oder S297A Citrin-Syk exprimieren, immunopräzipitiert und mittels Westernblot-Analyse mit einem Antikörper gegen phosphoryliertes Tyrosin auf ihre Phosphorylierung untersucht. Es zeigte sich, dass sowohl SLP65 (Abb. 26, links) als auch PLC-y2 (Abb. 26, rechts) in der Abwesenheit der Bindung von 14-3-3 an Syk stärker phosphoryliert werden. Übereinstimmend mit diesem Ergebnis wurde in der Abwesenheit der Bindung von 14-3-3 an Syk ein Phosphoprotein mit einem PLC-y2-ähnlichem Molekulargewicht stärker mit SLP65 kopräzipitiert. 

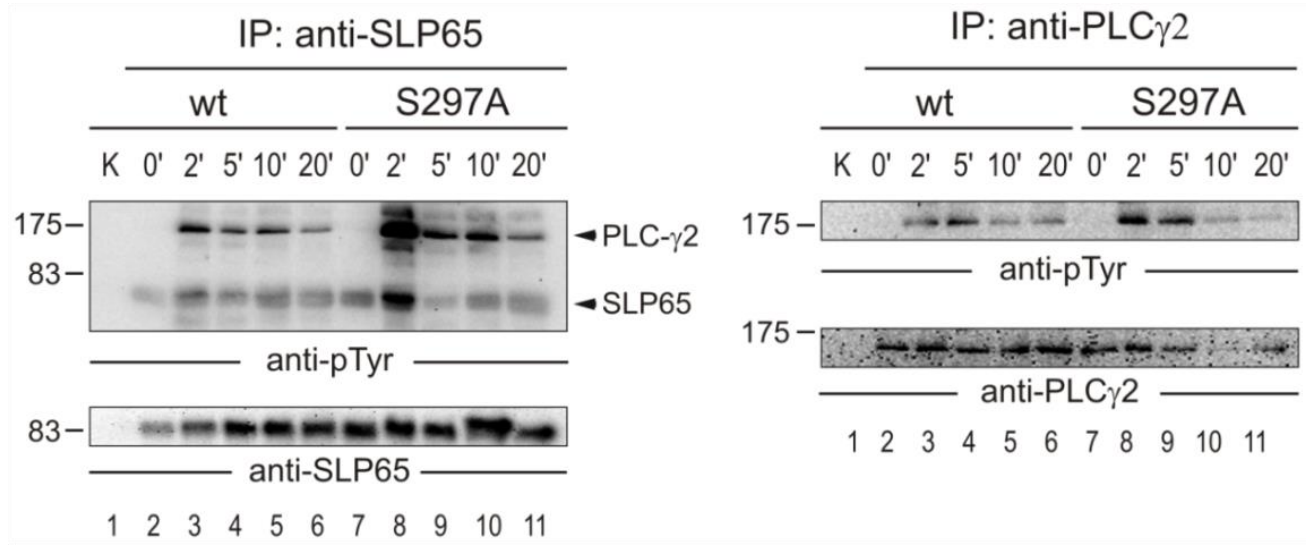

Abb. 26. Die Entstehung des Kalzium-Initiations-Komplexes ist verstärkt bei Abwesenheit der 14-3-3-Bindung an Syk. Die beschriebenen DT40-Zellen, die stabil Citrin-Syk wt oder S297A exprimieren, wurden unstimuliert belassen oder für angegebene Zeiten durch den BZR stimuliert. SLP65 (linke Seite) beziehungsweise PLC-y2 (rechte Seite) wurden immunopräzipitiert und einer Immunblotanalyse mit einem Antikörper gegen phosphoryliertes Tyrosin zugeführt. Als Immunopräzipitationskontrolle dienten isotypengleiche Antikörper. Immunoblot mit Antikörpern gegen SLP65 beziehungsweise PLC-y2 dienten als Ladekontrolle. Relative molekulare Massen des Proteinmarkers sind links in kDa angegeben. Die Daten sind repräsentativ für drei unabhängige Experimente. Modifiziert nach Bohnenberger et al. (2011, S.1557).

Diese Daten weisen darauf hin, dass der Kalzium-Initiations-Komplex in den Zellen, die die S297A-Variante von Syk exprimieren, effizienter gebildet wird. Entsprechend habe ich in diesen Zellen bei einer durchflusszytometrischen Analyse der zytosolischen Kalziumionenkonzentration festgestellt, dass diese Zellen nach BZRStimulation deutlich mehr Kalziumionen mobilisieren, als Zellen, die wildtypisches Syk exprimieren (siehe Abb. 27). Während der Kalziumionen-Einstrom nach drei Minuten in Syk wildtyp-exprimierenden Zellen fast auf den Ruhewert absinkt, ist in Syk S297A-exprimierenden Zellen auch noch nach circa 15 Minuten (siehe Abb. 27) und sogar noch nach 30 Minuten (siehe Abb. 35, Seite 73) ein Signal deutlich über dem Basalwert nachzuweisen.
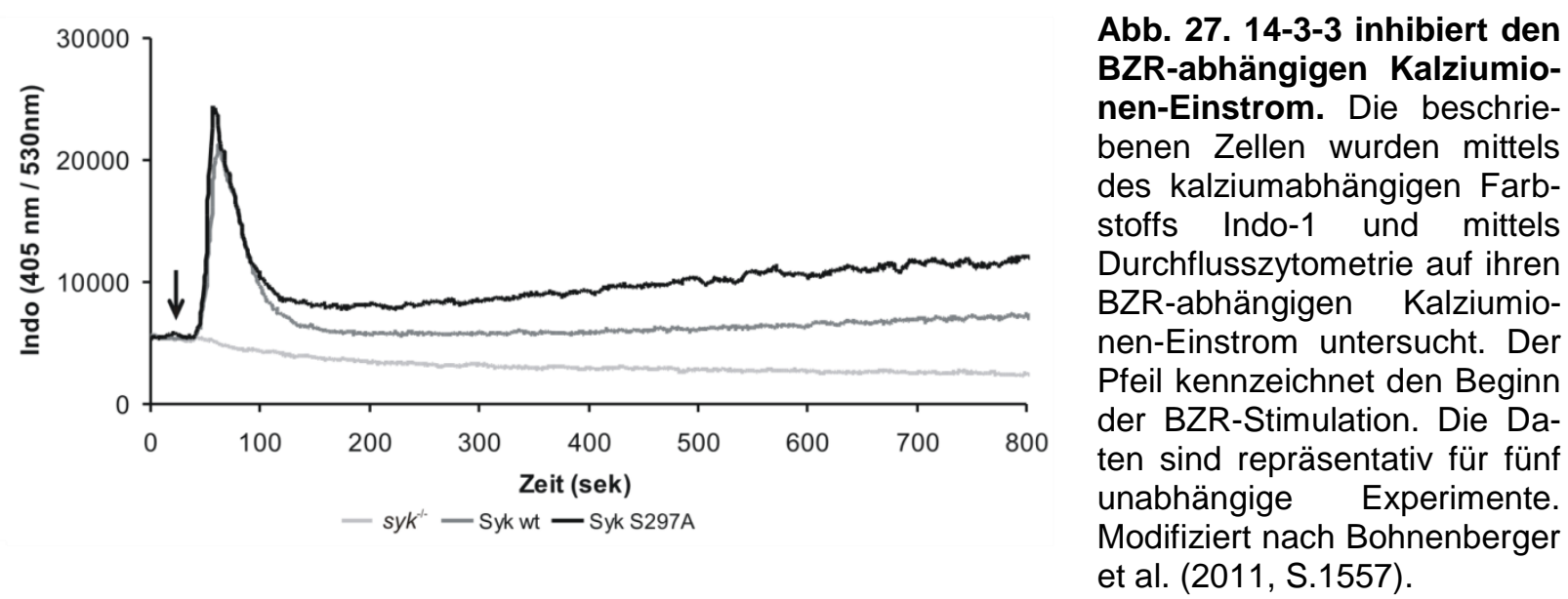
Mit dem Ziel zu untersuchen, ob die Unterschiede im Kalziumionen-Signal auf verschiedene Kalziumionenströme über die Plasmamembran zurückzuführen sind, habe ich eine Kalziumionen-Fluss-Analyse in Abwesenheit von Kalziumionen im Puffer durchgeführt. Dabei bestanden kaum Unterschiede im BZR-abhängigen Kalziumionen-Einstrom aus intrazellulären Speichern (siehe Abb. 28). Nach Zugabe von Kalziumionen wurde jedoch ein deutlich stärkeres Signal in den Zellen beobachtet, welche die S297A-Variante von Syk exprimieren. Dies deutet darauf hin, dass vornehmlich der Kalziumionen-Einstrom aus dem Extrazellulärraum durch 14-3-3 reguliert wird.

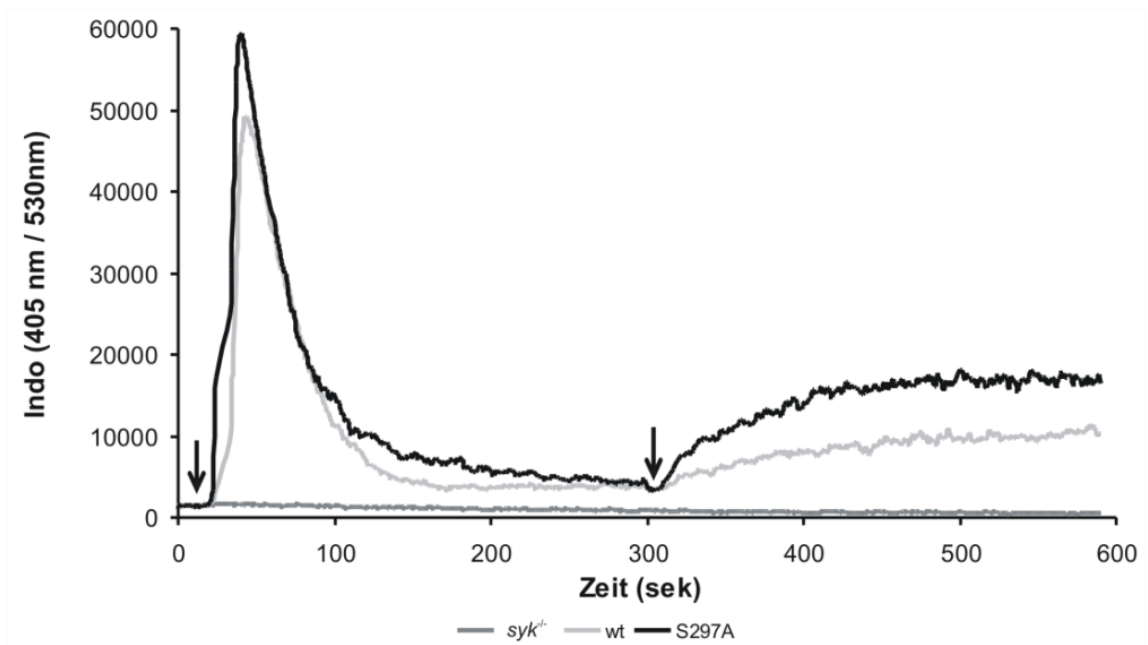

Abb. 28. 14-3-3 inhibiert vornehmlich den extrazellulären Anteil des BZR-abhängigen Kalziumionen-Einstroms. Die beschriebenen Zellen wurden mittels Durchflusszytometrie auf ihren BZRabhängigen Kalziumionen-Einstrom untersucht. Um zwischen dem Kalziumionen-Einstrom aus dem endoplasmatischen Retikulum und dem Extrazellulärraum zu unterscheiden, wurden extrazelluläre Kalziumionen durch die Zugabe von EGTA chelatiert. Nach fünf min wurden Kalziumionen zu den Proben hinzugegeben. Der linke Pfeil kennzeichnet den Beginn der BZR-Stimulation, der rechte Pfeil kennzeichnet die Zugabe von Kalziumionen. Die Daten sind repräsentativ für drei unabhängige Experimente.

Das Bindemotiv für 14-3-3 um Serin 297 liegt in einem Bereich der Interdomäne B, dem sogenannten linker insert, der in einer kürzeren Isoform von Syk (Syk-B) nicht enthalten ist (Rowley et al. 1995). Über Durchflusszytometrie konnte ich zeigen, dass das linker insert essentiell für die Mobilisation von Kalziumionen ist, da die kurze Isoform von Syk fast keine BZR-vermittelte Kalziumionenmobilisierung zeigt (siehe Abb. 29). Gleiche Expression der Varianten wurde über Durchflusszytometrie bestätigt. 

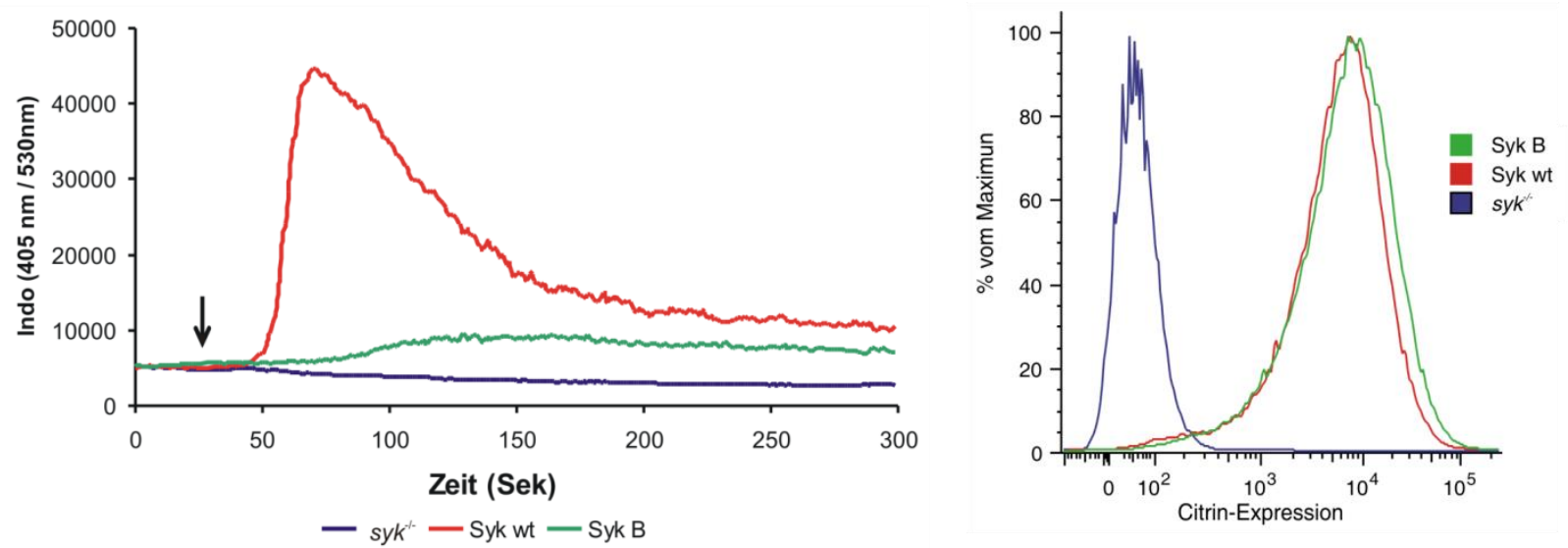

Abb. 29. Das linker insert ist essentiell für die Funktion von Syk. Syk-defiziente DT40-BLymphozyten, die Citrin-Syk wildtyp oder Citrin-Syk Isoform B exprimieren, wurden mittels Durchflusszytometrie auf die Expressionsstärke von Citrin-Syk (rechts) und auf ihren BZR-abhängigen KalziumionenEinstrom untersucht (links). Der Pfeil kennzeichnet den Beginn der BZR-Stimulation. Die Daten sind repräsentativ für drei unabhängige Experimente.

\subsection{4-3-3 inhibiert die Phosphorylierung und Rekrutierung von Syk}

Die Aktivität von Syk im frühen BZR-Signalweg wird einerseits über die Rekrutierung von Syk zur Plasmamembran und andererseits über die Phosphorylierung bestimmter Tyrosine in Syk reguliert (Tsang et al. 2008). Zur Plasmamembranrekrutierung von Syk ist bekannt, dass Syk nach BZR-Stimulation an die Membran in BZRMikrokluster rekrutiert wird, die dann miteinander verschmelzen und das sogenannte Cap bilden, aus dem Syk, nachdem es insgesamt circa zwanzig Minuten an der Membran verweilte, internalisiert wird (Ma et al. 2001).

In Zusammenarbeit mit Dr. M. Engelke konnte durch konfokale Laser-Mikroskopie lebender DT40- und DG-75-Zellen, die Citrin-Syk wildtyp oder die S297A-Variante exprimieren, der zeitliche Verlauf der Plasmamembranrekrutierung von Syk nach BZR-Stimulation bestätigt werden. In beiden Zellsystemen wurde dabei eine verstärkte und verlängerte Rekrutierung von Citrin-Syk S297A an die Plasmamembran beobachtet (siehe Abb. 30 und 31). Die quantitative Auswertung der Signalverteilung zwischen Plasmamembran und Zytosol von 30 - 50 Zellen pro Zelllinie und Zeitpunkt mit dem Programm ImageJ (siehe 3.2.11, Seite 39) bestätigte, dass die S297A Variante signifikant effizienter an die Plasmamembran rekrutiert wird $(p<0,01$ für jeden Zeitpunkt). 
$0^{\prime}$
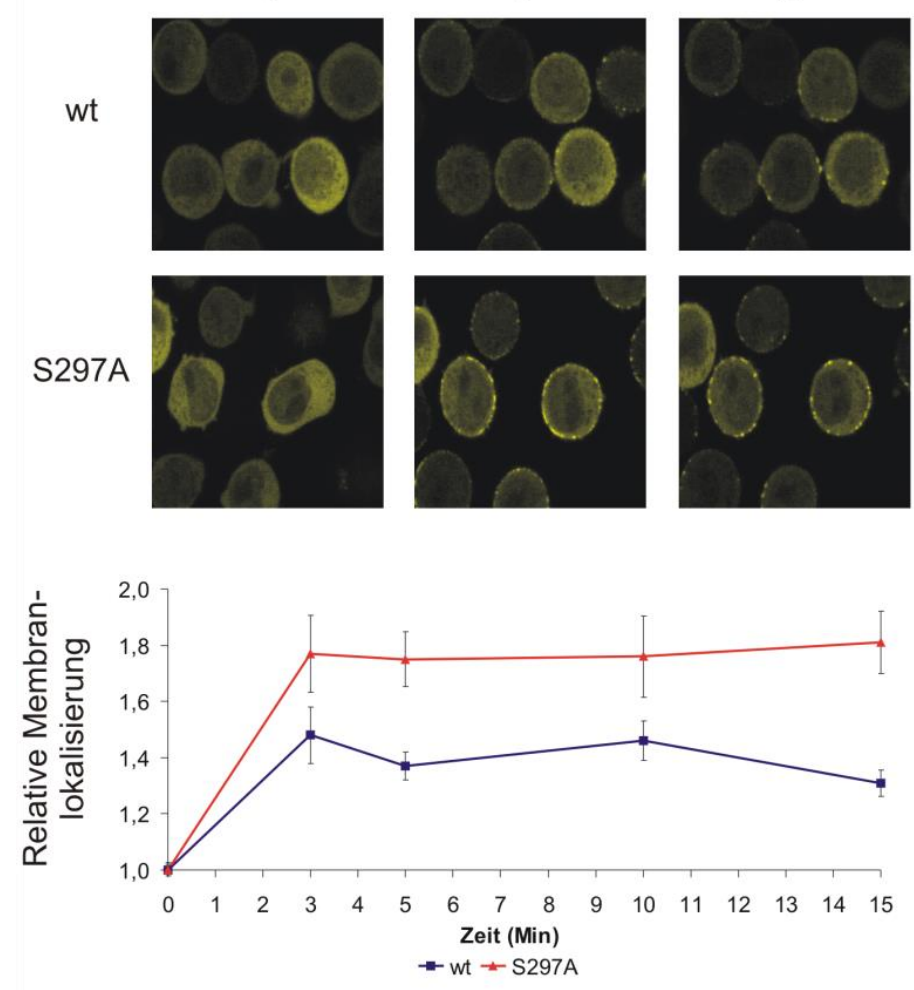

$0^{\prime}$

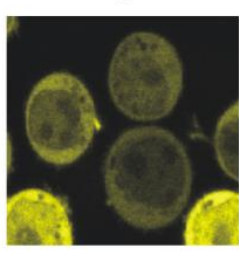

wt

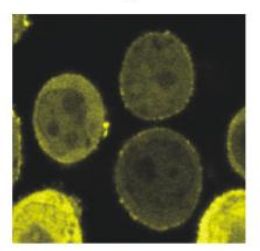

S297A
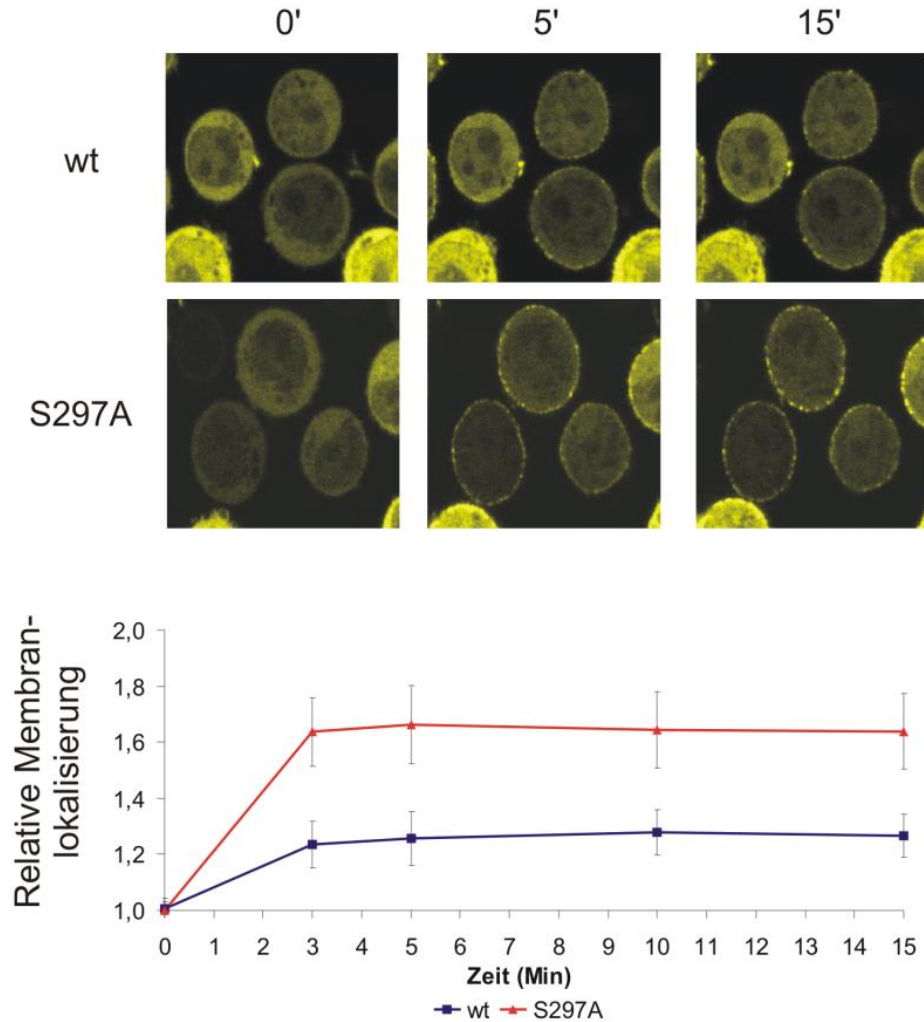

Abb. 30. 14-3-3 inhibiert die Rekrutierung von Syk an die Plasmamembran in DT40-Zellen. Die subzelluläre Lokalisation von Citrin-Syk wt und S297A wurde mittels konfokaler Laser-Mikroskopie in ruhenden und BZR-stimulierten (3, 5, 10 und $15 \mathrm{~min}$ ) DT40-Zellen untersucht. Repräsentative Bilder sind im oberen Abschnitt zu sehen. Mindestens 50 Zellen pro Zeitpunkt von Bildern aus fünf unabhängigen Messungen wurden mit ImageJ auf die Citrin-Signalintensität an der Plasmamembran und im Zytosol hin analysiert. Die dargestellten Werte (unten) stellen die relative Plasmamembranlokalisierung von Syk dar, errechnet als Mittelwert der Ratios der an der Membran und im Zytosol gemessenen Signalintensitäten normalisiert auf unstimulierte Zelle. Die Fehlerbalken zeigen das 95\%-Konfidenzintervall an. Der $\mathrm{p}$ Wert ist für jeden Zeitpunkt $<0,01$. Modifiziert nach Bohnenberger et al. (2011, S.1558).

Abb. 31. Die Bindung von 14-3-3 an Syk inhibiert die Rekrutierung von Syk an die Plasmamembran auch in humanen DG-75-Zellen. Die subzelIuläre Lokalisation von Citrin-Syk wildtyp und S297A wurde in ruhenden und BZR-stimulierten (3, 5, 10 und 15 min) humanen DG-75-Zellen untersucht und quantifiziert wie in Abb. 30 beschrieben. Repräsentative Bilder aus fünf unabhängigen Messungen sind im oberen Abschnitt zu sehen, die statistische Auswertung der Quantifizierung von mindestens 30 Zellen pro Zeitpunkt ist im unteren Abschnitt zu sehen. Die Fehlerbalken zeigen das 95\%-Konfidenzintervall an. Der p-Wert ist für jeden Zeitpunkt $<0,01$. Modifiziert nach Bohnenberger et al. (2011, S.1559).

Die verstärkte Membranlokalisierung von Syk wäre dabei prinzipiell auch durch eine unterschiedliche Expression des BZRs oder durch eine veränderte Kinetik in der Internalisierung des Rezeptors nach BZR-Stimulation zu erklären, jedoch konnte ich 
diese Möglichkeiten durch Markierung des BZR mit farbstoffgekoppelten Antikörpern und anschließender Durchflusszytometrie ausschließen (siehe Abb. 32). Somit ist von einem verstärkten Rekrutierungsmechanismus von Syk an die Plasmamembran auszugehen, beispielsweise und passend zu den in Abbildung 25 (Seite 65) dargestellten Ergebnissen über eine verstärkte Interaktion mit lg- $\beta$.

$0 \min$

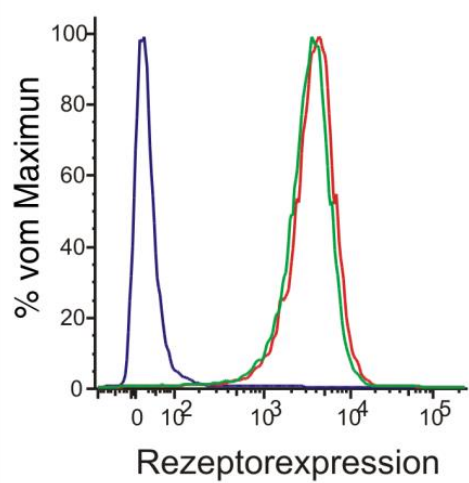

$5 \min$

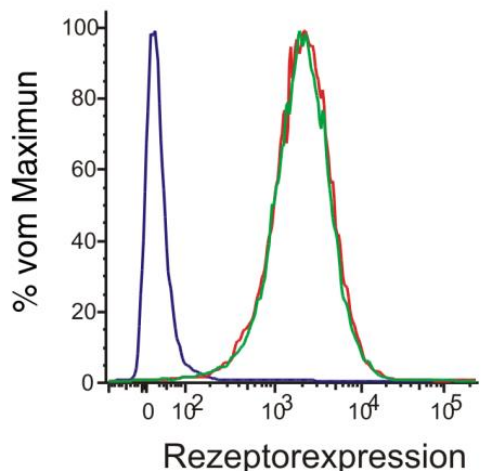

$15 \min$

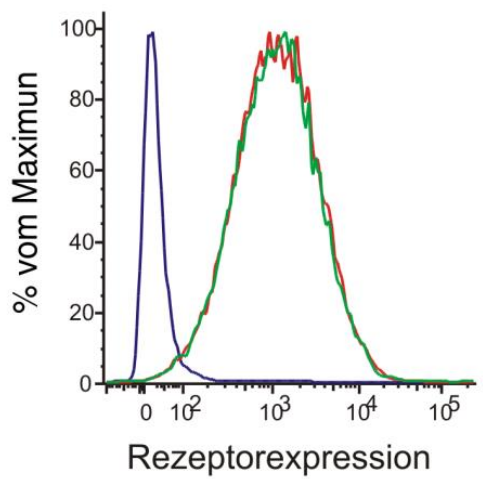

$$
\text { - Kontrolle - wt - S297A }
$$

Abb. 32. Die Internalisierung des BZR wird durch die Bindung von 14-3-3 an Syk nicht beeinflusst. DT40-Zellen, die stabil Citrin-Syk wt oder S297A exprimieren, wurden für angegebene Zeiten BZR-stimuliert und mit einem Cy-5-gekoppelten Antikörper, der gegen den Stimulations-Antikörper gerichtet ist, gefärbt. Mittels Durchflusszytometrie wurde die Intensität von Cy-5 auf der Zelloberfläche untersucht. Als Kontrolle wurden DT40-Zellen nur mit dem sekundären Antikörper inkubiert.

Neben der Rekrutierung an die Plasmamembran ist auch die Phosphorylierung für die Regulation der Funktion von Syk wichtig. Deshalb habe ich, um den Einfluss von 14-3-3 auf die Phosphorylierung zu ermitteln, Citrin-Syk wt und die S297A-Variante aus DT40-B-Zellen nach BZR-Stimulation immunopräzipitiert und die SykPhosphorylierung mittels Westernblot und phosphotyrosinspezifischen Antikörpern untersucht. Die Inaktivierung der 14-3-3-Bindestelle in Syk führt zu einer verstärkten Phosphorylierung von Syk nach zwei und fünf Minuten BZR-Stimulation. Durch die densitometrische Auswertung durch das Programm ImageJ konnte der Unterschied auf circa $40 \%$ quantifiziert werden (Siehe Abb. 33). 


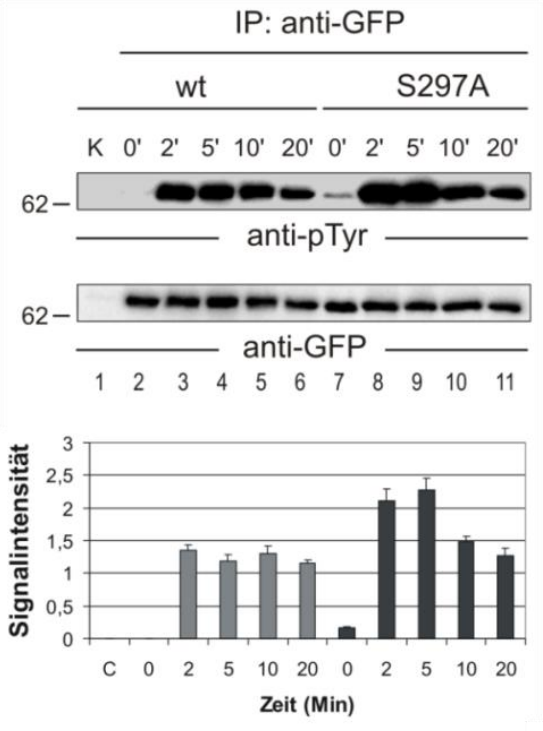

\begin{abstract}
Abb. 33. Die 14-3-3-Bindung an Syk inhibiert die Phosphorylierung von Syk. Die beschriebenen DT40Zellen, die stabil Citrin-Syk wt oder S297A exprimieren, wurden unstimuliert belassen oder für angegebene Zeiten durch den BZR stimuliert. Syk wurde immunopräzipitiert und einer Immunblotanalyse mit einem Antikörper gegen phosphorylierte Tyrosin-Reste zugeführt. Als Immunopräzipitationskontrolle dienten isotypengleiche Antikörper. Immunoblot mit Antikörpern gegen GFP diente als Ladekontrolle. Relative molekulare Massen des Proteinmarkers sind links in $\mathrm{kDa}$ angegeben. Die Daten sind repräsentativ für drei unabhängige Experimente. Der Immunoblot wurde einer densitometrischen Analyse zugeführt. Die Balken geben die Signalintensität der Banden an, die Fehlerbalken stehen für die Standardabweichung. Modifiziert nach Bohnenberger et al. (2011, S.1558).
\end{abstract}

Die Veränderungen im Phosphorylierungsstatus könnten die Kinase-Aktivität von Syk beeinflussen, so dass neben der veränderten zellulären Lokalisation der S297A Mutante auch eine verstärkte Kinase-Aktivität zu einer verstärkten Aktivierung von SykSubstraten führen könnte. Deshalb habe ich Citrin-Syk wildtyp und S297A aus DT40B-Zellen, die für fünf Minuten BZR-stimuliert wurden, immunopräzipitiert und einem in-vitro-Kinase-Experiment nach einem Protokoll von M. Lösing zugeführt. Dabei habe ich präzipitiertes Syk für 15 Minuten bei $37^{\circ} \mathrm{C}$ und als Negativkontrolle auf Eis mit einem synthetischen, Biotin-gekoppeltem Peptid, das von Syk phosphoryliert werden kann, inkubiert. Das Peptid konnte mit einer Streptavidin-beschichteten ELISA-Platte immobilisiert und nacheinander mit einem Antikörper gegen phosphoryliertes Tyrosin und einem peroxidasegekoppelten sekundären Antikörper inkubiert werden. Durch Zugabe von ABTS wurde eine peroxidaseabhängige Farbreaktion gestartet und die Absorption mittels eines ELISA-Auslesegerätes gemessen. Ich konnte zeigen, dass das Peptid von Syk phosphoryliert wird, jedoch konnte kein signifikanter Unterschied $(p=0.3, n=5)$ zwischen wildtyp und S297A in der Syk-abhängigen Phosphorylierung des Peptides gezeigt werden (siehe Abb. 34). Mittels Westernblot konnte ich einen Unterschied in der Menge an immunopräzipitiertem Syk ausschließen (siehe Abb. 34 links oben). Da Syk eine starke Tendenz zur Autophosphorylierung und damit auch Autoaktivierung in vitro zeigt, ist es jedoch möglich, dass bei der gewählten Phosphorylierungszeit von 15 Minuten geringe Unterschiede eventuell nicht erfasst wurden, so dass eine Wiederholung der Versuche mit unterschiedlichen Phosphorylierungszeiten weitere Erkenntnisse bringen könnte. 


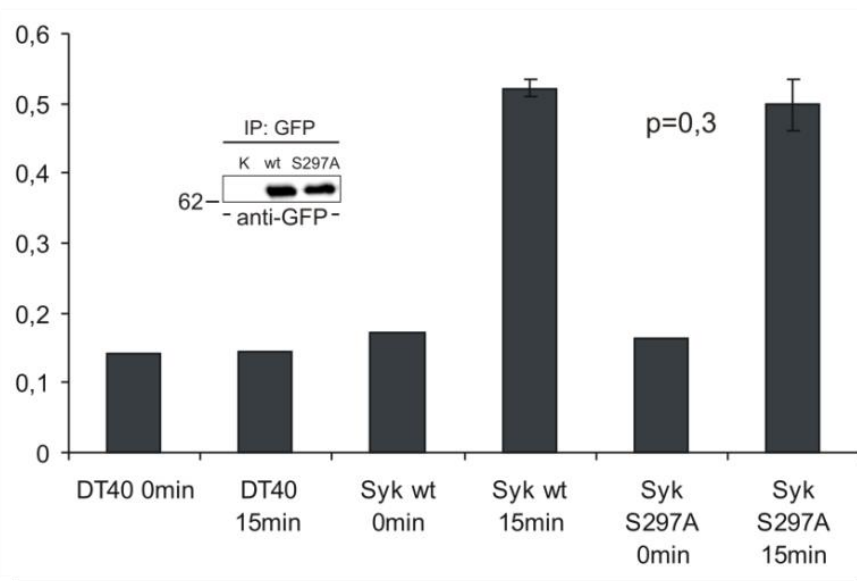

\subsection{Cbl und 14-3-3 inhibieren Syk unabhängig voneinander}

Neben der Inhibition von Syk durch 14-3-3 ist die Inhibition durch die Bindung von Cbl an das durch Lyn phosphorlyierte Tyrosin 323 in Syk beschrieben (Hong et al. 2002). Zum Vergleich der Inhibition des BZR-abhängigen Kalziumionen-Einstrom durch die beiden Mechanismen habe ich Syk-defiziente DT40-B-Zellen mit Citrin-Syk wildtyp, S297A, Y323F und S297A+Y323F retroviral rekonstituiert. Eine vergleichbare Expression von Syk konnte ich mittels Durchflusszytometrie zeigen (Abb. 35, rechts). Die Analyse des BZR-abhängigen Kalziumionen-Einstroms ergab, dass die Einzelmutanten von Syk einen vergleichbaren und jeweils stärkeren BZR-abhängigen Kalziumionen-Einstrom als die Citrin-Syk wildtyp-exprimierenden Zellen zeigten. Dabei war der Kalziumionen-Einstrom jeweils initial nur etwas stärker als in Citrin-Syk wildtyp-exprimierenden Zellen, hielt jedoch im weiteren Verlauf für mehr als 30 Minuten an, während der Kalziumionen-Einstrom der Citrin-Syk wildtyp exprimierenden Zellen annähernd auf den Ruhewert zurück ging (siehe Abb. 35, links). Beide Mechanismen scheinen also vergleichbar in der Bedeutsamkeit für den BZRabhängigen Kalziumionen-Einstrom zu sein. Die Doppelmutante von Syk zeigte einen sehr viel deutlicheren Anstieg im initialen Kalziumionenfluss, der dann direkt in ein Plateau von Kalziumionen-Einstrom überging, das auch nach 30 Minuten noch nicht endete. 14-3-3 und Cbl scheinen also Syk in unabhängiger und additiver Weise zu hemmen.
Abb. 34. Die Kinase-Aktivität von Syk wird durch interaktion mit 14-3-3 nicht signifikant veränZellen, die für fünf min durch den BZR stimuliert wurden, immunopräzipitiert und mit einem Biotin,

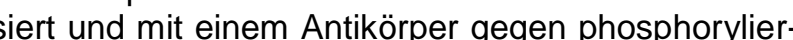
wurde An Peroxidase abhanglge on induziert und die Absorption mittels eines ELISA Auslesegerätes bestimmt. Als Kontrolle dienten Dein Citrin-Syk exprimieren. Die fünf unabhängigen Messungen an. Mittels Immunoblot wurde die Effizienz der Immunopräzipitation überprüft (links oben). 

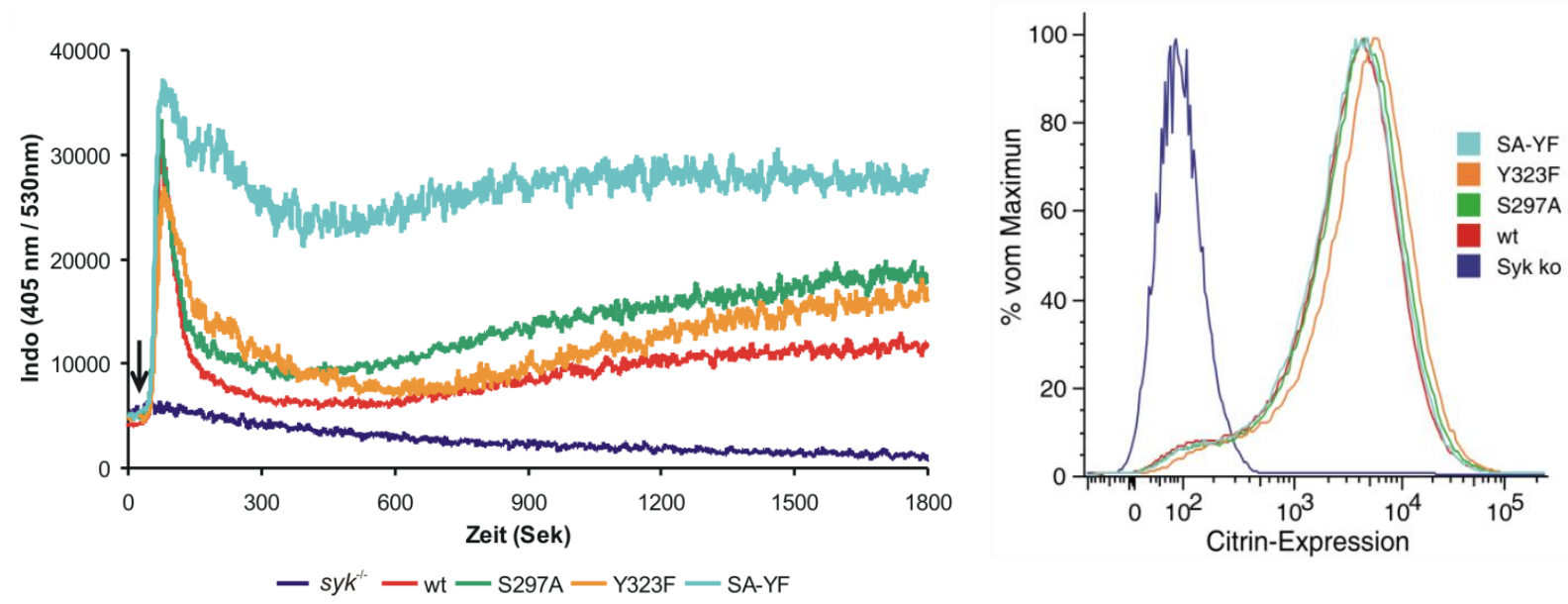

Abb. 35. Vergleich der Syk-Inhibition durch 14-3-3 und Cbl. Syk-defiziente DT40-Zellen wurden retroviral mit Konstrukten, die für die angegebenen Varianten von Citrin-Syk kodieren, transfiziert. SAYF steht für die Doppelmutante S297A und Y323F. Die resultierenden Zellen wurden mittels Durchflusszytometrie auf die Expression von Citrin-Syk hin analysiert (rechts) und mittels Durchflusszytometrie auf ihren BZR-abhängigen Kalziumionen-Einstrom untersucht (links). Der Pfeil kennzeichnet den Beginn der BZR-Stimulation. Die Daten sind repräsentativ für drei unabhängige Experimente

Die massenspektrometrische Analyse von Syk S297A ergab, dass S297A im Vergleich zum wildtyp stärker ubiquitinyliert wird. Dieses Ergebnis konnte ich mittels Immunopräzipitation von Citrin-Syk aus den beschriebenen BZR-aktivierten DT40Zellen und anschließender Westernblot-Analyse verifizieren (siehe Abb. 36).

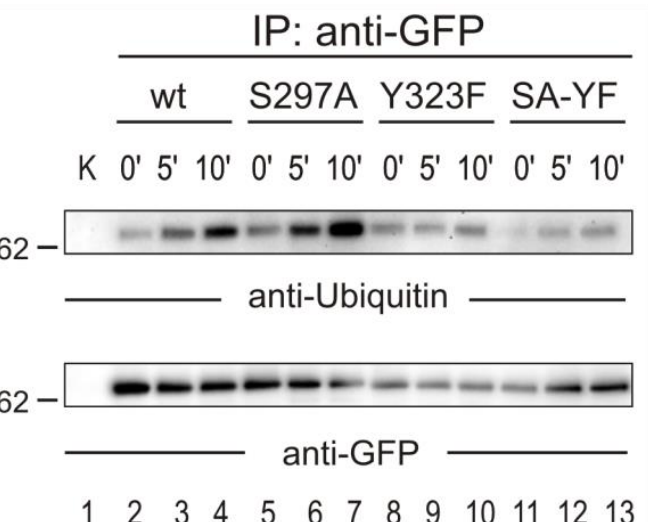
Abb. 36. Die Bindung von 14-3-3 an Syk inhibiert
die Ubiquitinylierung von Syk. Aus beschriebenen
unstimulierten oder BZR-stimulierten DT40-Zellen wur-
de Citrin-Syk immunopräzipitiert und einer Immun-
blotanalyse mit einem Antikörper gegen Ubiquitin zuge-
führt. Als Immunopräzipitationskontrolle dienten isoty-
pengleiche Antikörper. Immunoblot mit Antikörpern
gegen GFP diente als Ladekontrolle. Relative moleku-
lare Massen des Proteinmarkers sind links in kDa an-
gegeben. Die Daten sind repräsentativ für drei unab-
hängige Experimente.

$\begin{array}{llllllllllllll}1 & 2 & 3 & 4 & 5 & 6 & 7 & 8 & 9 & 10 & 11 & 12 & 13\end{array}$

\subsection{Serinphosphorylierung beeinflusst die SH2-Domänen von Syk}

In der Bindetasche von SH2-Domänen befindet sich die funktionell wichtige Sequenz F/Y L I/L R, im Folgenden als FLIR-Motiv bezeichnet (Waksman et al. 1993). In unmittelbarer Nachbarschaft dazu befindet sich in der N-terminalen SH2-Domäne von Syk Serin 44, das massenspektrometrisch als phosphoryliert identifiziert wurde (siehe Abb. 37). 


\section{N-terminale SH2-Domäne \\ ffgnitreeaedylvqggmsdglyllrqsrnylggfalsvahgrka hhytierelngtyaiaggrthaspadlchyhsqesdglvcllkkpf \\ C-terminale SH2-Domäne \\ wfhgkisreeseqivligsktngkflirardnngsyalcllhegkv lhyridkdktgklsipegkkfdtlwqlvehysykadgllrvltvpc}

Abb. 37. Aminosäure-Sequenz der N- und C-Terminalen SH2-Domäne von Syk. Die N-Terminale SH2-Domäne (oben) von Syk enthält in direkter Nachbarschaft zum YLLR-Motif (Fett gedruckt) das phosphorylierte Serin 44 (in Rot). In der Nähe des FLIR-Motives der C-terminalen SH2-Domäne befindet sich das nach BZR-Stimulation dephosphorylierte Serin 202.

Die C-terminale SH2-Domäne enthält das Motiv FLIR ohne ein benachbartes Serin, jedoch wird aus der Struktur ersichtlich, dass die SH2-Domäne eine zusätzliche Schleife enthält, die Serin 202 in unmittelbare Nähe zur Bindetasche der SH2Domäne bringt (siehe Abb. 38). Dieses Serin wurde als Phosphorylierungsstelle identifiziert, die nach BZR-Stimulation dephosphoryliert wird (siehe Abb. 13, Seite 53).

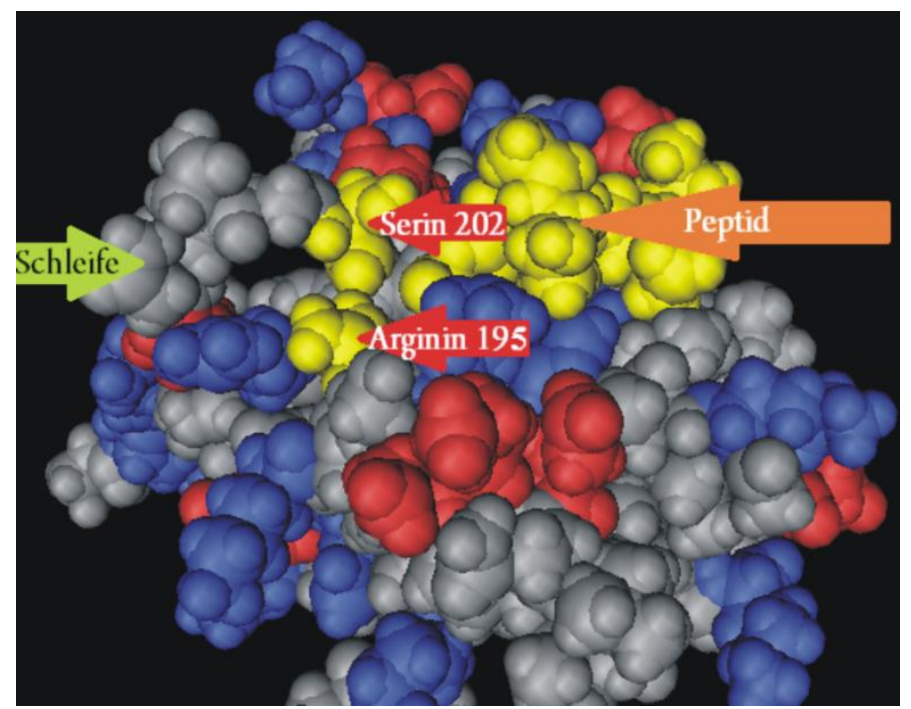

Abb. 38. Serin 202 liegt in der Struktur der C-Terminalen SH2Domäne von Syk dem FLIR-Motiv benachbart. Die Abb. zeigt die dreidimensionale Struktur der CTerminalen SH2-Domäne von Syk gebunden an ein tyrosinphosphoryliertes Phosphopeptid (in Gelb, durch orangenen Pfeil markiert). Außerdem sind in Gelb Serin 202 und Arginin 195, das zum FLIR-Motiv gehört, dargestellt und durch einen roten Pfeil gekennzeichnet. Mit einem grünen Pfeil ist die Schleife markiert, die Serin 202 in die Nähe von Arginin 195 bringt.

Mit dem Ziel, die Funktion dieser den SH2 Bindetaschen benachbarten Serinen zu untersuchen, habe ich DT40-Zellen retroviral mit Citrin-Syk Varianten, bei denen jeweils S44, S202 oder beide gegen Alanin oder negativ-geladenes Glutamat ersetzt wurde, rekonstituiert. Die Expression wurde mittels Durchflusszytometrie überprüft. Die Analyse des BZR-abhängigen Kalziumionen-Einstroms ergab, dass die Mutation eines oder beider Serine zu Alanin eine leichte Reduktion im Kalziumionen-Einstrom führt, während die Mutation von S202 zu Glutamat den Kalziumionen-Einstrom wei- 
testgehend und die Mutation von S44 oder beider Serine zu Glutamat vollständig verhindert (siehe Abb. 39).
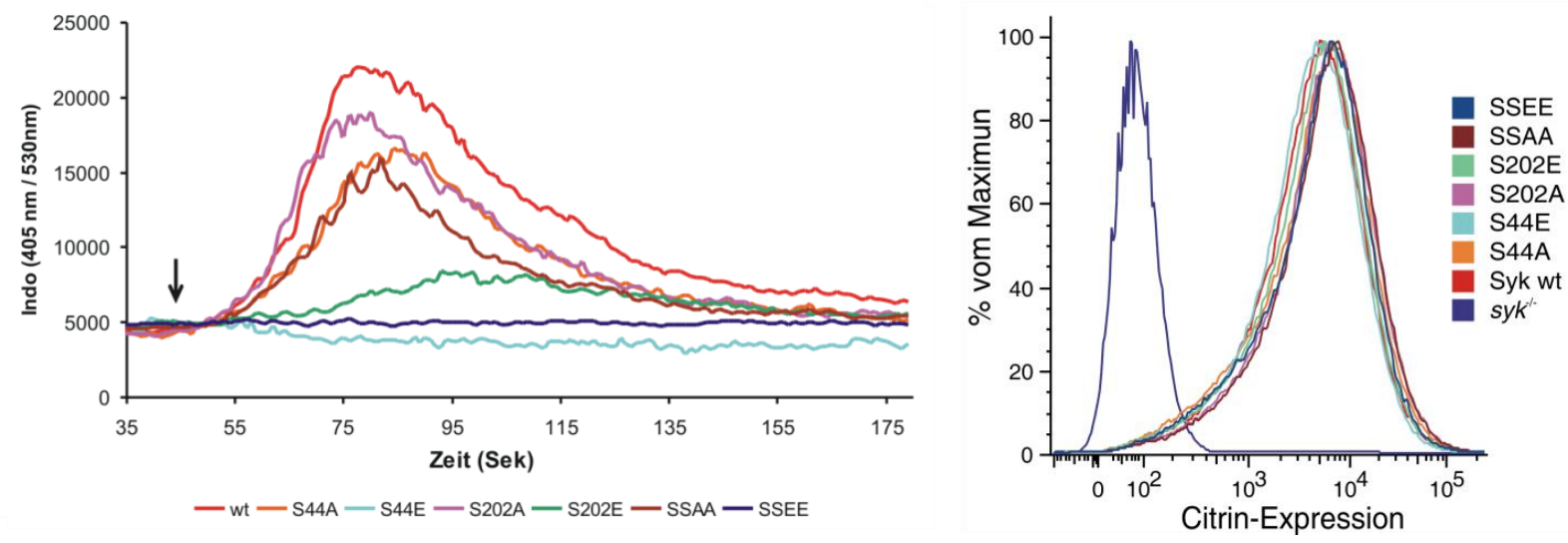

Abb. 39. Einfluss der Serine in den SH2-Domänen von Syk auf den BZR-abhängigen Kalziumionen-Einstrom. Syk-defiziente DT40-Zellen wurden retroviral mit angegebenen Varianten von CitrinSyk transfiziert und die resultierenden Zellen auf die Expression von Citrin-Syk (rechts) und auf ihren BZR-abhängigen Kalziumionen-Einstrom hin untersucht (links). Der Pfeil kennzeichnet den Beginn der BZR-Stimulation. Die Daten sind repräsentativ für drei unabhängige Experimente.

Ein Serin in vergleichbarer Position findet sich bei der überwiegenden Zahl der SH2Domänen, somit wäre ein genereller Regulationsmechanismus von SH2-Domänen denkbar (siehe Abb. 40).

\begin{tabular}{|c|c|}
\hline FER 2241 & \\
\hline \begin{tabular}{l|l|l|} 
FES & FPS & 2242 \\
\end{tabular} & $\mathrm{~K}-$ \\
\hline 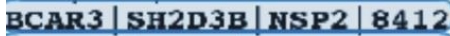 & \\
\hline \begin{tabular}{ll|l|l|} 
SE2D3C & NSP3 & 10044 \\
\end{tabular} & \\
\hline \begin{tabular}{l|l|l|} 
SE2D3A & NSPP1 & 10045 \\
\end{tabular} & \\
\hline SEC1 1 SHCA 6464 & \\
\hline \begin{tabular}{l|l|l|} 
SEC4 & RaLP & 399694 \\
\end{tabular} & \\
\hline SEC2 $\mid$ SHCB $\mid$ SCK $\mid 25759$ & \\
\hline \begin{tabular}{l|l|l|} 
SEC 3 & SHCC & NSHC \\
\end{tabular} & \\
\hline APS 10603 & GP- - - - R \\
\hline SE2B 25970 & TGGT----GS-H \\
\hline LNK 10019 & QG-D- - - -DA-H \\
\hline CHN2 |RhOGAP3 | 1124 & $--\mathrm{V}-\mathrm{E}$ \\
\hline CEN1|RhOGNP2 1123 & {$[\mathrm{~V}-\cdots-\cdots]$} \\
\hline RASA1 N|RASGAP N/5921 & $\mathrm{QA- \cdots --GK-S}$ \\
\hline PLCG2_N 5336 & EYCAETG \\
\hline PLCG1_N 5335 & TEYCIETGAI \\
\hline RASA1_C $\mid$ RASGAP_C|5921 & \\
\hline SHIP1 |INPP5D| $\mathbf{3 6 3 5}$ & Es- 1 \\
\hline 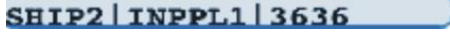 & \\
\hline
\end{tabular}

Abb. 40. Die meisten SH2Domänen haben ein dem FLIR-Motiv benachbartes Serin. Zu sehen ist ein Vergleich verschiedener $\mathrm{SH} 2$ Domänen. Dem FLIR-Motiv (in Blau, Grün und Rot) benachbart liegt in der überwiegenden Anzahl der Fälle ein Serin (in Grau). Modifiziert nach Liu et al. (2006, supplementäre Daten, S. 1).

\subsection{Prolinreiche Motive koppeln SLP65 über Cin85 an Syk}

Die Rolle von SLP65 als direktes Substrat von Syk und als zentrales Element des Kalzium-Initiations-Komplexes konnte mehrfach gezeigt werden (Engelke et al. 2007). Unklar blieb jedoch, in welcher Weise SLP65 an die Phosphorylierung von Syk gekoppelt wird. Oellerich et al. (2011) konnten zeigen, dass das Adapterprotein 
Cin85 mit seinen SH3-Domänen an Motive mit der Konsensussequenz PXPXPR (Kurakin et al. 2003) in SLP65 bindet und dass diese Interaktion essentiell für die Rekrutierung und Phosphorylierung von SLP65 und die Bildung des KalziumInitiations-Komplexes ist.

Das Adapterprotein SLP76 erfüllt in T-Zellen eine Aufgabe, die der von SLP65 in BZellen entspricht und hat einen ähnlichen Aufbau wie SLP65 (Koretzky et al. 2006). Jedoch finden sich in SLP76 keine der in SLP65 vorhandenen SH3-Bindemotive. Durch einen Vergleich der Proteinsequenz der beiden Proteine konnte ich drei Stellen in SLP76 ausfindig machen, die den Prolinmotiven in SLP65 ähnlich sind. Durch insgesamt fünf Punktmutationen konnte ich die Motive in SLP76 konstruieren (siehe Abb. 41).

\section{huSLP65 huSLP76 huSLP76*

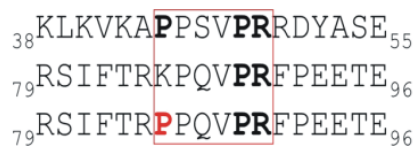

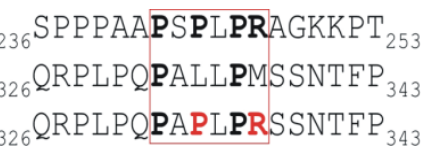

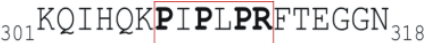
${ }_{393} A^{A E G R N F P L P L P N K P R P P S} \mathrm{~S}_{410}$ ${ }_{393} \mathrm{AEGRNF}$ PLPLPRKPRPPS $_{410}$

Abb. 41. Vergleich der drei prolinreichen Motive von SLP65, SLP76 und mutiertem SLP76*. Konservierte Proline und Arginine sind fett dargestellt, die atypischen Prolin-Arginin-Motive jeweils eingerahmt. Die durch Mutagenese eingefügten Proline und Arginine, welche die drei CIN85 Bindemotive in SLP76* wiederherstellen, sind jeweils rot markiert. Modifiziert nach Oellerich et al. (2011, S.3630).

Durch retrovirale Rekonstitution von SLP65-defizienten DT40-Zellen mit Citringekoppeltem SLP65, SLP76 wildtyp und mutiertem SLP76 (im Folgenden als SLP76* bezeichnet) konnte ich mittels Ko-Immunopräzipitation und anschließender Westernblot-Analyse zeigen, dass Cin85 sowohl an SLP65, als auch an SLP76*, nicht jedoch an SLP76 wildtyp bindet (Abb. 42).

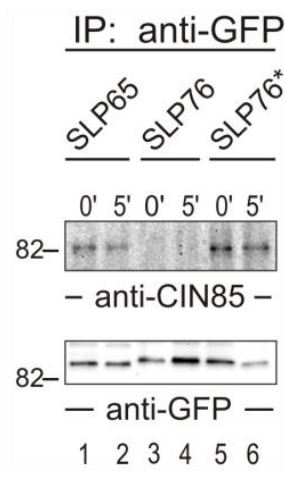

Abb. 42. SLP76* bindet an CIN85. SLP65-defiziente DT40-BLymphozyten wurden retroviral mit Citrin-markierten Versionen von wildtyp SLP65, wildtyp SLP76 und mutiertem SLP76* rekonstituiert. Die resultierenden Zellen wurden unstimuliert belassen oder für fünf min durch den BZR stimuliert und SLP65 beziehungsweise SLP76 wurde aus den Zellen durch Immunpräzipitation mittels eines Antikörpers gegen GFP isoliert. Die resultierenden Proben wurden durch Immunoblot mit Antikörpern gegen Cin85 untersucht. Immunoblot mit Antikörpern gegen GFP diente als Ladekontrolle. Relative molekulare Massen des Proteinmarkers sind links in kDa angegeben. Die Daten sind repräsentativ für drei unabhängige Experimente. Modifiziert nach Oellerich et al. (2011, S.3630).

Mittels Westernblot-Analyse von immunopräzipitiertem SLP65 beziehungsweise SLP76 über das gekoppelte Citrin und mittels durchflusszytometrischer Analyse des Kalziumionen-Einstroms konnte ich des Weiteren zeigen, dass SLP76 wildtyp auf 
einen BZR-Reiz hin weder phosphoryliert wird, noch dass es zu einem KalziumionenEinstrom kommt, hingegen SLP76* nach BZR-Stimulation phosphoryliert wird und einen Kalziumionen-Einstrom ermöglicht (siehe Abb. 43 und 44).
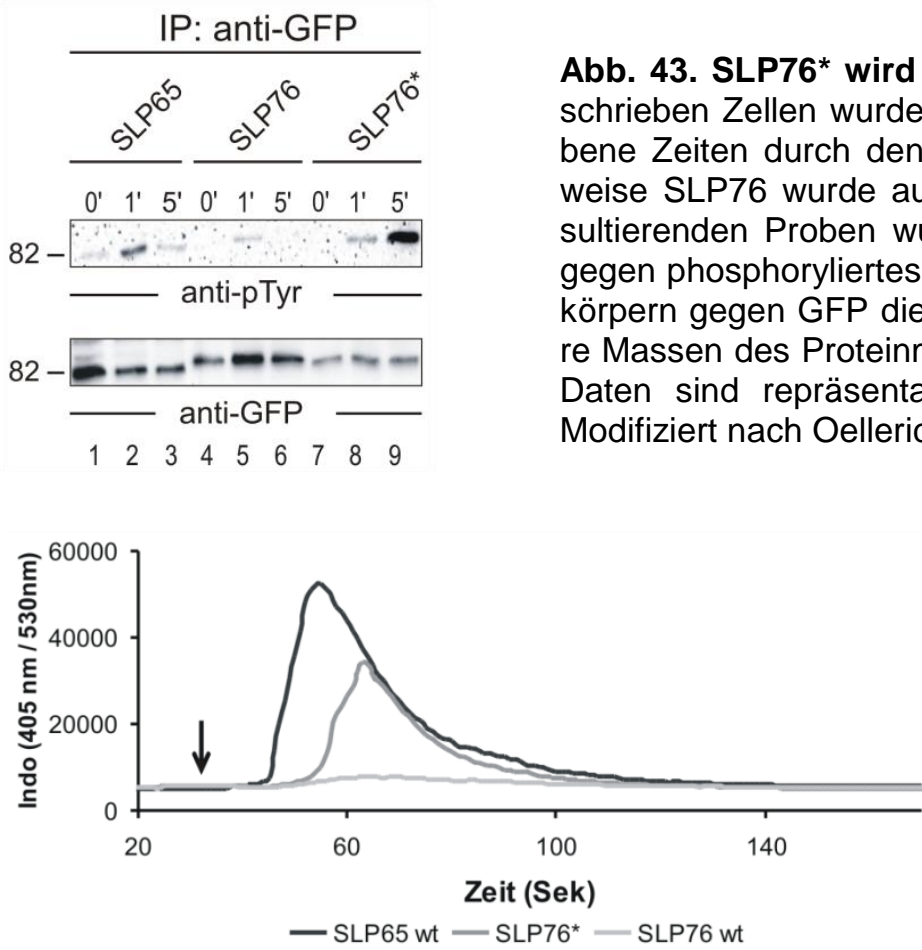

Abb. 43. SLP76* wird BZR-abhängig phosphoryliert. Die beschrieben Zellen wurden unstimuliert belassen oder für angegebene Zeiten durch den BZR stimuliert und SLP65 beziehungsweise SLP76 wurde aus den Zellen immunopräzipitiert. Die resultierenden Proben wurden durch Immunoblot mit Antikörpern gegen phosphoryliertes Tyrosin untersucht. Immunoblot mit Antikörpern gegen GFP diente als Ladekontrolle. Relative molekulare Massen des Proteinmarkers sind links in kDa angegeben. Die Daten sind repräsentativ für drei unabhängige Experimente. Modifiziert nach Oellerich et al. (2011, S.3630).

In Zusammenarbeit mit Dr. M. Engelke konnte mittels konfokaler Laser-Mikroskopie des Weiteren gezeigt werden, dass SLP76* in BZR aktivierten B-Zellen an die Plasmamembran rekrutiert wird, während SLP76 wildtyp im Zytoplasma verbleibt (siehe Abb. 45).

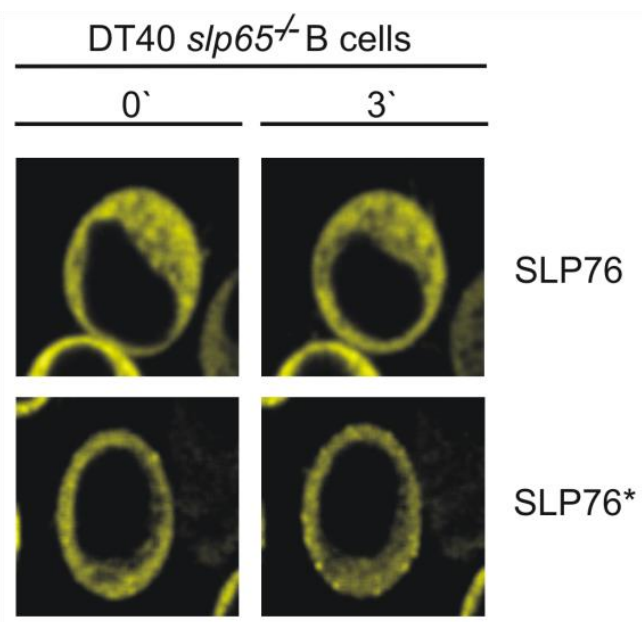

\begin{abstract}
Abb. 44. SLP76* stellt den BZR abhängigen Kalziumionen-Einstrom in SLP65 defizienten DT40-B-Zellen wieder her. In den beschriebenen Zellen wurde mittels Durchflusszytometrie der BZRabhängige Kalziumionen-Einstrom untersucht. Der Pfeil kennzeichnet den Beginn der BZR-Stimulation. Modifiziert nach Oellerich et al. (2011, S.3630).
\end{abstract}

Abb. 45. Durch die Herstellung von CIN85Bindemotiven kann SLP76* BZR-abhängig an die Membran rekrutiert werden. Die subzelluläre Lokalisation von Citrin gekoppeltem SLP76 und SLP76* wurde mittels konfokaler Laser-Mikroskopie in ruhenden und BZR-stimulierten (3 min) DT40-B-Zellen untersucht. Die Abbildung zeigt repräsentative Bilder aus drei unabhängigen Messungen. Modifiziert nach Oellerich et al. (2011, S.3630).

Insgesamt konnte ich also mit fünf Punktmutationen eine Interaktion zwischen SLP76 und Cin85 ermöglichen, die ausreichend ist, SLP76 in BZR-aktivierten B-Zellen an die Plasmamembran zu rekrutieren und dort die Funktion von SLP65 zu erfüllen. 


\section{Diskussion}

Die Beschreibung intrazellulärer Signalwege und ihrer Regulation hat sich zu einem zentralen Thema in der Erforschung zellulärer Funktionen entwickelt. Für das Verständnis der zahlreichen Aufgaben von Syk-abhängigen Signalwegen während der physiologischen Entwicklung und Aktivierung hämatopoetischer Zellen und ihrer malignen Transformation ist eine umfassende Kenntnis über die Regulation und Funktion von Syk nötig. Ziel dieser Studie war die Analyse der Phosphorylierungskinetik und des Interaktoms von Syk in Antigen-Rezeptor-stimulierten B-Lymphozyten und die Erforschung ihrer Bedeutung für die Regulation von Syk im BZR-Signalweg.

\subsection{Die Phosphorylierungskinetik und das Interaktom von Syk}

Mit der massenspektrometrischen Analyse der Phosphopeptide von affinitätspräzipitiertem humanem Syk aus Antigen-Rezeptor-stimulierten B-Lymphozyten konnten insgesamt 16 phosphorylierte Tyrosine, elf phosphorylierte Serine und sechs phosphorylierte Threonine gezeigt werden. Neben den 13 in B-Zellen bekannten Phosphorylierungsstellen (Geahlen 2009, Paris et al. 2010, Uckun et al. 2010 b) konnten 20 weitere als phosphoryliert identifiziert werden. Anzumerken sei, dass fast die Hälfte der gefundenen Phosphorylierungsstellen in der Interdomäne B liegen, die bereits als wichtig für die Regulation von Syk beschrieben wurde (Simon et al. 2005).

Für 26 dieser Phosphopeptide konnte mit Hilfe des SILAC-Verfahrens eine BZRabhängige Kinetik der Phosphorylierung gemessen werden. Dabei konnten die Phosphorylierungsstellen anhand ihrer Kinetik in vier Gruppen eingeteilt werden (Olsen et al. 2006): frühe, späte, dephosphorylierte und konstante Phosphorylierungsstellen. Alle gefundenen Tyrosine zeigten dabei einen starken Anstieg der Phosphorylierung schon nach zwei Minuten und sind damit der ersten Gruppe zuzuordnen, was der beschriebenen Schlüsselrolle bei der Aktivierung von Syk durch die Phosphorylierung an Tyrosinen durch Lyn oder Syk selbst entspricht (Keshvara et al. 1998, Tsang et al. 2008). Die stärkste Veränderung der Phosphorylierung nach BZRStimulation zeigte das doppelt-phosphorylierte Phosphopeptid mit Tyrosin 348 und Tyrosin 352 in der regulatorischen Interdomäne B und das Phosphopeptid mit Tyrosin 526 in der katalytischen Domäne von Syk. Die Phosphorylierung der entsprechenden Peptide änderte sich zwei Minuten nach Stimulation um mehr als den Faktor zehn. Diese Ergebnisse sind im Einklang mit der bereits beschriebenen Wichtig- 
keit dieser Phosphorylierungsstellen für die Aktivierung von Syk (Simon et al. 2005). Ein mehr als fünffacher Anstieg der Phosphorylierung wurde an dem aktivatorisch wirksamen Tyrosin 525 und dem inhibitorisch wirksamen Tyrosin 323 gemessen. Auch die Bedeutung dieser Phosphorylierungsstellen für die Funktion und Regulation von Syk ist mehrfach beschrieben worden (Zhang et al. 1998, Hong et al. 2002).

Eine ähnliche Kinetik und einen ebenfalls fünffachen Anstieg der Phosphorylierung konnte für Serin 297 gezeigt werden, dessen Bedeutung bisher unklar war. Die Phosphorylierung erfolgt etwas verzögert mit einem Maximum nach fünf Minuten.

Die Phosphorylierung der meisten anderen Serine und Threonine erfolgte ebenfalls etwas verzögert. Serin 579 zeigt einen Anstieg der Phosphorylierung noch nach zehn Minuten und ordnet sich damit der zweiten Gruppe zu. Für Serin 202 konnte eine BZR-abhängige Dephosphorylierung gezeigt werden, es gehört damit der dritten Gruppe an. Serin 379 scheint durch den BZR nicht beeinflusst zu werden. Insgesamt zeigt sich also, dass die Phosphorylierung von Syk nach BZR-Stimulation nicht nur sehr ausgeprägt, sondern auch differenziert ist.

Einige der Phosphopeptide konnten sowohl als einfach als auch als doppelt phosphorylierte Varianten identifiziert werden, wodurch die Existenz von verschieden phosphorylierten Gruppen von Syk zu vermuten ist.

Durch die Analyse des Phosphorylierungsprofils von Syk in Antigen-Rezeptorstimulierten humanen DG-75-B-Lymphozyten konnten viele der in DT40-Zellen gefundenen Phosphorylierungsstellen bestätigt werden, jedoch konnten insgesamt nur 17 Phosphorylierungsstellen identifiziert werden. Eine Erklärung für die Differenz könnten speziesabhängige Unterschiede sein. Jedoch wurden bei der Aufreinigung von Strep-Syk aus DG-75-Zellen insgesamt weniger Peptide gewonnen, so dass vermutlich einige Phosphopeptide nicht vom Massenspektrometer erfasst werden konnten.

Durch die massenspektrometrische Analyse des Interaktoms von Syk aus ruhenden und BZR-stimulierten B-Zellen konnten über 25 Bindepartner von Syk bestimmt werden. Der größte Teil davon zeigte eine durch Stimulation induzierbare Bindung an Syk, konstitutive Bindepartner wie zum Beispiel der BZR sprechen für die These eines tonisch-aktiven BZR-Signalweges. Für die gefundenen neuen Interaktionspartner von Syk wurden zum Teil sehr unterschiedliche Funktionen in anderen Zellsystemen 
beschrieben. Sek1 könnte als MAP-Kinase eine Verbindung zu Jnk und p38 (Moriguchi et al. 1995) darstellen, RhoH wurde als Adapterprotein in T-Zellen beschrieben ( $\mathrm{Li}$ et al. 2002) und für TOM1L1 wurden Funktionen bei der ubiquitinabhängigen Endozytose des Wachstumsfaktorrezeptors beschrieben (Franco et al. 2006). Verschiedene Bindepartner aus der Gruppe des Zytoskeletts wie Aktin, Coronin1c (Rosentreter et al. 2007) und Dynein legen eine Regulation des Zytoskeletts durch Syk nahe. Als eine weitere Gruppe von Bindepartnern nach Stimulation konnten verschiedene Isoformen der Familie von 14-3-3-Adapterproteinen, die an einer Vielzahl von zellulären Vorgängen beteiligt sind (Aitken 2006), gezeigt werden.

Für Syk wurden in verschiedenen zellulären Kontexten und nach Stimulation verschiedenster Rezeptoren weitere Bindepartner beschrieben. Die E3-Ubiquitin-Ligase $\mathrm{Cbl}$, für die gezeigt wurde, dass sie an phosphoryliertes Tyrosin 323 bindet (Yankee et al. 1999), konnte in diesem Experiment nicht als Bindepartner identifiziert werden. Eine mögliche Erklärung dafür ist, dass die p85-Untereinheit der PI3K ebenfalls und mit höherer Affinität an Tyrosin 323 bindet (Moon et al. 2005), so dass es zu einer Verdrängung von Cbl gekommen sein könnte. Des Weiteren wurde eine Interaktion von Syk mit der y1-Isoform der Phospholipase C (PLC) beschrieben (Groesch et al. 2006), welche in DT40-Zellen nicht exprimiert wird. Eine Interaktion von Syk mit anderen Isoformen der PLC konnte in diesem Versuchsaufbau nicht gezeigt werden. Insgesamt konnte durch die SILAC-basierte Analyse des Interaktoms von Syk in unstimulierten und BZR-stimulierten B-Zellen gezeigt werden, dass Syk in einem Netzwerk von Proteinen agiert, das viele Bereiche der zellulären Funktion beeinflusst. Es ist anzunehmen, dass die Basis der Organisation dieses Proteinnetzwerkes zumindest zum Teil in der komplexen und dynamischen Phosphorylierung von Syk nach BZR-Stimulation liegt.

Da weitere Bindepartner von Syk in anderen zellulären Systemen und nach Aktivierung anderer Syk-abhängiger Rezeptoren gefunden wurden, ist anzunehmen, dass das Interaktom von Syk abhängig ist vom jeweiligen zellulären Kontext und vom aktivierten Rezeptor. Mit dem beschriebenen Versuchsaufbau ist die Erforschung dieser Interaktome und auch die Phosphorylierungskinetik von Syk in anderen Sykabhängigen Signalwegen möglich und, wie für den BZR-Signalweg gezeigt, ein effektiver Weg zu einem größeren Verständnis der Regulation dieser Signalwege. 


\subsection{Die Inhibition von Syk durch 14-3-3}

14-3-3-Proteine, die als BZR-abhängige Interaktionspartner gefunden wurden, sind eine hochkonservierte Familie von sieben 30 kDa großen Adapterproteinen (Aitken 2006). Nach der Entdeckung 1965 (Moore und McGregor 1965) rückte diese Proteingruppe in den Interessensfokus der Forschung, als gezeigt werden konnte, dass sie an spezifische Bindemotive mit einem phosphorylierten Serin oder Threonin binden können (Muslin et al. 1996), wobei verschiedene Motive beschrieben wurden (Yaffe et al. 1997). Die beiden wichtigsten sind dabei das Typ-I-Motiv mit der Konsensussequenz R/KSXpSXP und das Typ-II-Motiv mit der Konsensussequenz RXF/YpSXP. Seither konnte für eine Vielzahl zellulärer Funktionen wie ZellzyklusKontrolle, Apoptose und Signaltransduktion eine wichtige regulatorische Rolle von 14-3-3 gezeigt werden (Aitken 2006). Eine Rolle im proximalen BZR-Signalweg war bisher jedoch unbekannt.

Mittels Ko-Immunopräzipitation und Far-Westernblot-Analyse konnte gezeigt werden, dass nach BZR-Aktivierung 14-3-3y direkt an phosphoryliertes Serin 297, das massenspektrometrisch als eines der Hauptziele BZR-abhängiger Phosphorylierung identifiziert wurde, bindet. Die Umgebung von Serin 297 stimmt dabei genau mit dem Typ-I-Bindemotiv für 14-3-3-Moleküle überein.

Durch den massenspektrometrischen Vergleich der Interaktome von Strep-Syk wt und S297A konnte des Weiteren gezeigt werden, dass neben 14-3-3y auch 14-3-3ع an Serin 297 bindet und dass 14-3-3 der einzige relevante Bindepartner von Serin 297 ist. Außerdem konnte eine verstärkte Bindung von Syk an Ig- $\beta$ und eine stärkere Ubiquitinylierung von 14-3-3-bindedefizientem Syk gezeigt werden. Die Inhibition der Bindung von Syk an Ig- $\beta$ durch 14-3-3 könnte auch die Funktion von Syk insgesamt hemmen, da die Bindung der Tandem-SH2-Domäne an phosphorylierte ITAM-Motive wie die in Ig- $\beta$ zur Aktivierung von Syk führt (Tsang et al. 2008). Über die Ubiquitinylierung, die ebenfalls durch 14-3-3 gehemmt zu werden scheint, ist ein inhibitorischer Effekt beschrieben (Rao et al. 2001).

Durch Analyse der Phosphorylierung und Bildung des Kalzium-Initiations-Komplexes sowie durch Analyse des BZR-abhängigen Kalziumionen-Einstroms in DT40-Zellen, welche die S297A Variante von Syk exprimieren, konnte jedoch gezeigt werden, dass die Bindung von 14-3-3 an Syk insgesamt inhibierend auf den BZR-Signalweg wirkt. Insgesamt überwiegt also die negative Regulation von Syk durch 14-3-3 durch 
die Reduktion der Bindung von Syk an Ig- $\beta$ die theoretisch denkbare positive Regulation durch die Verminderung der Ubiquitinylierung von Syk.

Beim Kalziumionen-Einstrom ist zu beachten, dass vor allem der Einstrom von Kalziumionen aus dem Extrazellulärraum gehemmt wird. Dieser erfolgt nach dem Einstrom aus intrazellulären Speichern über die Aktivierung von IP3-Rezeptoren im endoplasmatischen Retikulum durch sogenannte store operated Kalzium channels (Engelke et al. 2007), die neben einer stärkeren Aktivierung des Kalzium-InitiationsKomplexes ebenfalls durch Syk beeinflusst werden könnten.

Eine Beeinflussung der Syk-Aktivität hat über den BZR-abhängigen KalziumionenEinstrom hinaus vermutlich weitreichende Folgen für den gesamten BZR-Signalweg. In dieser Studie konnte auf diese Aspekte nicht näher eingegangen werden, es wäre jedoch interessant zu wissen, inwiefern die Bindung von 14-3-3 an Syk die Aktivierung von MAP-Kinasen wie Erk oder NF-kB oder die Aktivierung der antiapoptotischen Kinase Akt beeinflusst. Ebenfalls interessant wäre es zu wissen, welchen Einfluss die 14-3-3-bindedefiziente Syk-Variante auf die Entwicklung und Aktivierung von B-Zellen in vivo hat.

Durch die computergestützte Analyse der Sequenz von Syk konnten sechs weitere potentielle Bindemotive für 14-3-3 in Syk gefunden werden. In fünf dieser Motive konnte ein phosphoryliertes Serin oder Threonin massenspektrometrisch identifiziert werden, jedoch konnte durch Mutationsanalysen kein Einfluss dieser potentiellen Motive auf die Bindung von 14-3-3 an Syk gezeigt werden. Es ist nicht völlig auszuschließen, dass 14-3-3, nach dem es an Serin 297 gebunden hat, hierarchisch auch an eines oder mehrere der anderen potentiellen Bindemotive bindet. Es konnte jedoch gezeigt werden, dass die Mutation von Serin 297 zu Alanin ausreichend ist, um sowohl die Bindung zu 14-3-3 aufzuheben, als auch die Funktion von Syk im BZRSignalweg zu verändern.

Das Bindemotiv für 14-3-3 liegt in einem Bereich der Interdomäne B, dem sogenannten linker insert, das in einer kürzeren Isoform von Syk (Syk-B), nicht exprimiert wird (Rowley et al. 1995). Unterschiede dieser beiden Isoformen konnten bereits für verschiedene Signalwege gezeigt werden (Latour et al. 1998). Syk-B wird verstärkt im Knochenmark (Latour et al. 1996) und Brustkrebszellen (Wang L et al. 2003) exprimiert, was vermuten lässt, dass die Abwesenheit der 14-3-3-Bindung an Syk sowohl bei der Entwicklung von hämatopoietischen Zellen als auch von Syk-abhängigen Ma- 
lignomen eine Rolle spielt. Der BZR-abhängige Kalziumionen-Einstrom in B-Zellen, die Syk-B exprimieren, ist drastisch verringert. Es wurde bereits vermutet, dass das linker insert als eine Art Gelenkregion in Syk agiert, die für die Änderung der geschlossenen und inaktiven Form in die geöffnete und aktive Form zuständig ist (Latour et al. 1998). Die Interaktion mit 14-3-3 in diesem Bereich könnte die Gelenkfunktion stören und auf diesem Weg die Funktion von Syk beeinflussen. In dem Homolog von Syk in T-Zellen Zap70 fehlt ebenfalls das in Syk gefundene Motiv für die Bindung von 14-3-3, wodurch eine Unterscheidung der Regulation von Syk und Zap70 möglich wäre.

Vorstellbar wäre, dass durch die Bindung von 14-3-3 die Kinase-Aktivität von Syk inhibiert wird, womit die Inhibition der Phosphorylierung von SLP65 und PLC-ү2 erklärt werden könnte. Jedoch konnte durch ein ELISA-basiertes in vitro Experiment kein Unterschied in der Kinase-Aktivität von wildtyp zu S297A Syk gezeigt werden.

Deshalb erscheint die Erklärung, dass 14-3-3 die Aktivität von Syk im BZR-Signalweg über die Beeinflussung der subzellulären Lokalisation und damit der Verfügbarkeit von Substraten von Syk inhibiert, naheliegender. Passend dazu konnte gezeigt werden, dass durch Mutation von Serin 297 zu Alanin die Membranrekrutierung von Syk deutlich verstärkt und verlängert wird. Ein Modell wäre, dass Syk nach BZRStimulation über $\mathrm{lg}-\alpha$ und $\mathrm{lg}-\beta$ an die Plasmamembran rekrutiert und dort an Serin 297 phosphoryliert wird, wodurch 14-3-3 an Syk binden und es von der Plasmamembran sequestrieren kann. Diese Art der Regulation wurde auch für andere Signalproteine wie Gab2 beschrieben (Brummer et al. 2008). Da durch reverse Proteomik gezeigt werden konnte, dass S297A Syk stärker an Ig- $\beta$ bindet, ist denkbar, dass 14-3-3 die Interaktion von Syk und Ig- $\beta$ stört.

Mit diesem Modell wäre auch der Zusammenhang der 14-3-3- und der Cblabhängigen Hemmung von Syk zu erklären. Das Ausmaß der 14-3-3-abhängigen Hemmung der BZR-abhängigen Kalziumionen-Mobilisierung ist mit der Cblabhängigen Inhibition vergleichbar. Werden beide Inhibitionsmechanismen durch Mutation von Serin 297 und Tyrosin 323 ausgeschaltet, kommt es zur Addition der Effekte. Das deutet daraufhin, dass beide Mechanismen prinzipiell unabhängig voneinander sind. Jedoch zeigt die S297A Mutante eine stärkere BZR abhängige Ubiquitinylierung. Dieser Effekt scheint der inhibitorischen Funktion von Serin $297 \mathrm{zu}$ wiedersprechen, da die Ubiquitinylierung als inhibitorisch für Syk beschrieben wurde 
(Rao et al. 2001). Jedoch hat $\mathrm{Cbl}$ durch die stärkere und längere Rekrutierung von Syk S297A an die Plasmamembran auch verstärkten Substratzugang zu Syk. Der Effekt der S297A Mutation bedeutet insgesamt eine Verstärkung des proximalen BZR-Signalweges, somit ist davon auszugehen, dass quantitativ der Effekt der stärkeren Membranlokalisierung die verstärkte Hemmung durch $\mathrm{Cbl}$ überwiegt.

Insgesamt stellt die Assoziation von Syk mit 14-3-3 die erste beschriebene serinabhängige Inhibiton von Syk dar.

Während der Fertigstellung dieser Arbeit berichten Paris et al. (2010), dass murines Syk an Serin 291 (entspricht Serin 297 in humanem Syk) durch die Protein-Kinase C (PKC) BZR-abhängig phosphoryliert wird. Die in dieser Arbeit ermittelte Bindung von 14-3-3 an Syk und die nachfolgende Inhibition der Syk-Funktion im BZR-Signalweg würde zu der beschriebenen inhibitorischen Funktion der PKC im Sinne einer negativen Rückkopplungsschleife passen (Sidorenko et al. 1996).

Paris et al. (2010) zeigten jedoch, dass eine Mutation von Serin 291 zu Alanin zu einer verminderten Assoziation von Syk mit dem Chaperon-Protein Prohibition und zu einer verminderten Aktivierung des Transkriptionsfaktors NFAT in BZR-stimulierten DT40-Zellen führt. Eine Interaktion von 14-3-3 mit dem phosphorylierten Serin 291 konnte für 14-3-3 in dieser Studie nicht gezeigt werden. Prinzipiell wäre es möglich, dass für das beschriebene Serin ein Unterschied in der Regulierung von murinem und humanem Syk besteht, der auch erklären könnte, warum Prohibitin in den in dieser Arbeit durchgeführten SILAC-Experimenten des Interaktoms von humanem Syk nur als unspezifisches Hintergrundprotein auftaucht. Jedoch ist dies bei dem evolutionär-konservierten Typ-I-Bindemotives unwahrscheinlich. Weitere vergleichende Experimente müssten erfolgen, um einen Unterschied sicher auszuschließen.

Abbildung 46 zeigt ein mögliches Modell, wie 14-3-3 die Aktivität von Syk im BZRSignalweg nach den Ergebnissen dieser Arbeit regulieren könnte.

Da 14-3-3-Proteine ubiquitär exprimiert werden (Aitken 2006), ist generell vorstellbar, dass sie auch in anderen Zellen als der B-Zelle nach Rezeptorstimulation an Syk binden und so Syk inhibieren können. Die Erforschung der Funktionen der 14-3-3Bindung an Syk in anderen Zellsystemen könnte dies belegen. Die weitere Erforschung der Regulation von Syk durch 14-3-3 in maligne transformierten B-Zellen 
könnte Hinweise auf die Pathogenese von B-Zell-Lymphomen liefern. Es wäre beispielsweise interessant zu wissen, ob Mutationen von Serin 297 in Lymphomen vorliegen.
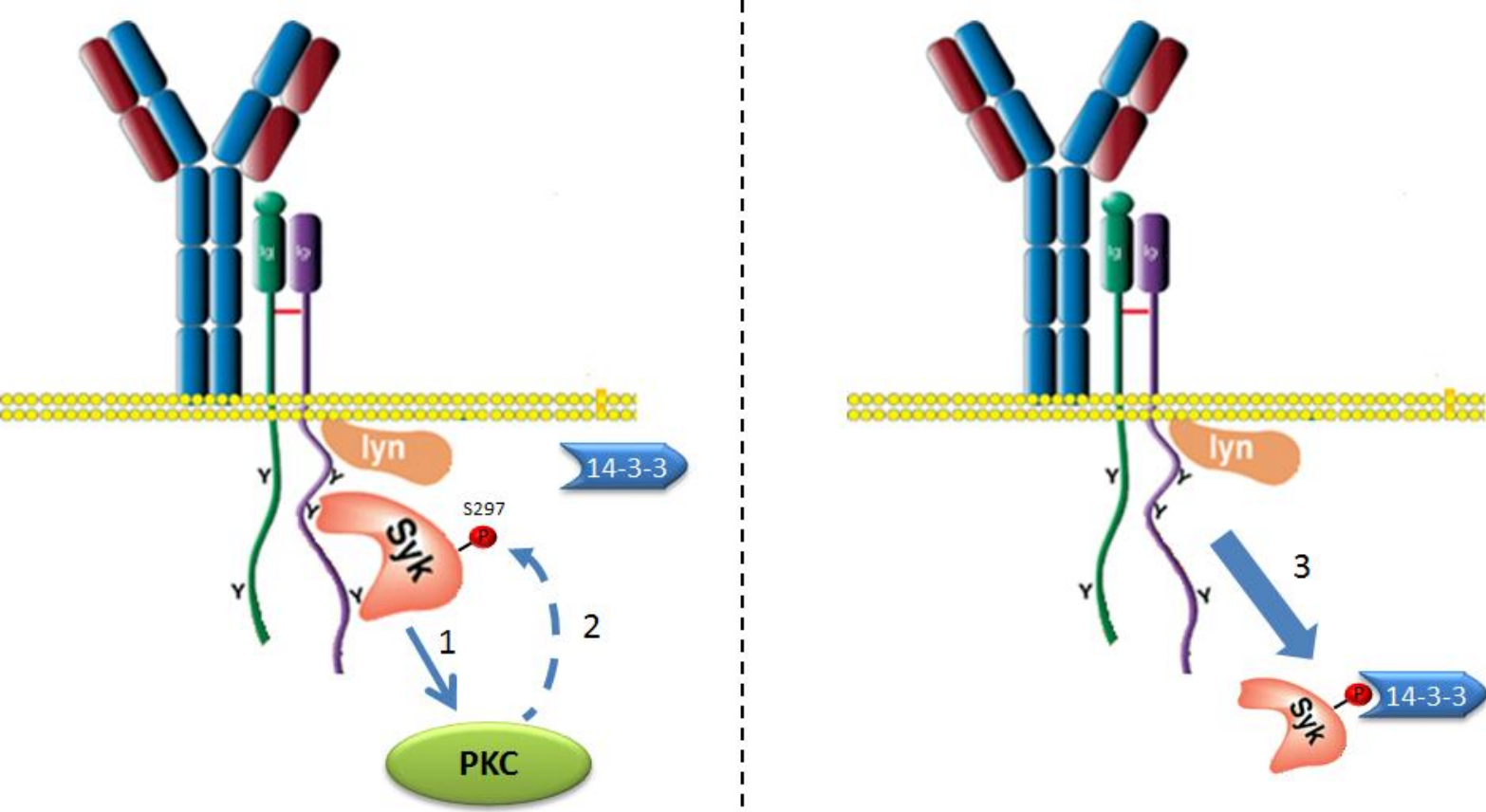

Abb. 46. Modell. Die Abbildung zeigt ein mögliches Modell, wie die Funktion von Syk nach Aktivierung des BZR durch 14-3-3 gehemmt werden könnte. Syk bindet nach Aktivierung des BZR mit der Tandem-SH2-Domäne an die Tyrosine in den ITAM-Motiven von Ig- $\alpha$ und Ig- $\beta$ und wird dadurch aktiviert. Über die Aktivierung der PLC-y kommt es unter anderem auch zur Aktivierung der PKC (linke Seite, 1). Die PKC phosphoryliert darauf hin Syk an Serin 297 (linke Seite, 2). Das phosphorylierte Serin 297 und die umliegenden Aminosäuren in Syk stellen ein Typ-I-Bindemotiv für 14-3-3 dar, das nun an Syk bindet und damit die Interaktion von Syk mit lg- $\beta$ stört, so dass Syk vom aktivierten BZR dissoziier, also von 14-3-3 sequestriert wird (rechte Seite, 3). Modifiziert nach Wang LD und Clark (2003, S.412).

\subsection{Serinabhängige Beeinflussung der SH2-Domänen von Syk}

Die massenspektrometrische Analyse der Phosphorylierung von Syk ergab, dass Syk ingesamt an 16 Tyrosinen und 17 Serinen und Threoninen phosphoryliert wird. Es ist anzunehmen, dass nicht nur Serin 297 wichtig für die Funktion und Regulation von Syk ist. Vier der gefundenen Phosphorylierungsstellen befinden sich in den SH2Domänen von Syk. Die Bindetasche der SH2-Domäne enthält dabei das funktionell essentielle Motiv F/Y L I/L R, im Folgenden als FLIR-Motiv bezeichnet (Waksman et al. 1993). Die N-terminale SH2-Domäne von Syk enthält direkt benachbart zu diesem Motiv das als phosphoryliert gefundene Serin 44. Das FLIR-Motiv der C-terminalen 
SH2-Domäne wird durch eine Schleife in der Tertiärstrukur von Serin 202, das ebenfalls als phosphoryliert gefunden wurde, flankiert.

Es ist vorstellbar, dass eine negative Ladung durch eine Phosphatgruppe an dieser Stelle die Interaktion der SH2-Domäne mit einem Phospho-Tyrosin-Motiv hemmt. Tatsächlich konnte durch gezielte Mutagenese dieser Serin-Reste zu negativ geladenem Glutamat eine weitestgehende (S202E) beziehungsweise vollständige Supprimierung des BZR-abhängigen Kalziumionen-Einstroms erreicht werden, vermutlich über eine Inhibition der Interaktion von Syk mit phosphorylierten ITAM-Motiven. Jedoch wurde auch durch die Mutation der Serine zu Alanin der Kalziumionen-Einstrom jeweils verringert. Es bleibt zu vermuten, dass das unphosphorylierte Serin an dieser Stelle die Interaktion der SH2-Domäne mit dem phosphoryliertem Tyrosin unterstützt, die Interaktion jedoch durch Phosphorylierung unterbrochen wird.

Für Serin 202 wurde eine BZR-abhängige Dephosphorylierung gezeigt. Möglich wäre, dass die Phosphorylierung von Serin 202 Syk in einen inaktiven Zustand versetzt, der durch BZR-Stimulation aufgehoben wird. Denkbar wäre auch die Regulation der BZR-Antwort in unterschiedlichen B-Zell-Subtypen durch den Phosphorylierungszustand von Serin 202. Weitere Experimente müssten jedoch folgen, um diese Annahmen zu überprüfen.

Ein Vergleich von SH2-Domänen verschiedener Proteine zeigt, dass sich bei der überwiegenden Anzahl aller FLIR-Motive ein Serin in vergleichbarer Position befindet. Für SLP65 konnte das entsprechende Serin 471 auch als späte Phosphorylierungsstelle gezeigt werden (Oellerich et al. 2009). Eine weitere Erforschung der Bedeutung der Serine in den SH2-Domänen von Syk könnte das Verständnis über die Regulation von $\mathrm{SH} 2-$ Domänen generell verbessern.

\subsection{Cin85 koppelt SLP65 an Syk}

SLP65 stellt eines der Hauptsubstrate von Syk dar und ist über die Rekrutierung der Phospholipase PLC-y2 und der Tyrosin-Kinase Btk essentiell für die Bildung des Kalzium-Initiations-Komplexes und den folgenden BZR-abhängigen KalziumionenEinstrom. Unklar ist, wie SLP65 an die Phosphorylierung durch Syk gekoppelt wird. Neben der wichtigen Rolle des N-terminalen Leucin-Zippers (Köhler et al. 2005) und der SH2-Domäne (Abudula et al. 2007) von SLP65 konnten Oellerich et al. (2011) die Bedeutung der Bindung von Cin85 an prolinreiche SH3-Bindemotiven für die 
Phosphorylierung und Rekrutierung von SLP65 und die Bildung des KalziumInitiations-Komplexes zeigen.

Prinzipiell ergeben sich zwei Möglichkeiten, wie Cin85 die Rekrutierung und Phosphorylierung von SLP65 beeinflusst. Entweder ist Cin85 über die Bindung seiner drei SH3-Domänen an die drei prolinreichen Motive wichtig für die Struktur von SLP65 oder Cin85 beeinflusst die subzelluläre Lokalisation von SLP65 und bringt es über weitere, bisher unbekannte Interaktionen in die Nähe des BZR und von Syk.

Zur Unterscheidung dieser beiden Möglichkeiten wurde ein Vergleich der Funktion von SLP65 zu SLP76 durchgeführt. SLP76 erfüllt in T-Zellen eine ähnliche Aufgabe wie SLP65 in B-Zellen, jedoch ist der Rekrutierungsmechanismus an die Plasmamembran für SLP76 über das Transmembranprotein LAT weitestgehend geklärt (Koretzky et al. 2006). SLP76 kann die Funktion von SLP65 als zentrales Element des Kalzium-Initiations-Komplexes in B-Zellen nicht übernehmen, wenn nicht gleichzeitig LAT exprimiert wird (Wong et al. 2000).

In SLP76 finden sich keine SH3-Bindemotive, die denen von SLP65 entsprechen, jedoch konnten alle drei in SLP65 enthaltenden Motive über insgesamt fünf Punktmutationen in SLP76 an vergleichbaren Stellen konstruiert werden. Es zeigte sich, dass das mutierte SLP76 (im Folgenden als SLP76* bezeichnet) an Cin85 binden und durch Syk phosphoryliert werden kann. Anders als SLP76 kann SLP76* so auch den BZR-abhängigen Kalziumionen-Einstrom in SLP65-defizienten DT40-BZellen wiederherstellen. Auch kann SLP76* BZR-abhängig an die Plasmamembran rekrutiert werden, während SP76 im Zytoplasma verbleibt.

Insgesamt konnte somit gezeigt werden, dass Cin85, neben einer weiterhin möglichen Beeinflussung der Struktur von SLP65, eine BZR-abhängig Kopplung von SLPAdapterproteinen an die Phosphorylierung durch Syk bewirkt. 


\section{Zusammenfassung}

Ziel dieser Arbeit war es, mit Hilfe massenspektrometrischer Analysen der Phosphorylierungskinetik und des Interaktoms von Syk neue regulatorische Elemente im BZR-Signalweg zu finden.

Es ist gelungen, 33 Phosphorylierungsstellen und die BZR-abhängige Kinetik von 25 dieser Stellen zu bestimmen, wobei die einzelnen Phosphorylierungsstellen eine differenzierte Kinetik aufweisen. Eine der am häufigsten nachgewiesenen Phosphorylierungsstellen ist Serin 297, das einen starken BZR-abhängigen Anstieg der Phosphorylierung zeitlich etwas nach dem Großteil der Tyrosine zeigt.

Durch die Analyse des Interaktoms konnte gezeigt werden, dass Syk in einem Netzwerk von über 25 Interaktionspartnern unterschiedlichster Funktion agiert. Damit stellt diese Arbeit eine Datenbank an Phosphorylierungsstellen und Bindepartnern von Syk dar, die zur Generierung neuer Hypothesen über die Funktionsweisen von Syk genutzt werden kann.

Eine neu gefundene Gruppe von Interaktionspartnern ist die 14-3-3-Familie von Adapterproteinen. Durch gezielte Mutation potentieller 14-3-3-Bindemotive, die gefundene Phosphoserine und Phosphothreonine enthalten, konnte gezeigt werden, dass 14-3-3 $\gamma$ nach BZR-Stimulation direkt an Phosphoserin 297 bindet. Dieser Komplex reduziert die Rekrutierung von Syk an die Plasmamembran, inhibiert dadurch den proximalen BZR-Signalweg und stellt damit die erste beschriebene serinabhängige Inhibiton von Syk dar. Die in dieser Arbeit erhobenen Daten leisten somit einen Beitrag zum Verständnis der Regulation von Syk im BZR-Signalweg und wegen der ubiquitären Expression von 14-3-3 ist davon auszugehen, dass auch in weiteren Zellund Rezeptorsystemen eine vergleichbare Inhibition von Syk stattfindet.

Durch die Mutation von als phosphoryliert gefundenen Serinen in den SH2-Domänen von Syk konnte zusätzlich gezeigt werden, dass es weitere Serin-abhängige Regulationsmechanismen von Syk geben könnte. Da die mutierten Serine in vergleichbarer Position in einer Vielzahl von SH2-Domänen vorliegen, könnte es sich um einen generellen Mechanismus handeln. 


\section{Literaturverzeichnis}

Abbas A, Lichtmann A, Pillai S: Cellular and Molecular Immunology. 6. Auflage. Elsevier Saunders, Philadelphia 2007

Abudula A, Grabbe A, Brechmann M, Polaschegg C, Herrmann N, Goldbeck I, Dittmann K, Wienands J (2007): SLP-65 signal transduction requires Src homology 2 domain-mediated membrane anchoring and a kinase-independent adaptor function of Syk. J Biol Chem 282, 29059-29066

Adams J (2003): Activation loop phosphorylation and catalysis in protein kinases: is there functional evidence for the autoinhibitor model? Biochemistry $\underline{42}, 601-607$

Aitken A (2006): 14-3-3 proteins: a historic overview. Semin Cancer Biol $\underline{16}, 162-172$

Arias-Palomo E, Recuero-Checa M, Bustelo X, Llorca O (2007): 3D structure of Syk kinase determined by single-particle electron microscopy. Biochim Biophys Acta 1774, 1493-1499

Arias-Palomo E, Recuero-Checa M, Bustelo X, Llorca O (2009): Conformational rearrangements upon Syk auto-phosphorylation. Biochim Biophys Acta 1794, 1211-1217

Baba T, Humphries E (1984): Differential response to avian leukosis virus infection exhibited by two chicken lines. Virology 135, 181-188

Ben-Bassat H, Goldblum N, Mitrani S, Goldblum T, Yoffey J, Cohen M, Bentwich Z, Ramot B, Klein E, Klein G (1977): Establishment in continuous culture of a new type of lymphocyte from a "Burkitt like" malignant lymphoma (line D.G.-75). Int J Cancer 19 , 27-33

Bohnenberger H, Oellerich T, Engelke M, Hsiao H, Urlaub H, Wienands J (2011): Complex phosphorylation dynamics control the composition of the Syk interactome in B cells. Eur J Immunol 411, 1550-1562

Brack C, Hirama M, Lenhard-Schuller R, Tonegawa S (1978): A complete immunoglobulin gene is created by somatic recombination. Cell $\underline{15}, 1-14$

Bradford M (1976): A rapid and sensitive method for the quantitation of microgram quantities of protein utilizing the principle of protein-dye binding. Anal Biochem $\underline{72}, 248-254$

Brummer T, Larance M, Herrera Abreu M, Lyons R, Timpson P, Emmerich C, Fleuren E, Lehrbach G, Schramek D, Guilhaus M, James D, Daly R (2008): Phosphorylation-dependent binding of 14-3-3 terminates signalling by the Gab2 docking protein. EMBO J $\underline{27}, 2305-2316$

Brunati A, Donella-Deana A, Ruzzene M, Marin O, Pinna L (1995): Site specificity of p72syk protein tyrosine kinase: efficient phosphorylation of motifs recognized by Src homology 2 domains of the Src family. FEBS Lett. 367, 149-152

Buchner M, Fuchs S, Prinz G, Pfeifer D, Bartholomé K, Burger M, Chevalier N, Vallat L, Timmer J, Gribben J, Jumaa H, Veelken H, Dierks C, Zirlik K (2009): Spleen tyrosine kinase is overexpressed and represents a potential therapeutic target in chronic lymphocytic leukemia. Cancer Res $\underline{69}, 5424-5432$ 
Campbell M, Sefton B (1992): Association between B-lymphocyte membrane immunoglobulin and multiple members of the Src family of protein tyrosine kinases. Mol Cell Biol $\underline{12}, 2315-2321$

Chan A, Iwashima M, Turck C, Weiss A (1992): ZAP-70: a 70 kd protein-tyrosine kinase that associates with the TCR zeta chain. Cell $\underline{71}, 649-662$.

Chen L, Monti S, Juszczynski P, Daley J, Chen W, Witzig T, Habermann T, Kutok J, Shipp M (2008): SYK-dependent tonic B-cell receptor signaling is a rational treatment target in diffuse large B-cell lymphoma. Blood 111, 2230-2237

Cheng A, Rowley B, Pao W, Hayday A, Bolen J, Pawson T (1995): Syk tyrosine kinase required for mouse viability and B-cell development. Nature $\underline{378}, 303-306$

Chiu C, Dalton M, Ishiai M, Kurosaki T, Chan A (2002): BLNK: molecular scaffolding through 'cis'-mediated organization of signaling proteins. EMBO J $\underline{21}, 6461$ 6472

Choudhary C, Mann M (2010): Decoding signalling networks by mass spectrometrybased proteomics. Nat Rev Mol Cell Biol 11, 427-439

Cook R, Wu C, Kang Y, Han J (2007): The role of the p38 pathway in adaptive immunity. Cell Mol Immunol 4, 253-259

Cooper N (1985): The classical complement pathway: activation and regulation of the first complement component. Adv Immunol 37, 151-216

Coughlin J, Stang S, Dower N, Stone J (2005): RasGRP1 and RasGRP3 regulate B cell proliferation by facilitating B cell receptor-Ras signaling. J Immunol $\underline{175}$, 7179-7184

Cox J, Mann M (2008): MaxQuant enables high peptide identification rates, individualized p.p.b.-range mass accuracies and proteome-wide protein quantification. Nat Biotechnol 26, 1367-1372

Cox J, Matic I, Hilger M, Nagaraj N, Selbach M, Olsen J, Mann M (2009): A practical guide to the MaxQuant computational platform for SILAC-based quantitative proteomics. Nat Protoc $\underline{4}, 698-705$

Crabtree G, Olson E (2002): NFAT signaling: choreographing the social lives of cells. Cell $\underline{109}, 67-79$

Davies D, Cohen G (1996): Interactions of protein antigens with antibodies. Proc Natl Acad Sci U S A $\underline{93}, 7-12$

Deckert M, Tartare-Deckert S, Couture C, Mustelin T, Altman A (1996): Functional and physical interactions of Syk family kinases with the Vav proto-oncogene product. Immunity $\underline{5}, 591-604$

DeFranco A, Chan V, Lowell C (1998): Positive and negative roles of the tyrosine kinase Lyn in B cell function. Semin Immunol 10, 299-307

Deindl S, Kadlecek T, Brdicka T, Cao X, Weiss A, Kuriyan J (2007): Structural basis for the inhibition of tyrosine kinase activity of ZAP-70. Cell 129, 735-746.

Diella F, Haslam N, Chica C, Budd A, Michael S, Brown N, Trave G, Gibson T (2008): Understanding eukaryotic linear motifs and their role in cell signaling and regulation. Front Biosci 13, 6580-6603 
Dower W, Miller J, Ragsdale C (1988): High efficiency transformation of E. coli by high voltage electroporation. Nucleic Acids Res 16, 6127-45

Engelke $M$, Friedrich $O$, Budde $P$, Schäfer $C$, Niemann $U$, Zitt $C$, Jüngling $E$, Rocks O, Lückhoff A, Frey J (2002): Structural domains required for channel function of the mouse transient receptor potential protein homologue TRP1beta. FEBS Lett $\underline{523}, 193-199$

Engelke M, Engels N, Dittmann K, Stork B, Wienands J (2007): Ca(2+) signaling in antigen receptor-activated B lymphocytes. Immunol Rev $\underline{218}$, 235-246

Falasca M, Logan S, Lehto V, Baccante G, Lemmon M, Schlessinger J (1998): Activation of phospholipase $\mathrm{C}$ gamma by $\mathrm{PI} 3$-kinase-induced $\mathrm{PH}$ domain-mediated membrane targeting. EMBO J $\underline{17}, 414-422$

Fearon D, Locksley $R$ (1996): The instructive role of innate immunity in the acquired immune response. Science 272, 50-53

Fenn J, Mann M, Meng C, Wong S, Whitehouse C (1989): Electrospray ionization for mass spectrometry of large biomolecules. Science 246, 64-71

Flaswinkel H, Reth M (1994): Dual role of the tyrosine activation motif of the Ig-alpha protein during signal transduction via the $\mathrm{B}$ cell antigen receptor. EMBO $\underline{\mathrm{J}} \underline{13}$, 83-89

Foletta V, Segal D, Cohen D (1998): Transcriptional regulation in the immune system: all roads lead to AP-1. J Leukoc Biol $\underline{63}, 139-152$

Franco M, Furstoss O, Simon V, Benistant C, Hong W, Roche, Risch, Schweiz S (2006): The adaptor protein Tom1L1 is a negative regulator of Src mitogenic signaling induced by growth factors. Mol Cell Biol 26, 1932-1947

Friedberg J, Sharman J, Sweetenham J, Johnston P, Vose J, Lacasce A, SchaeferCutillo J, De Vos S, Sinha R, Leonard J, Cripe L, Gregory S, Sterba M, Lowe A, Levy R, Shipp M (2010): Inhibition of Syk with fostamatinib disodium has significant clinical activity in non-Hodgkin lymphoma and chronic lymphocytic leukemia. Blood $\underline{115}$, 2578-2585

Fu C, Turck C, Kurosaki T, Chan A (1998): BLNK: a central linker protein in B cell activation. Immunity $\underline{9}$, 93-103

Furlong M, Mahrenholz A, Kim K, Ashendel C, Harrison M, Geahlen R (1997): Identification of the major sites of autophosphorylation of the murine protein-tyrosine kinase Syk. Biochim Biophys Acta 1355, 177-190

Geahlen R (2009): Syk and pTyr'd: Signaling through the B cell antigen receptor. Biochim Biophys Acta 1793, 1115-1127

Goitsuka R, Fujimura Y, Mamada H, Umeda A, Morimura T, Uetsuka K, Doi K, Tsuji S, Kitamura D (1998): BASH, a novel signaling molecule preferentially expressed in B cells of the bursa of Fabricius. J Immunol 161, 5804-5808

Goodnow C, Cyster J, Hartley S, Bell S, Cooke M, Healy J, Akkaraju S, Rathmell J, Pogue S, Shokat K (1995): Self-tolerance checkpoints in B lymphocyte development. Adv Immunol 59, 279-368

Goodnow C, Vinuesa C, Randall L, Mackay F, Brink R (2010): Control systems and decision making for antibody production. Nat Immunol 11, 681-688 
Groesch T, Zhou F, Mattila S, Geahlen R, Post C (2006): Structural basis for the requirement of two phosphotyrosine residues in signaling mediated by Syk tyrosine kinase. J Mol Biol 356, 1222-1236

Hanahan D (1983): Studies on transformation of Escherichia coli with plasmids. J Mol Biol $\underline{166}, 557-80$

Hong J, Yankee T, Harrison M, Geahlen R (2002): Regulation of signaling in B cells through the phosphorylation of Syk on linker region tyrosines. A mechanism for negative signaling by the Lyn tyrosine kinase. J Biol Chem 277, 31703-31714

Huse M, Kuriyan J (2002): The conformational plasticity of protein kinases. Cell $\underline{109}$, 275-282.

Hutchcroft J, Harrison M, Geahlen R (1992): Association of the 72-kDa proteintyrosine kinase PTK72 with the B cell antigen receptor. J Biol Chem 267, 86138619

Jacob J, Kelsoe G, Rajewsky K, Weiss U (1991): Intraclonal generation of antibody mutants in germinal centres. Nature $\underline{354}$, 389-392

Janeway C, Medzhitov R (2002): Innate immune recognition. Annu Rev Immunol 20, 197-216

Karakawa W, Sutton A, Schneerson R, Karpas A, Vann W (1988): Capsular antibodies induce type-specific phagocytosis of capsulated Staphylococcus aureus by human polymorphonuclear leukocytes. Infect Immun 56, 1090-1095

Kersey P, Duarte J, Williams A, Karavidopoulou Y, Birney E, Apweiler R (2004): The International Protein Index: An integrated database for proteomics experiments. Proteomics $\underline{4}, 1985-1988$

Keshvara L, Isaacson C, Yankee T, Sarac R, Harrison M, Geahlen R (1998): Sykand Lyn-dependent phosphorylation of Syk on multiple tyrosines following B cell activation includes a site that negatively regulates signaling. J Immunol $\underline{161}$, 5276-5283

Kitaura Y, Jang I, Wang Y, Han Y, Inazu T, Cadera E, Schlissel M, Hardy R, Gu H (2007): Control of the B cell-intrinsic tolerance programs by ubiquitin ligases $\mathrm{Cbl}$ and Cbl-b. Immunity 26, 567-578

Klein G, Giovanella B, Westman A, Stehlin J, Mumford D (1975): An EBV-genomenegative cell line established from an American Burkitt lymphoma; receptor characteristics. EBV infectibility and permanent conversion into EBV-positive sublines by in vitro infection. Intervirology $\underline{5}, 319-34$

Köhler F, Storch B, Kulathu Y, Herzog S, Kuppig S, Reth M, Jumaa H (2005): A leucine zipper in the $\mathrm{N}$ terminus confers membrane association to SLP65. Nat Immunol $\underline{6}, 204-210$

Koretzky G, Abtahian F, Silverman M (2006): SLP76 and SLP65: complex regulation of signalling in lymphocytes and beyond. Nat Rev Immunol $\underline{6}$, 67-78

Kulathu Y, Hobeika E, Turchinovich G, Reth M (2008): The kinase Syk as an adaptor controlling sustained Kalzium signalling and B-cell development. EMBO J $\underline{27}$, 1333-1344 
Kulathu Y, GRoth, Karlsruhee G, Reth M (2009): Autoinhibition and adapter function of Syk. Immunol Rev 232, 286-299

Kurakin A, Wu S, Bredesen D (2003): Atypical recognition consensus of CIN85/SETA/Ruk SH3-Domains revealed by target-assisted iterative screening. J Biol Chem 278, 34102-34109

Kurosaki T, Takata M, Yamanashi Y, Inazu T, Taniguchi T, Yamamoto T, Yamamura $H$ (1994): Syk activation by the Src-family tyrosine kinase in the B cell receptor signaling. J Exp Med 179. 1725-1729

Kurosaki T, Johnson S, Pao L, Sada K, Yamamura H, Cambier J (1995): Role of the Syk autophosphorylation site and $\mathrm{SH} 2-$ Domains in $\mathrm{B}$ cell antigen receptor signaling. J Exp Med 182, 1815-1823

Kurosaki T, Maeda A, Ishiai M, Hashimoto A, Inabe K, Takata M (2000): Regulation of the phospholipase C-gamma2 pathway in B cells. Immunol Rev $\underline{176}, 19-29$

Laemmli U (1970): Cleavage of structural proteins during the assembly of the head of bacteriophage T4. Nature 227, 680-685

Lam K, Kühn R, Rajewsky K (1997): In vivo ablation of surface immunoglobulin on mature $B$ cells by inducible gene targeting results in rapid cell death. Cell $\underline{90}$, 1073-83

Larsen M, Thingholm T, Jensen $O$, Roepstorff P, Jørgensen T (2005): Highly selective enrichment of phosphorylated peptides from peptide mixtures using titanium dioxide microcolumns. Mol Cell Proteomics $\underline{4}$, 873-486

Latour S, Chow L, Veillette A (1996): Differential intrinsic enzymatic activity of Syk and Zap-70 protein-tyrosine kinases. J Biol Chem 271, 22782-22790

Latour S, Zhang J, Siraganian R, Veillette A (1998): A unique insert in the linker domain of Syk is necessary for its function in immunoreceptor signalling. EMBO J $\underline{17}, 2584-2595$

Li X, Bu X, Lu B, Avraham H, Flavell R, Lim B (2002): The hematopoiesis-specific GTP-binding protein RhoH is GTPase deficient and modulates activities of other Rho GTPases by an inhibitory function. Mol Cell Biol 22, 1158-1171

Liu B, Jablonowski K, Raina M, Arcé M, Pawson T, Nash P (2006): The human and mouse complement of SH2-Domain proteins-establishing the boundaries of phosphotyrosine signaling. Mol Cell 22, 851-868

Löffert D, Schaal S, Ehlich A, Hardy R, Zou Y, Müller W, Rajewsky K (1994): Early Bcell development in the mouse: insights from mutations introduced by gene targeting. Immunol Rev 137, 135-53

Ma H, Yankee T, Hu J, Asai D, Harrison M, Geahlen R (2001): Visualization of Sykantigen receptor interactions using green fluorescent protein: differential roles for Syk and Lyn in the regulation of receptor capping and internalization. J Immunol $\underline{166}, 1507-1516$

Marshall A, Niiro H, Yun T, Clark E (2000): Regulation of B-cell activation and differentiation by the phosphatidylinositol 3-kinase and phospholipase Cgamma pathway. Immunol Rev $\underline{176}$, 30-46 
McHeyzer-Williams M, Okitsu S, Wang N, McHeyzer-Williams L (2011): Molecular programming of B cell memory. Nat Rev Immunol 12, 24-34

Mócsai A, Ruland J, Tybulewicz V (2010): The SYK tyrosine kinase: a crucial player in diverse biological functions. Nat Rev Immunol $\underline{10}$, 387-402

Moon K, Post C, Durden D, Zhou Q, De P, Harrison M, Geahlen R (2005): Molecular basis for a direct interaction between the Syk protein-tyrosine kinase and phosphoinositide 3-kinase. J Biol Chem 280, 1543-1551

Moore B und McGregor D (1965): Chromatographic and electrophoretic fractionation of soluble proteins of brain and liver. J Biol Chem 240: 1647-1653

Moriguchi T, Kawasaki H, Matsuda S, Gotoh Y, Nishida E (1995): Evidence for multiple activators for stress-activated protein kinase/c-Jun amino-terminal kinases.

Existence of novel activators. J Biol Chem 270, 12969-12972

Morita S, Kojima T, Kitamura T (2000): Plat-E: an efficient and stable system for transient packaging of retroviruses. Gene Ther $\underline{7}, 1063-1066$

Mullis K, Faloona F, Scharf S, Saiki R, Horn G, Erlich H (1986): Specific enzymatic amplification of DNA in vitro: the polymerase chain reaction. Cold Spring Harb Symp Quant Biol $\underline{51 \mathrm{Pt} 1}$, 263-273

Murphy K, Travers P, Walport M: Janesway's Immunobiology. 7. Auflage. Garland Science, New York 2008

Muslin A, Tanner J, Allen P, Shaw A (1996): Interaction of 14-3-3 with signaling proteins is mediated by the recognition of phosphoserine. Cell $\underline{84}, 889-897$

Obenauer J, Cantley L, Yaffe M (2003): Scansite 2.0: Proteome-wide prediction of cell signaling interactions using short sequence motifs. Nucleic Acids Res $\underline{31}$, 3635-3641

Oellerich T, Grønborg M, Neumann K, Hsiao HH, Urlaub H, Wienands J (2009): SLP65 phosphorylation dynamics reveals a functional basis for signal integration by receptor-proximal adaptor proteins. Mol Cell Proteomics $\underline{8}, 1738-1750$

Oellerich T, Bremes V, Neumann K, Bohnenberger H, Dittmann K, Hsiao HH, Engelke M, Schnyder T, Batista F, Urlaub H, Wienands J (2011): The B-cell antigen receptor signals through a preformed transducer module of SLP65 and CIN85. EMBO J $\underline{30}, 3620-3634$

Olsen J, Blagoev B, Gnad F, Macek B, Kumar C, Mortensen P, Mann M (2006): Global, in vivo, and site-specific phosphorylation dynamics in signaling networks. Cell 127, 635-648

Ong S, Blagoev B, Kratchmarova I, Kristensen D, Steen H, Pandey A, Mann M (2002): Stable isotope labeling by amino acids in cell culture, SILAC, as a simple and accurate approach to expression proteomics. Mol Cell Proteomics $\underline{1}$, 376-386

Paris L, Hu J, Galan J, Ong S, Martin V, Ma H, Tao W, Harrison M, Geahlen R (2010): Regulation of Syk by phosphorylation on serine in the linker insert. J Biol Chem 285, 39844-39854 
Perkins D, Pappin D, Creasy D, Cottrell J (1999): Probability-based protein identification by searching sequence databases using mass spectrometry data. Electrophoresis 20, 3551-3567

Pogue S, Kurosaki T, Bolen J, Herbst R (2000): B cell antigen receptor-induced activation of Akt promotes B cell survival and is dependent on Syk kinase. J Immunol $\underline{165}, 1300-1306$

Rao N, Ghosh A, Ota S, Zhou P, Reddi A, Hakezi K, Druker B, Wu J, Band H (2001): The non-receptor tyrosine kinase Syk is a target of $\mathrm{Cbl}$-mediated ubiquitylation upon B-cell receptor stimulation. EMBO J 므, 7085-7095

Reth M (1989): Antigen receptor tail clue. Nature 338, 383-384

Rinehart J, Maksimova Y, Tanis J, Stone K, Hodson C, Zhang J, Risinger M, Pan W, Wu D, Colangelo C, Forbush B, Joiner C, Gulcicek E, Gallagher P, Lifton R (2009): Sites of regulated phosphorylation that control K-Cl cotransporter activity. Cell $\underline{138}, 525-536$

Rolli V, Gallwitz M, Wossning T, Flemming A, Schamel W, Zürn C, Reth M (2002): Amplification of $B$ cell antigen receptor signaling by a Syk/ITAM positive feedback loop. Mol Cell 10, 1057-1069

Rosentreter A, Hofmann A, Xavier CP, Stumpf M, Noegel AA, Clemen C (2007): Coronin 3 involvement in F-Aktin-dependent processes at the cell cortex. Exp Cell Res $\underline{313}$, 878-895

Rowland S, DePersis C, Torres R, Pelanda R (2010): Ras activation of Erk restores impaired tonic BZR signaling and rescues immature B cell differentiation. J Exp Med 207, 607-621

Rowley R, Bolen J, Fargnoli J (1995): Molecular cloning of rodent p72Syk. Evidence of alternative mRNA splicing. J Biol Chem 270, 12659-12664

Sada K, Takano T, Yanagi S, Yamamura H (2001): Structure and function of Syk protein-tyrosine kinase. J Biochem 130, 177-186

Sadygov R, Cociorva D, Yates J (2004): Large-scale database searching using tandem mass spectra: looking up the answer in the back of the book. Nat Methods $1,195-202$

Saito K, Scharenberg A, Kinet J (2001): Interaction between the Btk PH domain and phosphatidylinositol-3,4,5-trisphosphate directly regulates Btk. J Biol Chem $\underline{276}$, 16201-16206

Salomons F, Acs K, Dantuma N (2010): Illuminating the ubiquitin/proteasome system. Exp Cell Res $\underline{316}, 1289-1295$

Sanchez M, Misulovin Z, Burkhardt AL, Mahajan S, Costa T, Franke R, Bolen J, Nussenzweig M (1993): Signal transduction by immunoglobulin is mediated through Ig alpha and Ig beta. J Exp Med 178, 1049-1055

Sanger F, Nicklen S, Coulson A (1977): DNA sequencing with chain-terminating inhibitors. Proc Natl Acad Sci U S A 프, 5463-5467

Saouaf S, Mahajan S, Rowley R, Kut S, Fargnoli J, Burkhardt A, Tsukada S, Witte O, Bolen J (1994): Temporal differences in the activation of three classes of non- 
transmembrane protein tyrosine kinases following B-cell antigen receptor surface engagement. Proc Natl Acad Sci U S A 91, 9524-9528.

Schulze W, Mann (2004): A novel proteomic screen for peptide-protein interactions. J Biol Chem 279, 10756-64

Scigelova M, Makarov A (2006): Orbitrap mass analyzer--overview and applications in proteomics. Proteomics $\underline{6}, 16-21$

Shevchenko A, Tomas H, Havlis J, Olsen J, Mann M (2006): In-gel digestion for mass spectrometric characterization of proteins and proteomes. Nat Protoc 1 , 2856-2860

Shinohara H, Kurosaki T (2009): Comprehending the complex connection between PKCbeta, TAK1, and IKK in BZR signaling. Immunol Rev 232, 300-318

Sidorenko S, Law C, Klaus S, Chandran K, Takata M, Kurosaki T, Clark E (1996): Protein kinase $\mathrm{C}$ mu (PKC mu) associates with the B cell antigen receptor complex and regulates lymphocyte signaling. Immunity $\underline{5}, 353-363$

Simon M, Vanes L, Geahlen R, Tybulewicz V (2005): Distinct roles for the linker region tyrosines of Syk in FcepsilonRI signaling in primary mast cells. J Biol Chem $\underline{280}, 4510-4517$

Sohn H, Tolar P, Jin T, Thermo, Waltham, Massachusetts S (2006): Fluorescence resonance energy transfer in living cells reveals dynamic membrane changes in the initiation of B cell signaling. Proc Natl Acad Sci U S A $\underline{103}, 8143-8148$

Stavnezer J, Guikema JE Schrader CE (2008): Mechanism and regulation of class switch recombination. Annu Rev Immunol 26, 261-292

Steen H, Mann M (2004): The ABC's (and XYZ's) of peptide sequencing. Nat Rev Mol Cell Biol $\underline{5}, 699-711$

Takata M, Sabe H, Hata A, Inazu T, Homma Y, Nukada T, Yamamura H, Kurosaki T (1994): Tyrosine kinases Lyn and Syk regulate B cell receptor-coupled Ca2+ mobilization through distinct pathways. EMBO J $\underline{13}, 1341-1349$

Tonegawa S, Brack C, Hozumi N, Pirrotta V (1978): Organization of immunoglobulin genes. Cold Spring Harb Symp Quant Biol 42,921-31

Tsang E, Giannetti A, Shaw D, Dinh M, Tse J, Gandhi S, Ho H, Wang S, Papp E, Bradshaw J (2008): Molecular mechanism of the Syk activation switch. J Biol Chem 283, 32650-32659

Tsubata T, Wienands J (2001): B cell signaling. Introduction. Int Rev Immunol 20, $675-678$

Turner M, Mee P, Costello P, Williams O, Price A, Duddy L, Furlong M, Geahlen R, Tybulewicz V (1995): Perinatal lethality and blocked B-cell development in mice lacking the tyrosine kinase Syk. Nature $\underline{378}, 298-302$

Uckun F, Ek R, Jan S, Chen C, Qazi S (2010 a): Targeting SYK kinase-dependent anti-apoptotic resistance pathway in B-lineage acute lymphoblastic leukaemia (ALL) cells with a potent SYK inhibitory pentapeptide mimic. Br J Haematol 149, 508-517 
Uckun F, Ozer Z, Qazi S, Tuel-Ahlgren L, Mao C (2010 b): Polo-like-kinase 1 (PLK1) as a molecular target to overcome SYK-mediated resistance of B-lineage acute lymphoblastic leukaemia cells to oxidative stress. $\mathrm{Br} \mathrm{J}$ Haematol $\underline{148}, 714-725$

von Behring E, Kitasato S (1890): Über das Zustandekommen der DiphterieImmunität und der Tetanus-Immunität bei Thieren. Dtsch Med Wochenschr 16, $1145-1148$

Waksman G, Shoelson S, Pant N, Cowburn D, Kuriyan J (1993): Binding of a high affinity phosphotyrosyl peptide to the Src SH2-Domain: crystal structures of the complexed and peptide-free forms. Cell $\underline{72}, 779-790$

Walther T, Mann M (2010): Mass spectrometry-based proteomics in cell biology. J Cell Biol 190, 491-500

Wang L, Duke L, Zhang P, Arlinghaus R, Symmans W, Sahin A, Mendez R, Dai J (2003): Alternative splicing disrupts a nuclear localization signal in spleen tyrosine kinase that is required for invasion suppression in breast cancer. Cancer Res $\underline{63}, 4724-4730$

Wang LD, Clark M (2003): B-cell antigen-receptor signalling in lymphocyte development. Immunology 110, 411-420

Weiel J, Ahn N, Seger R, Krebs E (1990): Communication between protein tyrosine and protein serine/threonine phosphorylation. Adv Second Messenger Phosphoprotein Res $\underline{24}, 182-195$

Wienands J (2000): The B-cell antigen receptor: formation of signaling complexes and the function of adaptor proteins. Curr Top Microbiol Immunol 245, 53-76

Wienands J, Freuler F, Baumann G (1995): Tyrosine-phosphorylated forms of Ig beta, CD22, TCR zeta and HOSS are major ligands for tandem SH2-Domains of Syk. Int Immunol $\underline{7}, 1701-1708$

Wienands J, Schweikert J, Wollscheid B, Jumaa H, Nielsen P, Reth M (1998): SLP65: a new signaling component in $B$ lymphocytes which requires expression of the antigen receptor for phosphorylation. J Exp Med 188, 791-795

Winding P, Berchtold M (2001): The chicken B cell line DT40: a novel tool for gene disruption experiments. J Immunol Methods 249, 1-16

Witze E, Old W, Resing K, Ahn N (2007): Mapping protein post-translational modifications with mass spectrometry. Nat Methods 4, 798-806

Wong J, Ishiai M, Kurosaki T, Chan A (2000): Functional complementation of BLNK by SLP76 and LAT linker proteins. J Biol Chem 275, 33116-33122

Yaffe M, Rittinger K, Volinia S, Caron P, Aitken A, Leffers H, Gamblin S, Smerdon S, Cantley $L$ (1997): The structural basis for 14-3-3:phosphopeptide binding specificity. Cell $\underline{91}, 961-71$

Yanagi S, Inatome R, Takano T, Yamamura H (2001): Syk expression and novel function in a wide variety of tissues. Biochem Biophys Res Commun 288, 495498

Yankee T, Keshvara L, Sawasdikosol S, Harrison M, Geahlen R (1999): Inhibition of signaling through the $\mathrm{B}$ cell antigen receptor by the protooncogene product, $\mathrm{C}-$ 
$\mathrm{cbl}$, requires Syk tyrosine 317 and the c-Cbl phosphotyrosine-binding domain. J Immunol 163, 5827-5835

Zhang J, Kimura T, Siraganian R (1998) Mutations in the activation loop tyrosines of protein tyrosine kinase Syk abrogate intracellular signaling but not kinase activity. J Immunol 161, 4366-4374

Zhao Y, Jensen O (2009): Modification-specific proteomics: strategies for characterization of post-translational modifications using enrichment techniques. Proteomics $\underline{9}, 4632-4641$

Zioncheck T, Harrison M, Geahlen R (1986): Purification and characterization of a protein-tyrosine kinase from bovine thymus. J Biol Chem 261, 15637-15643

Zioncheck T, Harrison M, Isaacson C, Geahlen R (1988): Generation of an active protein-tyrosine kinase from lymphocytes by proteolysis. J Biol Chem $\underline{263}$, 19195-19202 


\section{Danksagung}

Bedanken möchte ich mich bei Prof. Dr. Jürgen Wienands, der mir diese Promotion ermöglich hat, für sein großes Vertrauen, das er in mich und meine Arbeit gesetzt hat und für die Freiheiten, die er mir bei der Erarbeitung dieses Projektes gelassen hat.

Dr. Michael Engelke möchte ich dafür danken, dass ich inn stets um Rat fragen konnte, und insbesondere für die Zusammenarbeit bei der konfokalen Mikroskopie. Für die technische Unterstützung im Labor gilt mein Dank Ines Heine und Gabriele Sonntag.

Für die Überlassung von Vektoren und Antikörpern möchte ich mich bei Dr. Manfred Jücker vom UKE Hamburg, bei Dr. Deborah Yablonski vom Technion-Israel Institute of Technology Haifa, Israel, bei Dr. Sandra Beer-Hammer vom Universitätsklinikum Düsseldorf und bei Dr. Tomohiro Kurosaki vom National Institute of Infectious Diseases Tokyo, Japan bedanken.

Diese Arbeit ist in Kooperation mit der "Bioanalytical Mass Spectrometry Group“ am MPI für biophysikalische Chemie entstanden. Für die gelungene Zusammenarbeit und die Ermöglichung der massenspektrometrischen Messungen möchte ich Prof. Dr. Henning Urlaub als Leiter der Gruppe und Dr. He-Hsuan Hsiao für die Unterstützung bei der Aufreinigung von Phosphopeptiden danken. Vielen Dank auch für die technische Unterstützung bei der Durchführung der massenspektrometrischen Messungen an Uwe Plessmann, Monika Raabe und Johanna Lehne.

Schließlich möchte ich mich für die hervorragende Zusammenarbeit der letzten Jahre bei Herrn Dr. Thomas Oellerich bedanken.

Die Erstellung dieser Arbeit wurde durch das Stipendium A des Stipendienprogrammes innerhalb der "Gö4med" des Universitätsklinikums Göttingen gefördert. 